\title{
Balanceamento de Carga em Ambientes Paralelos Virtuais com Aplicações no PVM-W95
}

Flávio Arnaldo Braga da Silva

Orientador: Prof. Dr. Marcos José Santana

Dissertação apresentada ao Instituto de Ciências Matemáticas de São Carlos da Universidade de São Paulo ICMSC/USP, como parte dos requisitos para a obtenção do título de Mestre em Ciências - Área: Ciências de Computação e Matemática Computacional.

$$
\begin{gathered}
\text { USP - São Carlos } \\
\text { Junho/1997 }
\end{gathered}
$$


À memória de Otávio e Nair 


\section{Agradecimentos}

Aos meus pais, Cícero e Marilda.

À Rita, pelo apoio de todas as horas, pelo amor e dedicação.

Ao Prof. Dr. Marcos José Santana e à Profa. Dra. Regina Helena C. Santana, pela orientação, paciência e amizade.

Ao Márcio Augusto de Souza, companheiro de futebol, pela amizade e ajuda.

Ao Paulo Sérgio, pelo apoio e pelas idéias.

A todos do grupo de Sistemas Distribuídos e Programação Concorrente.

Aos colegas de mestrado, e, em especial, ao Shiro, Mário, Sílvio, Robson, Rogério e Fábio.

A todos os que colaboraram, de uma forma ou de outra, e aos que não atrapalharam, o que não deixa de ser uma grande contribuição. 


\section{Resumo}

Esta dissertação de mestrado aborda o problema de balanceamento de carga em ambientes paralelos virtuais, com aplicações desenvolvidas em PVM-W95.

São considerados no desenvolvimento deste trabalho algoritmos de balanceamento estáticos e dinâmicos, incluindo métodos de distribuição e de migração de tarefas.

O trabalho apresenta uma vasta revisão bibliográfica que cobre os principais métodos e algoritmos de balanceamento de cargas em ambientes distribuídos e paralelos, propostos nos últimos anos.

Os métodos e algoritmos relevantes para o domínio de aplicação considerado são cuidadosamente investigados.

Os algoritmos estudados são implementados como parte dos programas de aplicação e o estudo desenvolvido abrange fundamentalmente programas com alto processamento numérico.

Os resultados obtidos mostram claramente que o método gradiente e os algoritmos globais são os mais eficientes para os programas aplicativos desenvolvidos e para o ambiente paralelo virtual adotado. 


\section{Abstract}

This MSc dissertation approaches the load balancing problem in parallel virtual environments, with applications developed in the PVM-W95.

Static and Dynamic load balancing algorithms are considered in the developement of this work, including methods for both task distribution and task migration.

The work shows a wide literature review covering the main methods and algorithms for load balancing in distributed and parallel environments, proposed over the last few years.

The relevant methods and algorithms for the application domain considered are carefully investigated.

The algorithms studied are implemented inbeded into the application programs and the study developed mainly covers programs with high numerical processing tasks.

The results obtained clearly shows that the gradient method and the global algorithms are the more efficient ones for the application programs developed and for the parallel virtual environment adopted. 


\section{Conteúdo}

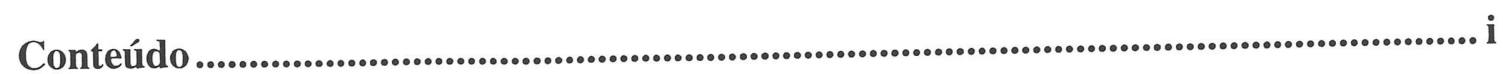

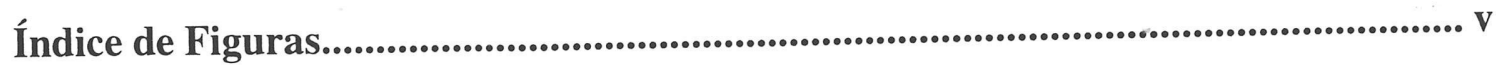

Capítulo 1

Introdução

Capítulo 2.

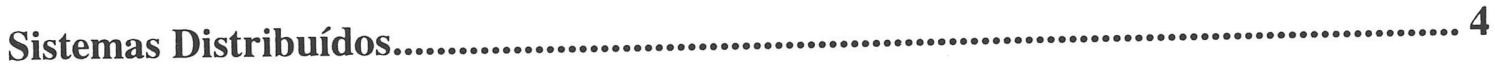

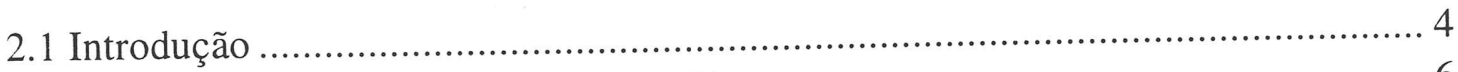

2.2 Caracterização dos Sistemas Distribuídos ........................................................ 6

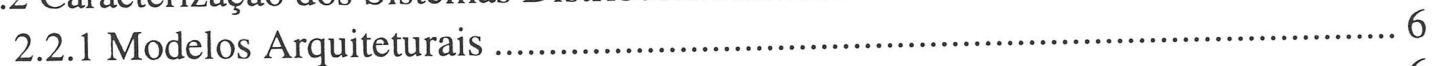

Estação de trabalho/Servidor ......................................................................... 6

Banco de processadores ……................................................................ 7

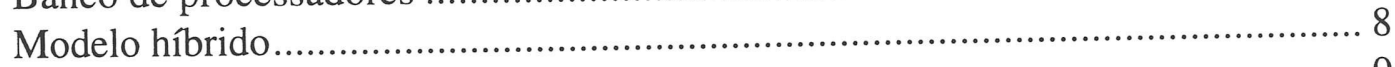

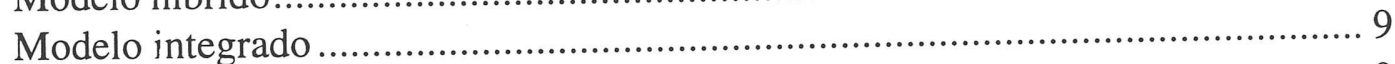

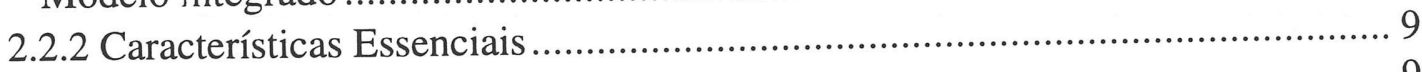

Compartilhamento de Recursos ............................................................. 9

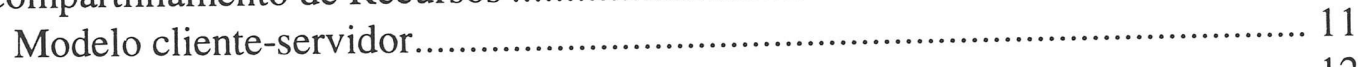

Modelo baseado em objetos ................................................................ 12

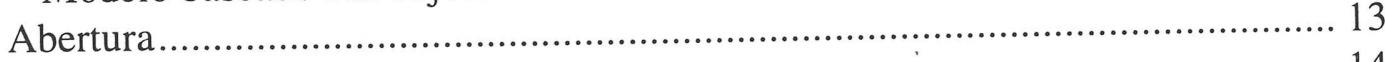

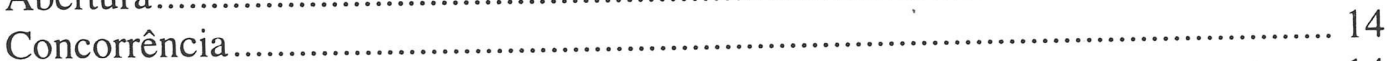

Independência de Escala ............................................................................ 14

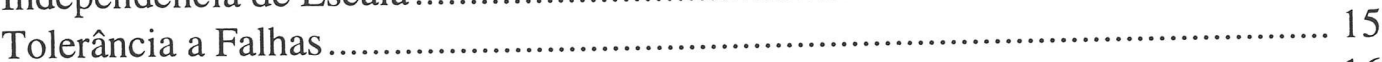

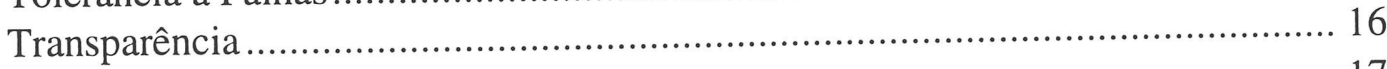

2.3 Aplicações de Sistemas Distribuídos................................................................... 17

Aplicações em Sistemas de Telefonia .................................................................. 17

Aplicações Financeiras................................................................................. 17

Aplicações para Estúdios de Cinema ................................................................... 18

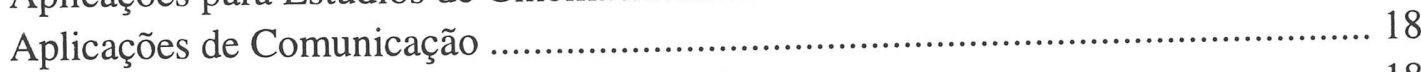

Aplicações para Seguradoras ............................................................................ 18

Aplicações para Institutos de Pesquisa .............................................................. 18

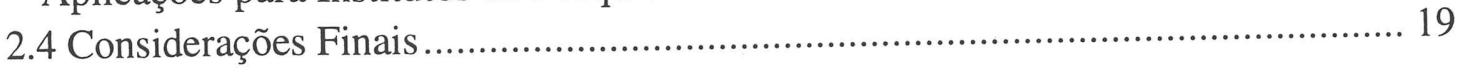

Capítulo 3................................................................................................................... 20

Arquiteturas Paralelas ....................................................................................................... 20

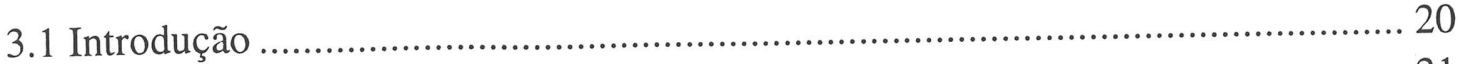

3.2 Classificação de Arquiteturas Paralelas ............................................................... 21 


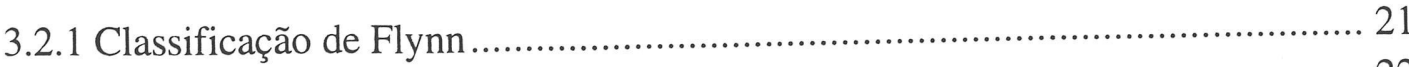

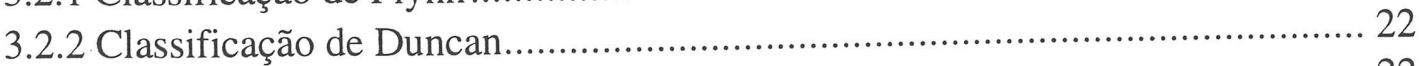

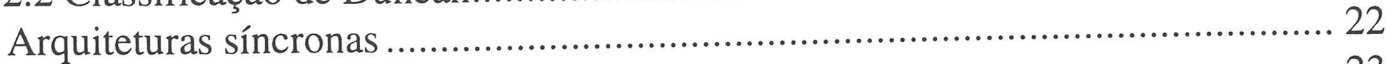

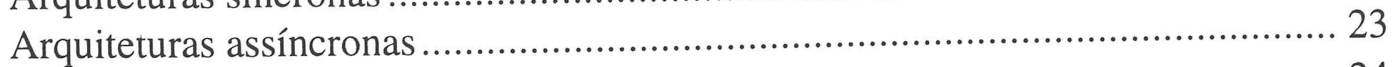

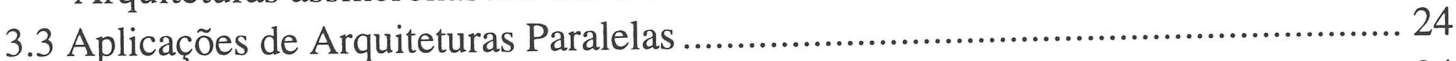

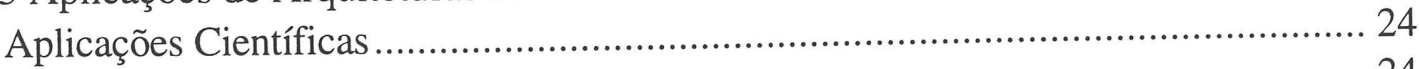

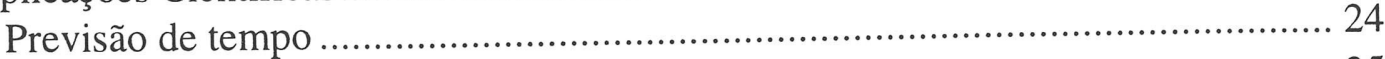

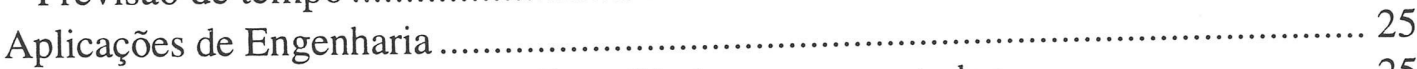

Projeto de processadores VLSI auxiliado por computador ................................. 25

Sistemas de Banco de Dados ........................................................................... 26

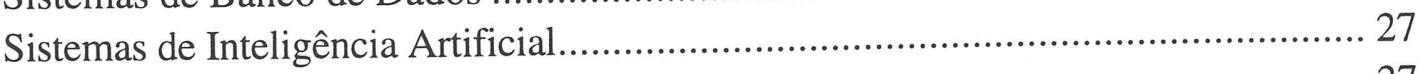

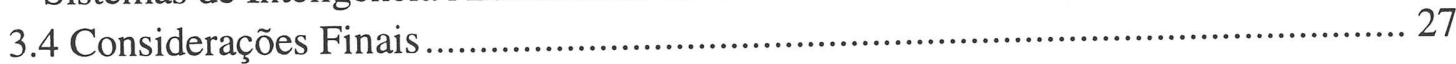

Capítulo 4 ..1.

Sistemas Distribuídos para Computação Paralela......................................................... 28

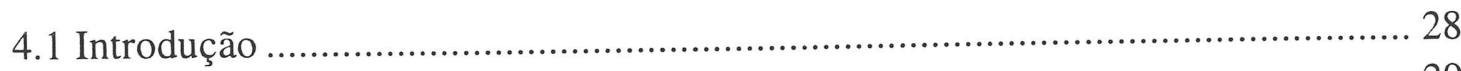

4.2 Ambientes de Passagem de Mensagens .......................................................... 29

4.3 Exemplos de Ambientes de Passagem de Mensagens .......................................... 31

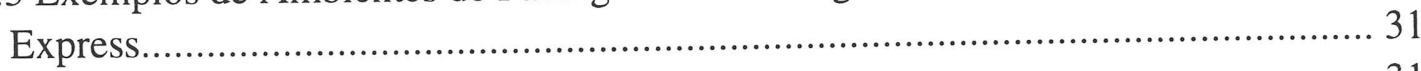

Linda

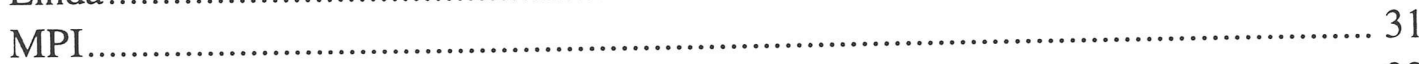

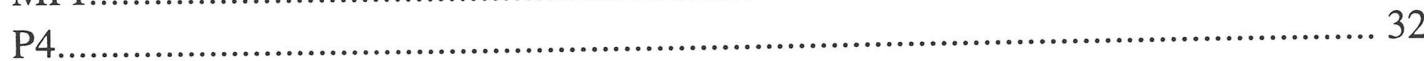

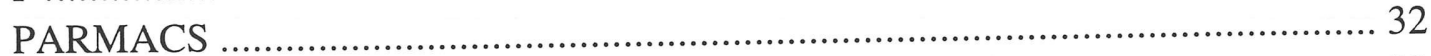

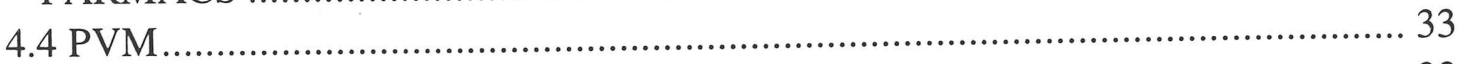

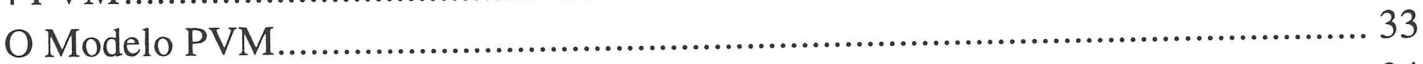

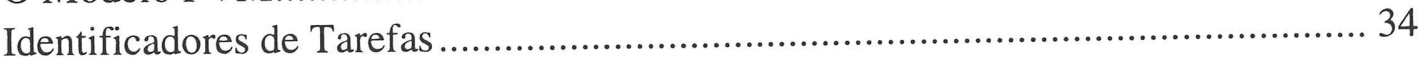

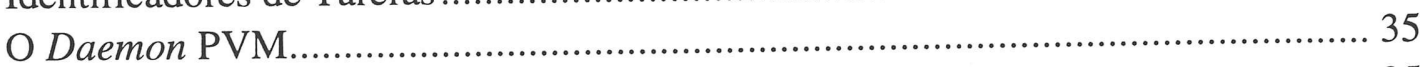

A Biblioteca de Programação.............................................................................. 35

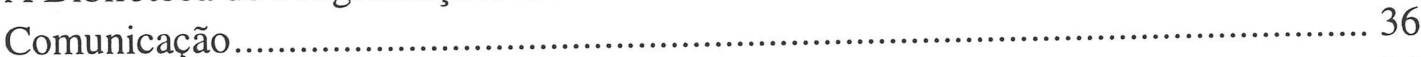

Grupos Dinâmicos de Processos ..................................................................... 36

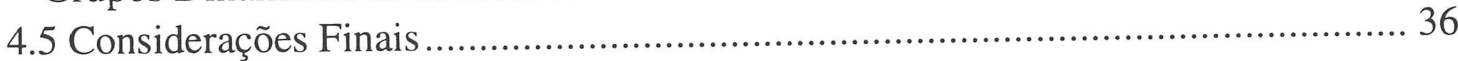

Capítulo 5...

Escalonamento e Balanceamento de Carga .................................................................. 38

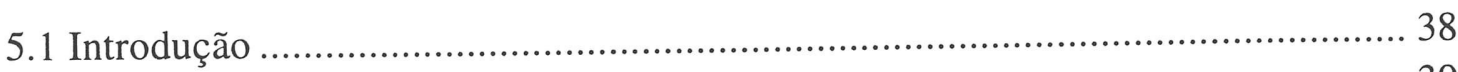

5.2 Classificação dos Métodos de Escalonamento .................................................... 39

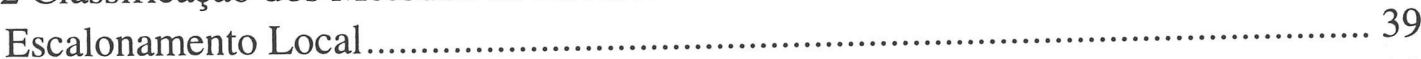

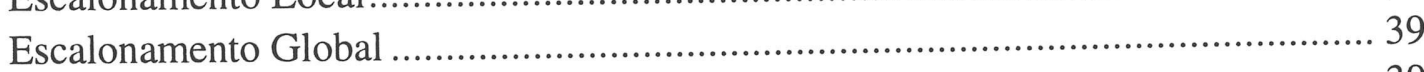

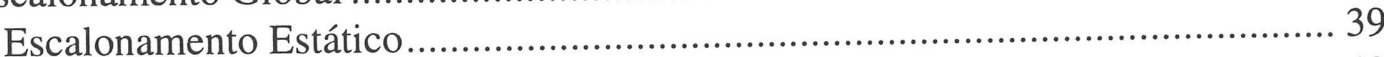

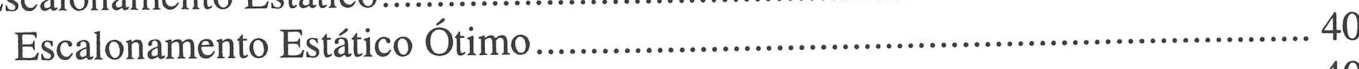

Escalonamento Estático Sub-ótimo ............................................................. 40

Escalonamento Dinâmico............................................................................. 41

Escalonamento Dinâmico Fisicamente não Distribuído.................................... 42

Escalonamento Dinâmico Fisicamente Distribuído ............................................. 43 
Políticas Combinadas. 43

Outras Características 43

Sistemas Adaptativos e não Adaptativos 43

Protocolo de Convite (Bidding) 43

Transferência Preemptiva e não Preemptiva ..................................................... 44

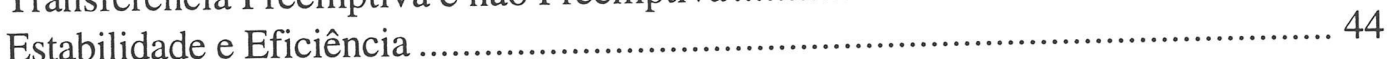

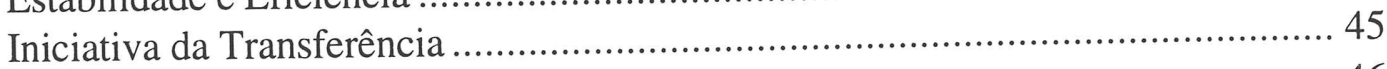

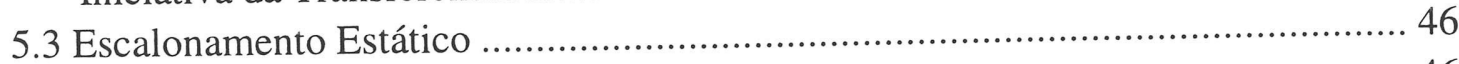

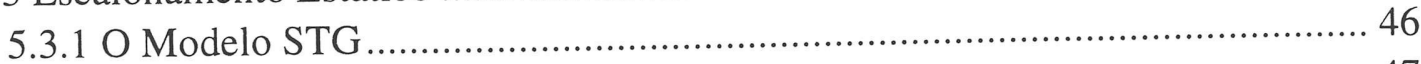

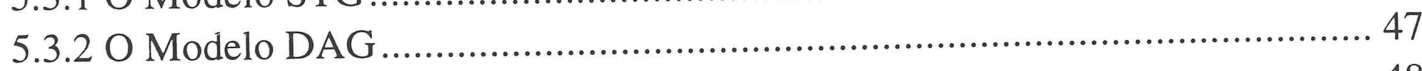

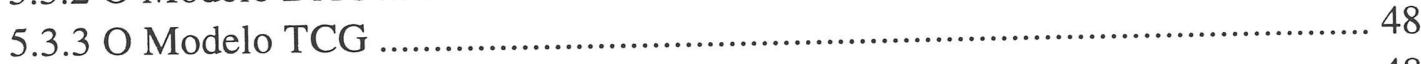

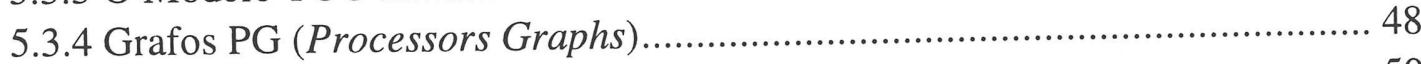

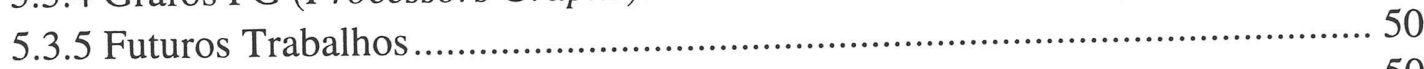

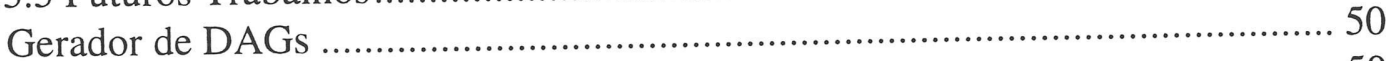

Ferramentas para estimativas de tempo de execução ……….............................. 50

Gerador de perfis de desempenho ................................................................ 51

Ferramentas de distribuição de dados............................................................ 51

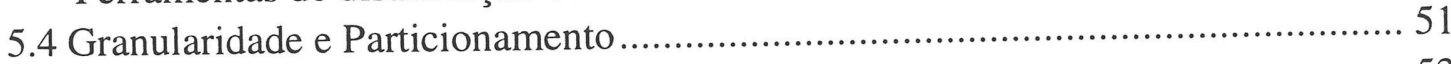

Algoritmos de Particionamento .......................................................................... 53

Particionamento pelo Caminho Crítico ................................................................ 53

Particionamento por Eliminação da Comunicação ............................................... 53

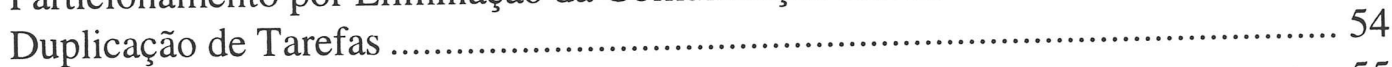

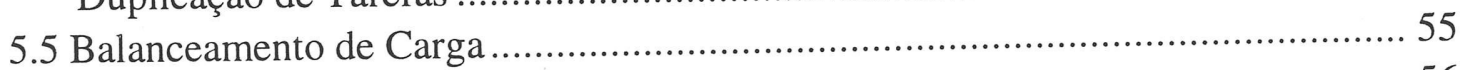

5.5.1 Mecanismos de Migração de Processos ...................................................... 56

5.5.2 Algoritmos de Balanceamento de Carga ..................................................... 58

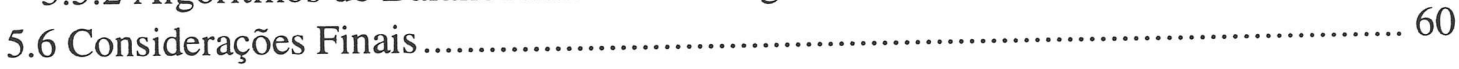

Capítulo 6:

Avaliação dos Métodos de Balanceamento de Carga ................................................... 62

6.1 Introdução $\ldots . \ldots 62$

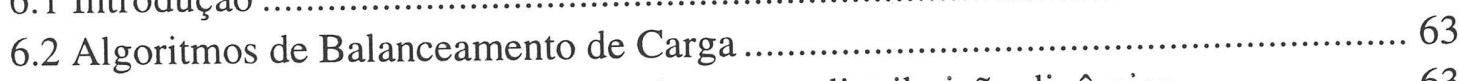

6.2.1 Algoritmos de balanceamento de carga - distribuição dinâmica...................... 63

6.2.2 Algoritmos de balanceamento de carga - migração de tarefas ........................6 65

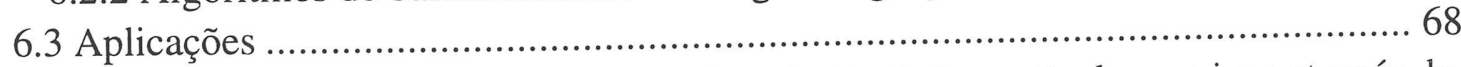

6.3.1 Resolução de sistemas lineares pelo método de inversão de matrizes através de

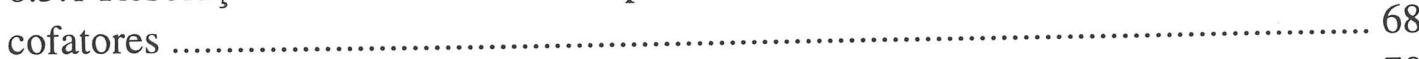

6.3.2 Resolução do problema do caixeiro viajante .............................................. 70

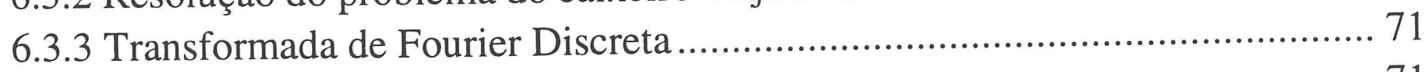

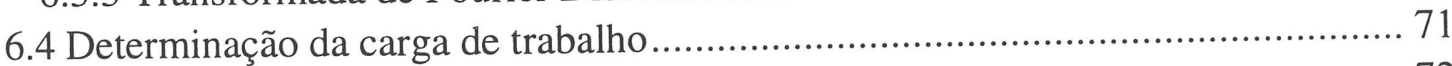

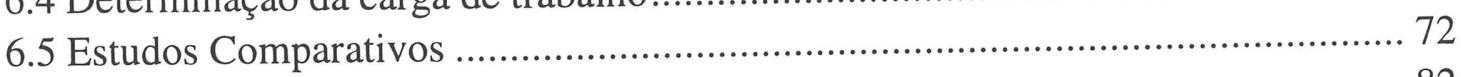

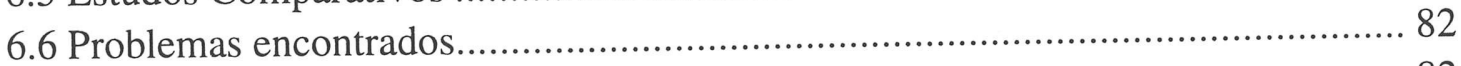

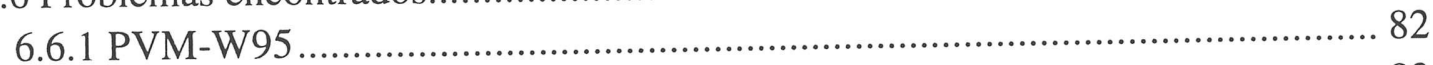

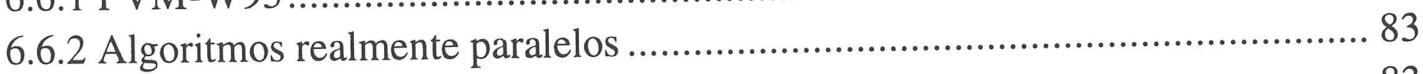

6.6.3 Transformada de Fourier.................................................................... 83 
7 Conclusões .

7.1 Considerações iniciais 85

7.2 Conclusões 85

7.3 Contribuições deste trabalho 86

7.4 Trabalhos futuros 87

Referências Bibliográficas 


\section{Índice de Figuras}

Figura 2.1. O modelo Estação de Trabalho/Servidor..................................................... 7

Figura 2.2. O modelo Banco de Processadores........................................................ 7

Figura 2.3. O modelo híbrido. ........................................................................... 8

Figura 2.4. Gerentes de Recursos (G) e Usuários de Recursos ( o ) ............................... 11

Figura 2.5. Processos Clientes (C) e Servidores (G)................................................. 12

Figura 2.6. Objetos $(\Delta)$ e Gerentes $(\mathrm{M})$. Alguns nós apenas tem acesso aos objetos.

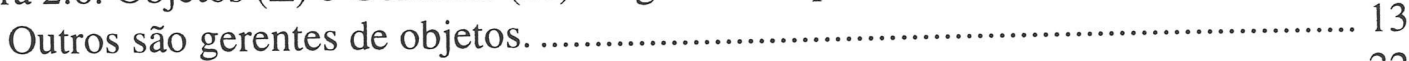

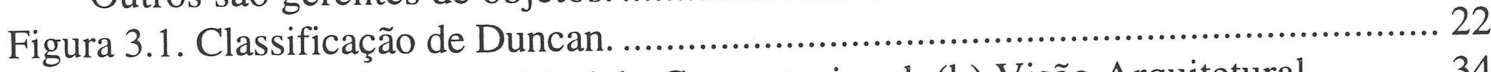

Figura 4.1. Sistema PVM. (a) Modelo Computacional. (b) Visão Arquitetural ............. 34

Figura 4.2. Identificador de Tarefas (TID) .......................................................... 34

Figura 4.3. Panorama de alguns ambientes de passagem de mensagens [MAL96] ........ 37

Figura 5.1. Classificação dos Métodos de Escalonamento.......................................... 38

Figura 5.2. Exemplo de um STG.

Figura 5.3. Exemplo de um DAG. ............ 47

Figura 5.4. (a) Um TCG estático. (b) Um TCG-DAG para o algoritmo $n$-body ............ 49

Figura 5.5. Um grafo representando uma malha de 4 processadores............................ 49

Figura 5.6. Gráfico de Gantt com a distribuição das tarefas entre 4 EPs e os tempos de execução.

Figura 5.7. (a) Um DAG com pesos. (b) Particionamento não linear. (c) Particionamento linear.

Figura 5.8. (a) Um DAG. (b) Sua classificação horizontal. (c) Seu particionamento vertical.

Figura 5.9. (a) Um DAG mostrando a relação E/C de cada tarefa. (b) Agrupamento das

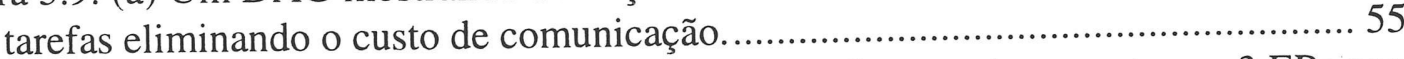

Figura 5.10. (a) O DAG de um programa genérico. (b) Seu escalonamento em 3 EPs por duplicação de tarefas.

Figura 5.11. Mapeamento dos algoritmos de balanceamento de carga............................. 58

Gráfico 6.2. AP1, 3 máquinas $\ldots$

.

Gráfico 6.4. AP1, 5 máquinas

Gráfico 6.5. AP2, 2 máquinas.

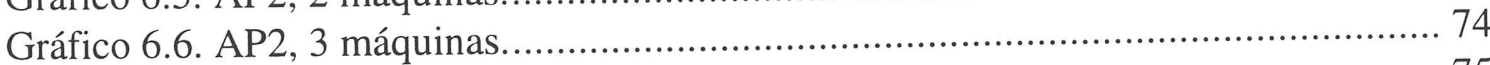

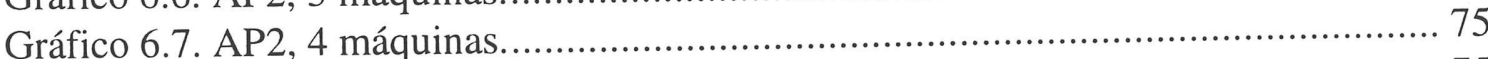

Gráfico 6.8. AP2, 5 máquinas $\ldots$

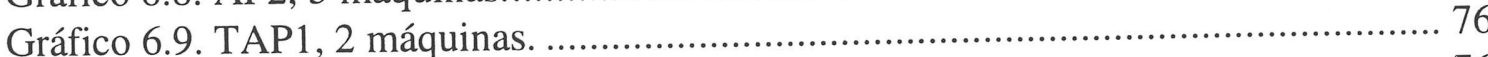

Gráfico 6.10. TAP1, 3 máquinas.

Gráfico 6.11. TAP1, 4 máquinas.

Gráfico 6.12. TAP1, 5 máquinas.

Gráfico 6.13. TAP2, 2 máquinas.

Gráfico 6.14. TAP2, 3 máquinas.

Gráfico 6.15. TAP2, 4 máquinas.

Gráfico 6.16. TAP2, 5 máquinas.

Gráfico 6.17. CAP1, 2 máquinas. .......... 78

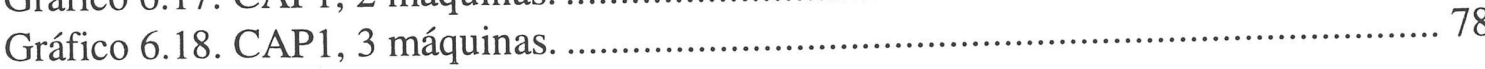


Gráfico 6.19. CAP1, 4 máquinas.

Gráfico 6.20. CAP1, 5 máquinas.

Gráfico 6.21. CAP2, 2 máquinas.

Gráfico 6.22. CAP2, 3 máquinas.

Gráfico 6.23. CAP2, 4 máquinas.

Gráfico 6.24. CAP2, 5 máquinas.

Tabela 6.1. Tempos de execução (em segundos) da Transformada de Fourier em algumas máquinas. 


\section{Capítulo 1}

\section{Introdução}

A pesquisa na área de sistemas distribuídos tem sido bastante intensa nos últimos anos. No levantamento bibliográfico deste trabalho, foi possível encontrar diversos produtos em estágio avançado de desenvolvimento em várias universidades e institutos de pesquisas pelo mundo inteiro. Há um grande número de profissionais envolvidos nesses trabalhos e várias universidades de renome apresentam em seus cursos de informática disciplinas de sistemas distribuídos, além de possuírem grupos de trabalho específicos nessa área.

Em paralelo às instituições acadêmicas, várias empresas privadas e órgãos governamentais também têm despendido grandes esforços nessa área. Essas pesquisas resultaram em alguns produtos que já estão sendo comercializados.

Em função de todo esse trabalho, a evolução dos sistemas distribuídos tem sido muito grande. Parte dos problemas que restringiam sua aplicação foram solucionados e o avanço tecnológico atual deve apresentar respostas para alguns outros muito em breve. Boa parte dessas conquistas é em função dos objetivos que se procura alcançar com sua utilização:

- Melhor aproveitamento do poder computacional dos sistemas [SHI95].

- Compartilhamento de recursos [TAN95].

- Economia [TAN95].

- Melhor representação da realidade [SYB95].

Por outro lado, os sistemas paralelos surgiram e se desenvolveram porque alguns problemas não podiam ser resolvidos satisfatoriamente com máquinas seqüenciais. Elas não apresentam velocidade suficiente para certas aplicações e dificilmente conseguirão, já que os limites tecnológicos para sua evolução estão cada vez mais próximos [ALM94]. Assim sendo, procuraram-se alternativas na exploração do paralelismo em potencial dessas aplicações.

Há várias possibilidades de paralelismo em um programa genérico que podem ser exploradas a fim de reduzir o tempo necessário para que esse programa produza um determinado resultado [HWA84]:

- Módulos independentes podem ser executados em processadores diferentes.

- Repetições que aplicam determinados procedimentos aos elementos de uma tabela podem ser vetorizadas.

- Grandes conjuntos de dados, em que cada elemento precisa receber o mesmo processamento dos demais, podem ser tratados em sistemas com múltiplas unidades de controle.

Apesar de terem evoluído por razões distintas, observou-se uma forte convergência nas pesquisas envolvendo sistemas distribuídos e arquiteturas paralelas, particularmente quando se começou a pesquisar o uso de sistemas distribuídos para a realização de processamento paralelo. Isso foi possível em função do desenvolvimento 
dos sistemas de passagem de mensagens. Projetados originalmente para sistemas multiprocessadores, sua adaptação para redes de estações de trabalho e microcomputadores foi bem sucedida, facilitando a programação de aplicações paralelas.

Isso não significa que um sistema distribuído possa substituir um sistema paralelo de alta capacidade. Aplicações que precisam de supercomputadores para produzir resultados com rapidez ainda não podem ser executadas com o mesmo desempenho em outras plataformas. Porém, é possível alcançar bons resultados em aplicações mais simples. Mesmo alguns programas que exigem computadores mais potentes podem ser executados em sistemas distribuídos com o mesmo desempenho e considerável economia de custos.

Essa nova possibilidade vem acompanhada de novos problemas. A principal função de um sistema distribuído é atender seus usuários. Durante o período de trabalho dos funcionários de uma empresa, por exemplo, cada um utiliza seu computador para executar suas aplicações e a rede fornece acesso aos recursos compartilhados do sistema. Para executar aplicações paralelas nesse ambiente, buscam-se aproveitar os ciclos de processador ociosos dos nós da rede e as máquinas que eventualmente ficam livres. É lógico que isso é bastante volátil. A carga de trabalho desses computadores pode apresentar grandes variações. Assim, é preciso monitorar freqüentemente a taxa de utilização de cada processador e desviar o processamento paralelo dos computadores sobrecarregados para aqueles que ficam ociosos.

Isso leva ao estudo do balanceamento de carga, técnica que busca exatamente o melhor desempenho de um conjunto de processadores que trabalham de forma cooperativa para resolver problemas em paralelo.

O balanceamento busca equilibrar a carga dos processadores de um sistema visando alcançar um melhor desempenho global. As pesquisas na área conseguiram produzir muitas técnicas de balanceamento e hoje é possível encontrar vários algoritmos na literatura. Portanto, para cada aplicação paralela é preciso avaliar que algoritmo produz os melhores resultados.

Basicamente, as atividades desenvolvidas neste trabalho abrangem:

- Levantamento bibliográfico de trabalhos publicados sobre balanceamento de carga, métodos e algoritmos conhecidos.

- Implementação de alguns desses algoritmos em um Ambiente Paralelo Virtual (APV).

- Identificação de aplicações numéricas que possam ser utilizadas para os testes.

- Realização dos testes, medições e comparações, para conclusão final.

O objetivo pretendido com este projeto é a identificação de quais métodos de balanceamento de carga são mais apropriados em um ambiente paralelo virtual. Para isso, são considerados os seguintes elementos:

- O Ambiente Paralelo Virtual utilizado neste projeto é um sistema distribuído baseado em uma rede local de computadores da linha PC com sistema operacional Windows 95. O APV é implementado através de uma plataforma de passagem de mensagens.

- O hardware escolhido é o que está disponível no Laboratório de Sistemas Distribuídos (LASD). Não foi usado o laboratório público do ICMSC-USP porque seus equipamentos apresentam intensa utilização 
por parte dos alunos de graduação e pós-graduação. Como os testes exigiam um ambiente controlado, o LASD foi a melhor opção.

- O Windows 95 foi utilizado porque já era a base das máquinas do LASD.

- A plataforma de passagem de mensagens escolhida foi o PVM versão PVM-W95, concluída na época em que este projeto foi iniciado. Assim, o trabalho apresentado nesta dissertação também serviu para validar aquela plataforma. Por esse motivo, não foi utilizado o Linux como sistema operacional dos equipamentos do LASD.

- As aplicações escolhidas para os testes são algoritmos de cálculo numérico de intenso processamento e cuja versão seqüencial apresenta longa duração. Foi necessário implementar versões paralelas desses algoritmos e dividir o trabalho total por um número determinado de processos. A quantidade de trabalho de cada processo precisa ser dividida em lotes de forma que os métodos de balanceamento de carga consigam fazer a redistribuição da carga de trabalho para equilibrar o sistema.

- Os métodos de balanceamento de carga utilizados neste projeto são de propósito geral. Métodos específicos para determinadas aplicações foram descartados porque exigiriam também a utilização das aplicações.

Esta dissertação está organizada em 7 capítulos, compreendendo (além desta introdução):

- O capítulo 2, que trata dos sistemas distribuídos, apresentando os principais conceitos, características e algumas aplicações.

- O capítulo 3, que aborda as arquiteturas paralelas, suas classificações e algumas aplicações existentes.

- O capítulo 4, tratando de sistemas distribuídos para computação paralela, no qual são discutidas as plataformas de passagem de mensagens e, em particular, o PVM.

- O capítulo 5, que discute escalonamento e balanceamento de carga. São apresentados: o sistema de classificação dos métodos de balanceamento, o escalonamento estático, os conceitos de granularidade e particionamento e o balanceamento de carga propriamente dito.

- O capítulo 6, apresentando o trabalho realizado e o resultado dos testes.

- O capítulo 7 finaliza o trabalho, apresentando as conclusões e considerações finais. 


\section{Capítulo 2}

\section{Sistemas Distribuídos}

\subsection{Introdução}

Existem várias definições de sistemas distribuídos disponíveis na literatura. Entretanto, nenhuma delas é completamente satisfatória e dificilmente concordam umas com as outras [TAN95], como pode ser observado a seguir:

- "Nós usamos o termo sistema distribuído com o sentido de um sistema operacional distribuído" [TAN85].

- "Um sistema distribuído é um sistema com vários elementos de processamento e vários dispositivos de armazenamento, conectados entre si por uma rede" [MUL89].

- "Um sistema distribuído é aquele que não permite que você produza qualquer tipo de trabalho quando ocorre uma pane numa máquina que você nem sabia que existia" - Lamport [MUL89].

- "Um sistema distribuído consiste de um conjunto de computadores autônomos conectados por uma rede, cada um deles equipado com um software de sistemas distribuídos" [COU94].

Apesar de propostas por pesquisadores importantes da Ciência da Computação, as definições acima não conseguem transmitir uma idéia exata sobre o que realmente é um sistema distribuído. Deixando de lado a definição de Lamport, a de Mullender descreve, na verdade, uma rede comum, enquanto Tanenbaum restringe-se a tratar dos sistemas operacionais distribuídos. A definição de Coulouris é mais interessante, mas ele não propõem o que seria um software de sistemas distribuídos.

Tanenbaum, no mesmo artigo [TAN85] (e mais recentemente, também [TAN95]), apresenta essa outra definição:

"Um sistema operacional distribuído é aquele que, para os seus usuários, parece um sistema operacional centralizado, mas executa sobre múltiplas CPUs independentes. O conceito chave aqui é transparência, ou seja, os múltiplos processadores utilizados devem ser invisíveis (transparentes) para o usuário. Outra forma de expressar a mesma idéia é dizer que o usuário enxerga o sistema como um 'processador virtual único', e não como um conjunto de máquinas distintas".

Lembrando que o autor usa uma versão restrita do conceito, essa definição apresenta uma condição necessária para um sistema distribuído, mas não a única.

Mullender [MUL89] é mais realista e afirma que tentar definir exatamente o que é um sistema distribuído pode ser perigoso, já que alguma característica importante (ou que venha a ser considerada importante no futuro) pode ser esquecida. Por sua vez, 
Schroeder [MUL89] propõem que se avalie um candidato a sistema distribuído através de alguns sintomas, apresentando, em seguida, uma lista com 4 itens. Se um sistema apresenta todos esses sintomas, provavelmente ele é um sistema distribuído:

- Vários EPs (elementos de processamento).

- Hardware de interconexão.

- Os elementos de processamento falham independentemente.

- Estado do sistema compartilhado (no sentido de que o registro da situação de um sistema não deve ser centralizado em um único computador, já que ele se tornaria um ponto de falha desse sistema).

Mais recentemente, Coulouris [COU94] propõem que as características básicas, responsáveis por determinar o que vem a ser um sistema distribuído, são as seguintes:

- Compartilhamento de recursos.

- Abertura.

- Concorrência.

- Independência de escala.

- Tolerância a falhas.

- Transparência.

Todas essas características serão abordadas posteriormente, nesse trabalho.

Tanenbaum [TAN85] afirma que vários sistemas já construídos, apresentados como sendo distribuídos, não possuíam todas as características necessárias para isso. Como regra geral, ele esclarece, caso seja possível dizer qual é o computador responsável por alguma atividade, então não se está utilizando um sistema distribuído.

Fazendo um contraste, pode-se comparar um sistema distribuído com um sistema operacional de rede. Uma configuração típica, no caso, é um conjunto de computadores pessoais, um servidor de impressão e um servidor de arquivos, conectados por uma rede local. Geralmente, as características identificáveis num sistema desse tipo são as seguintes:

- Cada computador tem o seu próprio sistema operacional. Não há um sistema global para a rede inteira.

- Cada usuário trabalha em sua própria máquina. Essa contém os arquivos e programas de seu uso pessoal. Caso esse usuário precise utilizar outra máquina que não a sua, precisa fazer algum tipo de login remoto. Se a sua máquina não estiver funcionando por algum problema, esse usuário estará impossibilitado de trabalhar (ou, pelo menos, estará bastante limitado).

- O sistema de arquivos permite que se compartilhe informações até certo ponto. Entretanto, isto deve ser feito de forma explícita. Os usuários precisam saber a localização dos arquivos e um gerente de rede deve fornecer atributos aos usuários para que o acesso aos recursos compartilhados seja possível.

- Centralizar todos os dados em um servidor de arquivos é perigoso. Caso ele sofra algum tipo de pane, todos os usuários podem ter suas atividades paralisadas até que o problema seja solucionado. 


\subsection{Caracterização dos Sistemas Distribuídos}

Vários modelos de arquitetura foram sugeridos, ao longo de duas décadas de desenvolvimento, como base de projetos para sistemas distribuídos, diferindo uns dos outros conforme o hardware utilizado e sua localização na rede, e a localização dos componentes de software do sistema.

\subsubsection{Modelos Arquiteturais}

O modelo arquitetural de um sistema define seus componentes principais, sua finalidade e o relacionamento entre eles. Procura-se definir o modelo arquitetural de um sistema para classificar e analisar suas propriedades. Na década de 80, foram propostos vários modelos arquiteturais. Os principais modelos discutidos na literatura [COU88][COU94][MUL93][TAN85] são:

- Estação de trabalho/servidor.

- Banco de processadores.

- Modelo híbrido.

- Modelo integrado.

\section{Estação de trabalho/Servidor}

A maioria dos sistemas distribuídos existentes, ou em desenvolvimento, é baseada nesse modelo. As estações de trabalho não precisam ser do mesmo tipo e modelo, podendo apresentar características diferentes umas das outras [COU88].

Uma estação de trabalho possui o poder computacional necessário para executar aplicativos e fornecer suporte a interfaces gráficas para um único usuário. Entretanto, várias aplicações precisam ter acesso a arquivos compartilhados ou outros recursos. Com esse fim, pode-se integrar várias estações através de um software de comunicação, permitindo que todas elas tenham acesso ao mesmo conjunto de servidores. Esses, por sua vez, fornecem serviços de acesso aos recursos compartilhados de toda a rede (ver figura 2.1) [COU88][COU94][MUL93][TAN85]. 


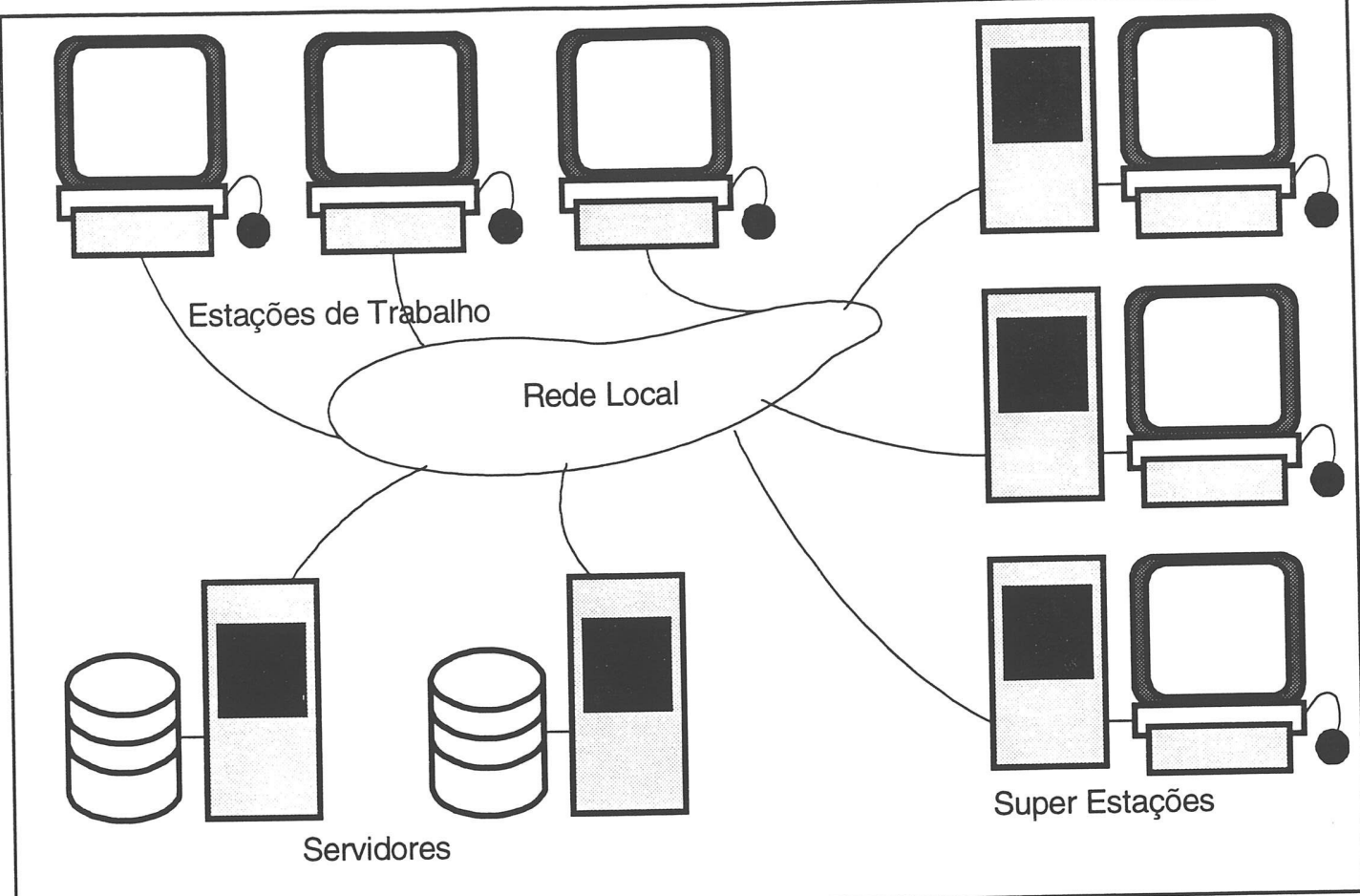

Figura 2.1. O modelo Estação de Trabalho/Servidor.

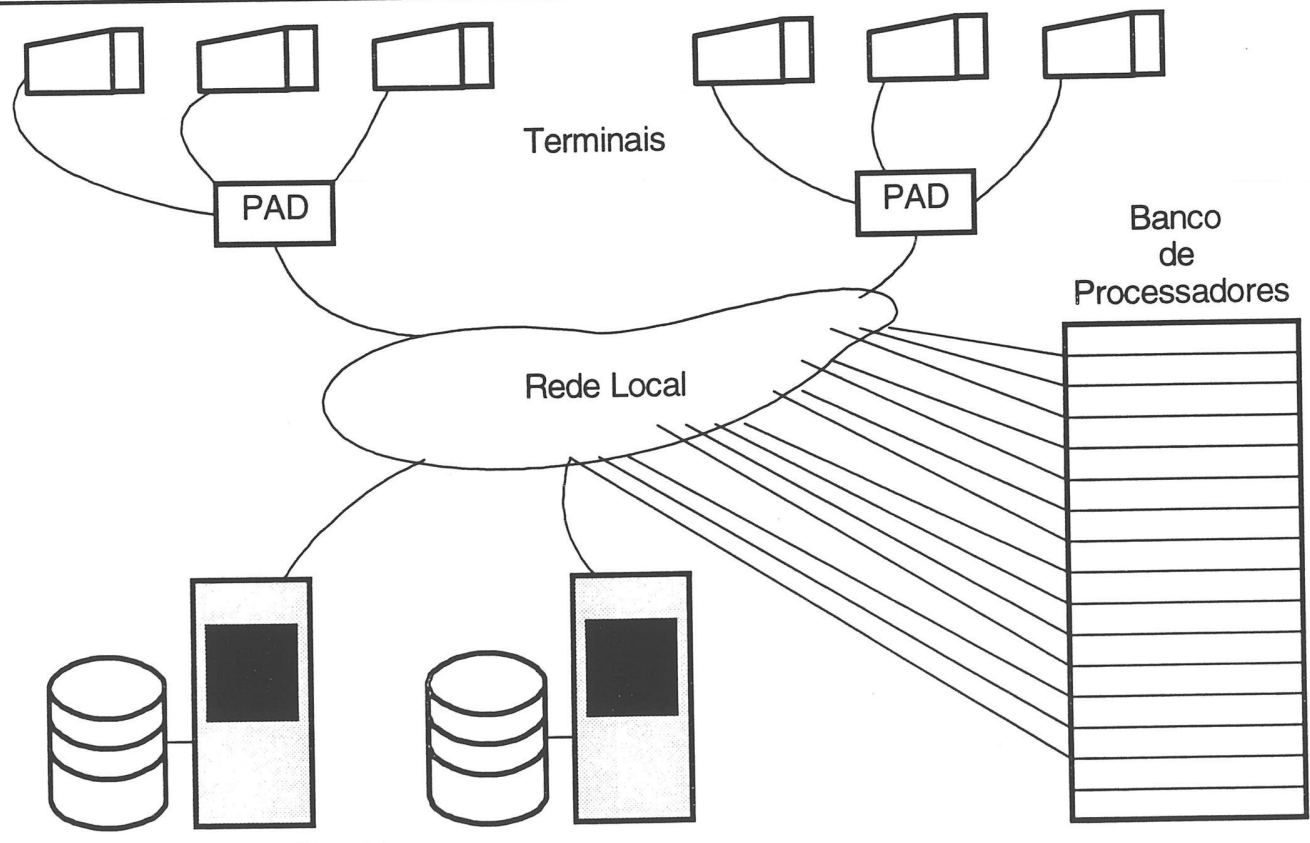

Servidores

Figura 2.2. O modelo Banco de Processadores.

\section{Banco de processadores}

O primeiro sistema distribuído baseado no modelo de banco de processadores foi o Cambridge Distributed Computing System, desenvolvido no Laboratório de Computação da Universidade de Cambridge, na Inglaterra [COU88].

Como definido originalmente, nesse modelo não há estações de trabalho. Os usuários têm acesso ao sistema através de terminais conectados à rede via computadores 
PSE (Packet Switching Exchanges). O banco de processadores é formado por um número considerável de micro e minicomputadores conectados à rede. Cada um desses processadores possui memória suficiente para carregar e executar qualquer aplicação disponível no sistema. Porém, o banco de processadores não possui terminais ou discos conectados a ele, diretamente. Os usuários podem ter acesso tanto ao banco de processadores quanto aos dispositivos de armazenamento através dos terminais ligados aos computadores PSE [COU88].

Esse modelo (ver figura 2.2) apresenta algumas vantagens sobre o anterior (estações de trabalho/servidor). O número de processadores deve ser suficiente para atender o número máximo de usuários ativos possível em qualquer instante, e não o número total de usuários que um sistema possua. Além disso, os serviços do sistema podem ser expandidos sem que seja necessário aumentar o número de computadores [COU88].

Porém, mesmo com essas vantagens, esse modelo ainda não satisfaz as necessidades de alto desempenho em programas interativos, principalmente com interfaces gráficas. O problema principal é que a velocidade de comunicação necessária entre os programas de aplicação e os terminais dificilmente é satisfatória, mesmo numa rede de alta velocidade [COU88][TAN85].

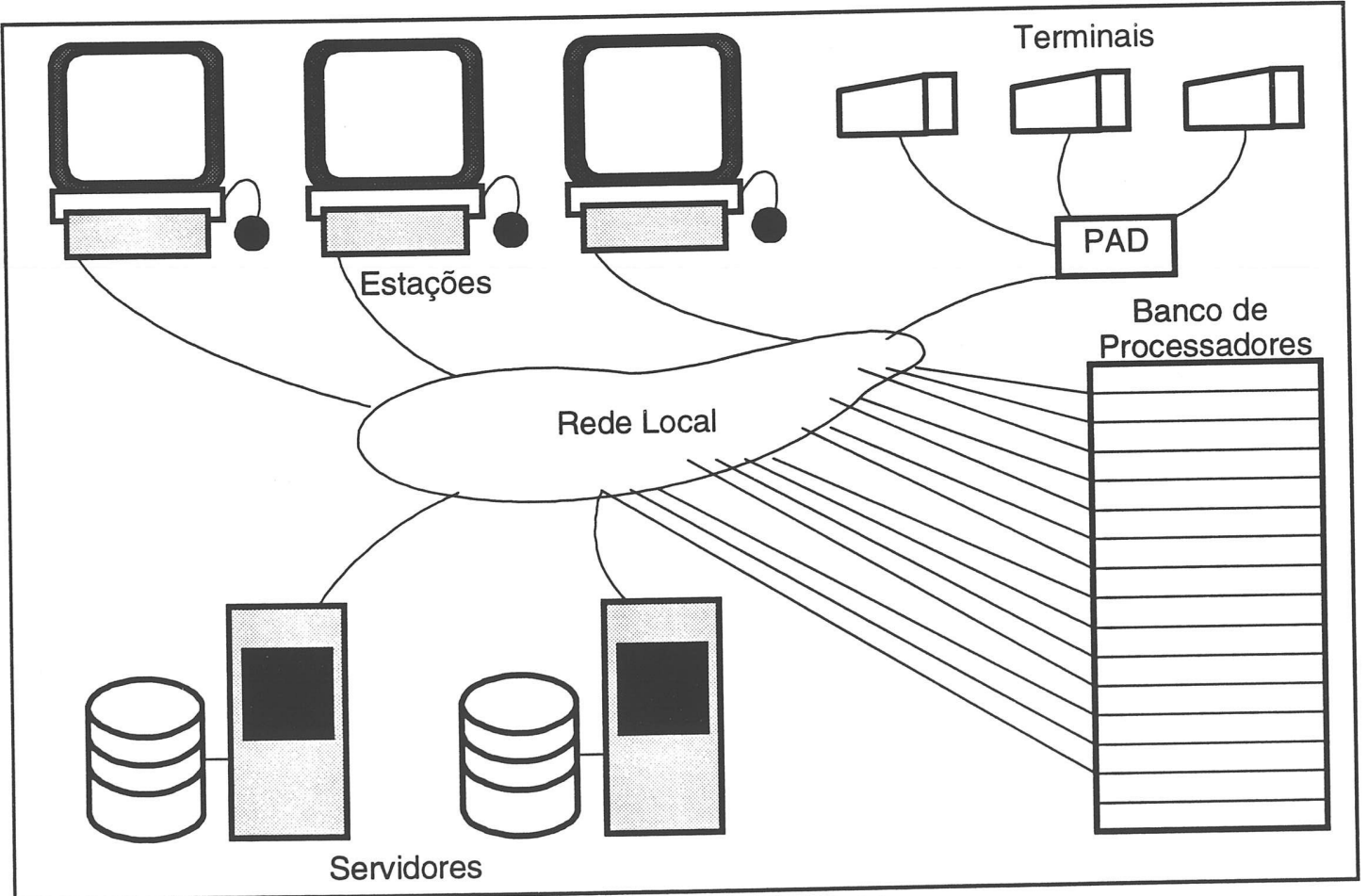

Figura 2.3. O modelo híbrido.

\section{Modelo híbrido}

Ao menos um sistema foi desenvolvido utilizando uma abordagem híbrida, que inclui um banco de processadores em um sistema de estações de trabalho/servidor. $\mathrm{O}$ sistema Amoeba [TAN93], desenvolvido por Mullender e Tanenbaum como um projeto de pesquisa em sistemas distribuídos na Universidade de Vrije, em Amsterdã, é um exemplo desse modelo (ver figura 2.3). Essa abordagem oferece muitas das vantagens de ambos os modelos. Os usuários podem usar estações de trabalho para executar 
aplicações gráficas ou de alta interatividade, enquanto o banco de processadores fornece elementos de processamento de diferentes tipos e desempenho para outras aplicações, ou caso um programa necessite de mais do que um processador para realizar uma tarefa específica [COU88][TAN85].

\section{Modelo integrado}

Esse modelo permite integrar, no mesmo sistema, minicomputadores multiusuários e estações de trabalho.

Os sistemas operacionais de computadores multiusuários centralizados interpretam nomes de arquivos e de usuários de forma relativa ao sistema de arquivos local. Os programas executados nesses sistemas utilizam o processador, a memória e outros recursos do sistema local [COU88][TAN95].

Quando vários desses sistemas são conectados por uma rede local, cada sistema operacional é estendido para permitir trocas de arquivos entre sistemas, processamento remoto de tarefas e outras facilidades. Porém, isso não é automático. Os usuários precisam fornecer explicitamente os nomes das máquinas destino [COU88][TAN95].

Num nível mais ambicioso, um conjunto de computadores pode ser gerenciado por um único sistema operacional distribuído, que parece para os usuários um único sistema de computação. O sistema Locus [POP85], desenvolvido na Universidade da Califórnia, em Los Angeles, é um exemplo de um sistema operacional distribuído UNIXlike multiusuário. Sistemas desse tipo fornecem um ambiente distribuído integrado, no qual cada computador tem um alto grau de autonomia, mas todos podem compartilhar dados através de um esquema global de nomes [COU88].

\subsubsection{Características Essenciais}

Segundo Coulouris [COU94], as características fundamentais de um sistema distribuído, responsáveis por sua funcionalidade e poder computacional, são as seguintes:

- Compartilhamento de recursos.

- Abertura.

- Concorrência.

- Independência de escala.

- Tolerância a falhas.

- Transparência.

\section{Compartilhamento de Recursos}

O termo recurso é um tanto vago, mas parece ser o mais adequado para definir a gama de coisas que podem ser compartilhadas em um sistema distribuído. Um recurso pode ser desde um componente de hardware, como discos e impressoras, até entidades lógicas, como arquivos, bancos de dados, programas, etc. [COU94].

O conceito de compartilhamento de recursos surgiu no começo dos anos 60, com os sistemas time-sharing (ou multiusuários) e foi consolidado com os sistemas UNIX nos anos 70 [COU94][TAN95]. 
Enquanto alguns dispositivos (como impressoras e discos de grande capacidade) são compartilhados por conveniência ou para redução de custos, o compartilhamento de dados é essencial em várias aplicações [COU94]:

- Em uma equipe de desenvolvimento de software, o trabalho de cada um deve ser acessível aos demais e é interessante que todos utilizem as mesmas ferramentas para compilar, editar ou depurar programas. Se uma única cópia de um programa é compartilhada, há economia de espaço em disco e, quando uma nova versão é instalada, todos os usuários obtêm acesso imediato a ela.

- Várias aplicações comerciais permitem aos usuários ter acesso às informações de um banco de dados de forma compartilhada.

- Uma área de aplicação de redes e sistemas distribuídos que está em rápida expansão é o suporte a grupos de trabalho, que dependem intensivamente do compartilhamento de dados por programas que são executados em diferentes estações.

Os recursos de um sistema distribuído são mantidos fisicamente por um dos computadores da rede e, portanto, o acesso compartilhado a eles não é automático. Primeiro, é preciso haver comunicação entre as diversas estações. Em seguida, é preciso organizar o compartilhamento. Nesse ponto, aparece o conceito de gerente de recursos, responsável por apresentar aos usuários uma interface que permita ter acesso, manipular e atualizar um recurso de forma segura e consistente [COU94].

Um gerente de recursos, na verdade, é um módulo de software que gerencia um conjunto de recursos de um determinado tipo. Cada tipo de recurso apresenta necessidades diferentes em termos de políticas e de métodos de gerenciamento, mas também existem necessidades comuns a vários deles. Por exemplo, um esquema de nomes para cada classe, que permita que se tenha acesso a recursos específicos de qualquer ponto do sistema, ou o método de relacionamento entre nomes de recursos e endereços de comunicação, e ainda a coordenação de acessos concorrentes que mudem o estado de recursos compartilhados para garantir a sua consistência [COU94].

A figura 2.4 ilustra um modelo de sistema distribuído em que cada nó representa um programa. Esse sistema é composto por dois grupos principais: um de gerentes e outro de recursos. Os usuários comunicam-se com os gerentes para obter acesso aos recursos compartilhados desse sistema [COU94].

A partir desse modelo simples, é possível desenvolver dois modelos muito interessantes em se tratando de sistemas distribuídos [COU94]:

- O modelo cliente-servidor.

- O modelo baseado em objetos. 


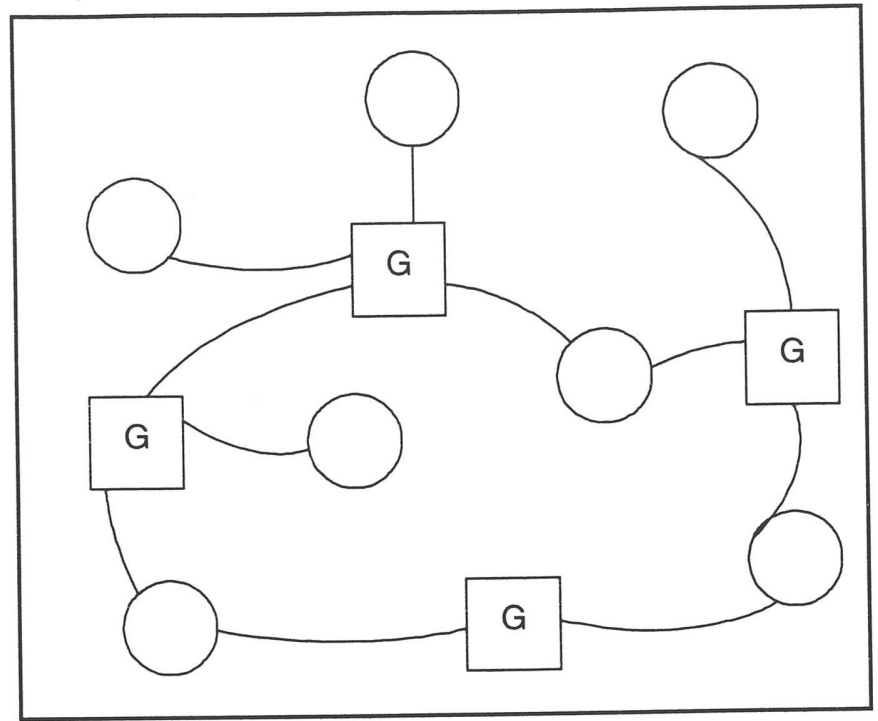

Figura 2.4. Gerentes de Recursos (G) e Usuários de Recursos ( o ).

\section{Modelo cliente-servidor}

Atualmente, o modelo cliente-servidor (ver figura 2.5) é o mais adotado em sistemas distribuídos e foi apareceu juntamente com os sistemas UNIX distribuídos. Nele, é possível identificar um grupo de processos servidores, que atuam como gerentes de recursos de determinados tipos, e um grupo de processos clientes que, para realizar suas tarefas, precisam ter acesso a recursos compartilhados de software e hardware. Os servidores, por sua vez, podem precisar ter acesso a recursos controlados por outros gerentes. Assim, alguns processos podem ser clientes e servidores ao mesmo tempo, nesse modelo [COU94].

$\mathrm{O}$ modelo cliente-servidor permite uma abordagem efetiva e geral para o compartilhamento de informações e recursos em um sistema distribuído. Ele pode ser implementado em uma gama muito grande de plataformas de hardware e software. Os computadores que executam tanto os processos clientes quanto os servidores podem ser configurados de várias formas, não sendo necessário distinguir um do outro para utilizar o sistema [COU94].

Numa forma simplificada, pode-se pensar que um processo servidor centraliza os recursos que ele gerencia. Já que componentes centralizados são indesejáveis em um sistema distribuído, essa visão está equivocada. Existe uma distinção entre servidor e o serviço que ele fornece. Um serviço é uma entidade abstrata que pode ser fornecida por vários servidores, executando em computadores diferentes e cooperando entre si através da rede e de alguma forma de comunicação. Assim, há meios de garantir que o acesso a um serviço continue existindo mesmo que um servidor torne-se inoperante [COU94].

Exemplos de sistemas distribuídos que adotam esse modelo são:

- Amoeba [TAN90][TAN92][TAN93], desenvolvido na Universidade de Vrije, em Amsterdã.

- Mach [ACE86], projeto da Universidade de Carnegie-Mellon.

- Chorus [ROZ88][ROZ90], projeto iniciado no Institut National de Recherche en Informatique et Automatique (INRIA), na França.

- Andrew File System [MOR86], desenvolvido na Universidade de CarnegieMellon.

- Kerberos [STE88], desenvolvido no MIT. 


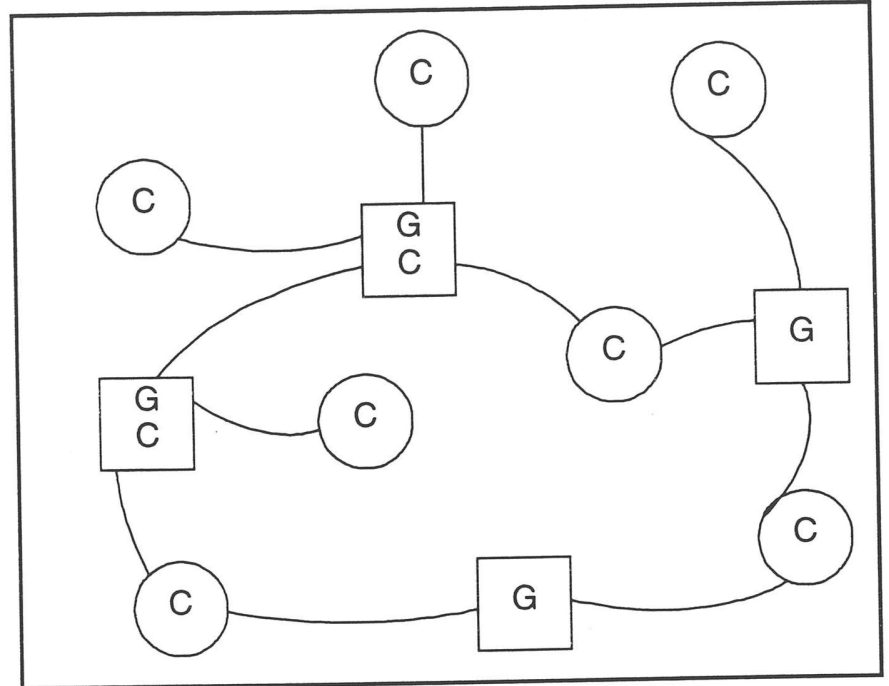

Figura 2.5. Processos Clientes (C) e Servidores (G).

\section{Modelo baseado em objetos}

O modelo baseado em objetos (figura 2.6) não tem relação com o modelo de programação orientada a objetos, mas é um modelo de sistemas distribuídos no qual cada recurso compartilhado é visto como um objeto.

Objetos são únicos, identificados e podem ser movidos pela rede sem perder suas características. Quando um programa usuário quer ter acesso a um recurso, ele envia uma mensagem requisição ao objeto correspondente. A mensagem é encaminhada ao processo apropriado e esse, ao recebê-la, realiza a operação solicitada. Caso seja necessário, o objeto envia uma mensagem resposta ao requisitante [COU94].

O modelo baseado em objetos é simples e flexível. Ele permite que todos os recursos sejam vistos de maneira uniforme pelos usuários. A interface de um recurso é padronizada, permitindo que a programação seja mais produtiva e o código final mais simples. Não há restrições ao se comparar com o modelo anterior. Assim como na abordagem cliente-servidor, os objetos também podem atuar como usuários e gerentes de recursos ao mesmo tempo [COU94].

A implementação desse modelo, porém, é mais complexa. Ele exige que se crie um gerente de objetos em todo ambiente no qual exista um objeto. A razão disso é que um objeto possui uma representação de seu estado de execução que o gerente só pode obter se estiver no mesmo ambiente que ele. Isto não seria importante se os objetos fossem fixos. Mas, como eles podem ser movidos pela rede, esse passa a ser um ponto fundamental no funcionamento do modelo [COU94].

Exemplos de sistemas distribuídos que adotam o modelo baseado em objetos:

- Argus [LIS88], desenvolvido no MIT.

- Amoeba [TAN90][TAN92][TAN93].

- Mach [ACE86].

- Arjuna [SHR89][SHR91], projeto da Universidade de Newcastle.

- Clouds [DAS91], desenvolvido no Instituto de Tecnologia da Geórgia.

- Emerald [BLA87], projeto do Cambridge Research Laboratory, da Digital Equipment Corporation. 


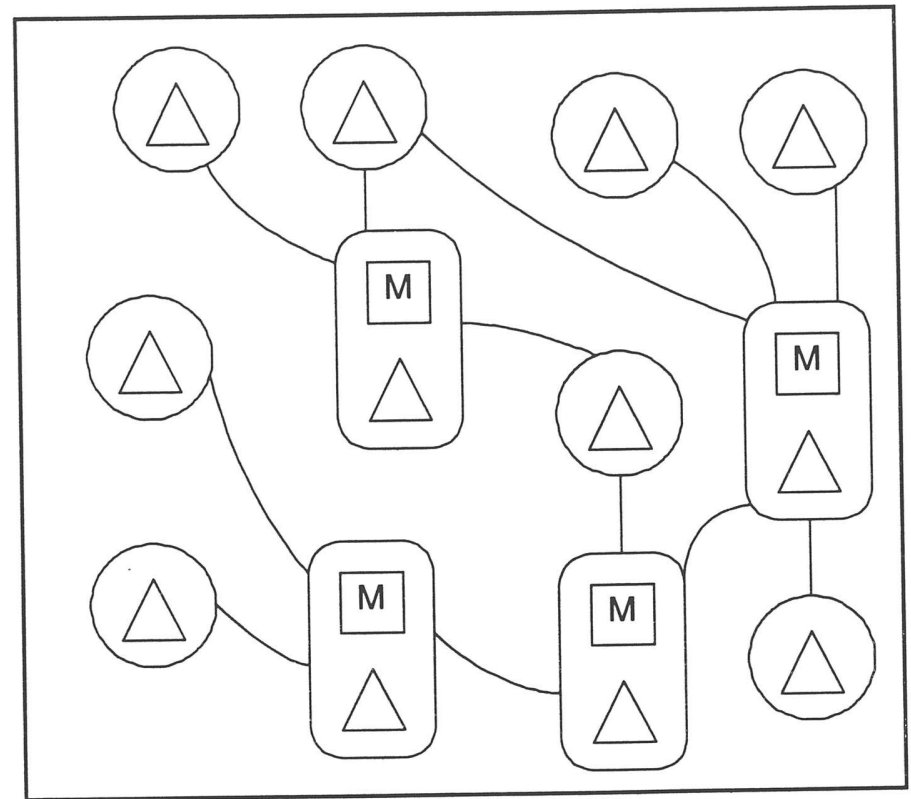

Figura 2.6. Objetos $(\Delta)$ e Gerentes $(M)$. Alguns nós apenas tem acesso aos objetos. Outros são gerentes de objetos.

\section{Abertura}

O grau de abertura de um sistema determina de que maneira ele pode ser estendido. Um sistema pode ser aberto em relação a uma característica e fechado em relação a outra. A abertura de um sistema distribuído pode ser determinada medindo-se a possibilidade de acrescentar novos serviços ou recursos compartilhados sem causar problemas para os já existentes [COU94].

Um sistema torna-se mais aberto à medida que a sua especificação e a documentação das suas interfaces vão sendo produzidas e colocadas à disposição de outros desenvolvedores. Esse processo é o início da padronização de um sistema [COU94].

Historicamente, os primeiros sistemas de computação eram fechados em larga escala. Apesar de permitir o desenvolvimento de aplicações em várias linguagens, os programadores não podiam estender a semântica de uma linguagem para explorar novos recursos de hardware ou software [COU94].

Isso começou a mudar quando surgiu o sistema operacional UNIX. Ele trouxe consigo uma linguagem de programação de alto nível, o $\mathrm{C}$, que permite aos programadores ter acesso a todos os recursos controlados pelo sistema operacional e é potencialmente portável, ou seja, um programa escrito em $\mathrm{C}$ pode ser compilado e executado em uma grande variedade de computadores diferentes [COU94].

O acesso aos recursos do sistema operacional UNIX é feito através de um conjunto de procedimentos, as chamadas ao sistema (system calls), documentadas e disponíveis aos programas escritos em $\mathrm{C}$ ou outra linguagem que tenha suporte às chamadas de procedimentos. As chamadas ao sistema são pontos de entrada no próprio núcleo (kernel) do sistema operacional. Assim, o seu projeto é o que define, de fato, os recursos compartilhados a que um programa pode ter acesso ou não [COU94].

Uma grande contribuição à abertura dos sistemas foi o surgimento da comunicação entre processos (IPC), que permite a processos servidores, executando em 
qualquer computador ou sistema operacional, colocar seus serviços à disposição de processos usuários da mesma rede. Os recursos de um sistema, com isso, não são mais restringidos pelas chamadas ao sistema disponíveis no sistema operacional local [COU94].

\section{Concorrência}

Quando vários processos residem no mesmo computador e ele só possui um processador central, eles são executados de forma concorrente [TAN92]. Isso só é possível porque a execução de todos eles é intercalada em um período de tempo. Se o computador possui $N$ processadores, então $N$ processos podem ser executados simultaneamente, ou seja, em paralelo. Se, em um sistema distribuído, há $M$ computadores, cada um deles com $N$ processadores, então $M \times N$ processos podem executar simultaneamente. Se o número de processos for maior do que isso, então os processos seguintes serão executados concorrentemente [COU94].

Em um sistema distribuído baseado em compartilhamento de recursos, há dois motivos principais para a existência de paralelismo [COU94]:

1. Muitos usuários interagem ao mesmo tempo com os programas de aplicação.

2. Muitos processos servidores executam concorrentemente, atendendo a requisições diferentes de processos clientes.

Em função disso, a existência de concorrência e paralelismo em sistemas distribuídos é uma conseqüência natural, decorrente das atividades dos usuários, da independência dos recursos e da localização dos processos servidores em computadores separados [COU94].

\section{Independência de Escala}

Os sistemas distribuídos operam com eficiência em várias escalas diferentes. O menor sistema possível consiste de duas estações e um servidor de arquivos, enquanto em uma rede local pode haver centenas de estações e muitos servidores diferentes. Podese conectar várias redes locais para formar uma rede internet, que pode conter milhares de computadores formando um único sistema distribuído, com até centenas de milhares de recursos compartilhados por todas essas máquinas [COU94].

Tanto o sistema quanto o software de aplicação não precisam ser alterados quando a escala da rede aumenta. Essa característica é garantida principalmente pela quantidade de pesquisa feita nessa área, já que as redes internet aumentam dia a dia e as redes de alto desempenho difundem-se cada vez mais [COU94].

A demanda por independência de escala em sistemas distribuídos levou a uma filosofia de projeto na qual não se permite que nenhum recurso em particular tenha qualquer restrição de fornecimento. Quando a demanda por algum recurso cresce, deve ser possível estender o sistema para atendê-la [COU94].

Esse problema foi um tema dominante, na década de 80, no desenvolvimento em sistemas distribuídos. Várias técnicas mostraram-se bem sucedidas nas pesquisas feitas nesse sentido e hoje são bastante difundidas, mesmo em outras áreas da Ciência da Computação [COU94]: 
- Replicação de dados.

- Cache.

- Grupos de servidores.

\section{Tolerância a Falhas}

Falhas são inevitáveis. Pior ainda, são imprevisíveis! Sendo assim, deve-se projetar qualquer sistema tendo isso como um de seus componentes principais. Afinal, não é uma questão de se vão ocorrer, mas sim de quando vão ocorrer [COU94].

O projeto de sistemas tolerantes a falhas é baseado em duas abordagens principais [COU94]:

- Redundância de hardware.

- Software recuperável.

Sistemas tolerantes a falhas de hardware podem, por exemplo, empregar duas máquinas interligadas para uma única aplicação, uma servindo de reserva para a outra. Nesse caso, o custo do hardware é duplicado para se alcançar maior segurança contra falhas [COU94].

Como forma de aproveitar melhor o custo de um sistema redundante, pode-se utilizar as máquinas reservas em aplicações não críticas enquanto não for detectado algum problema. Porém, tão logo uma falha ocorra, essas aplicações devem ser paralisadas, ou mesmo terminadas, para que as máquinas sejam desviadas para sua finalidade principal. Essa possibilidade deve ser prevista no projeto de aplicações não críticas [COU94].

O projeto de software recuperável deve prever que um estado consolidado de dados permanentes (por exemplo, arquivos em disco) possa ser restaurado (roll-back) quando uma falha for detectada. Em geral, o processamento feito por um programa fica incompleto quando ocorre uma falha. Além disso, os dados já atualizados podem estar em um estado inconsistente. Por isso, deve haver mecanismos para restaurar os dados ao estado anterior à execução do programa que falhou [COU94].

Os sistemas distribuídos permitem um alto grau de disponibilidade em relação a falhas e isto pode ser medido pela proporção de tempo em que um sistema fica disponível para os seus usuários. Num computador multiusuário, quase todas as falhas tornam-no indisponível a qualquer pessoa. Quando um componente de um sistema distribuído falha, somente o trabalho que o estava utilizando é afetado. Um usuário pode usar outra estação se a sua deixar de funcionar, ou um processo servidor pode ser reiniciado em outro computador [COU94].

Entretanto, as redes nas quais os sistemas distribuídos são baseados normalmente não são redundantes. Portanto, falhas nessas redes podem interromper a comunicação entre os componentes de um sistema, paralisando os serviços dos usuários. Mesmo sobrecargas no tráfego de rede podem afetar o desempenho e, portanto, a qualidade do serviço prestado [COU94].

Por outro lado, os sistemas cliente-servidor normalmente exigem organizações de software específicas para explorar tanto a concorrência em larga escala quanto a tolerância a falhas. Um paradigma muito interessante para a construção de programas concorrentes com replicação é o de grupo de processos [COU94]. 
Um grupo de processos é uma construção que permite a um número de processos concorrentes trabalharem de forma cooperativa para fazer um determinado serviço. O grupo pode ser aumentado ou reduzido conforme a demanda e, caso um dos processos venha a falhar, os demais assumem as suas tarefas [COU94].

\section{Transparência}

A transparência, em um sistema distribuído, é a capacidade de ocultar do usuário e do programador de aplicação a separação de seus componentes, de forma que percebese o sistema como um todo e não como um conjunto de elementos independentes [COU94].

A separação de seus componentes é uma propriedade inerente a um sistema distribuído. Como consequiência dela, existe a necessidade de comunicação, de gerenciamento explícito do sistema e de técnicas de integração. Por outro lado, a separação permite executar programas com paralelismo real, a contenção de falhas em componentes e a recuperação de falhas sem interrupção de todo o sistema, o uso de isolamento e controle dos canais de comunicação como política de segurança e o crescimento do sistema pela adição de novos componentes [COU94].

Nos trabalhos de padronização dos sistemas distribuídos, a ANSA (Advanced Network Systems Architecture) [ANS89] e a ISO (International Standards Organization) [ISO92] identificaram 8 formas de transparência, a saber [COU94]:

1. Transparência de acesso: permite que objetos locais e remotos possuam operações de acesso idênticas.

2. Transparência de localização: faz com que o acesso a qualquer objeto seja possível sem a necessidade de conhecer sua localização.

3. Transparência de concorrência: permite que vários processos trabalhem concorrentemente sobre informações compartilhadas sem interferência entre eles.

4. Transparência de replicação: permite usar múltiplas instâncias de objetos para aumentar o desempenho e a tolerância a falhas, sem que usuários ou programas de aplicação tenham conhecimento de sua existência.

5. Transparência de falhas: oculta as falhas de usuários e programas de aplicação, permitindo que eles completem suas tarefas de forma confiável.

6. Transparência de migração: permite movimentar objetos dentro de um sistema sem afetar a funcionalidade de qualquer de seus componentes.

7. Transparência de desempenho: permite a um sistema se reconfigurar para melhorar o seu próprio desempenho a medida que a sua carga de trabalho varie.

8. Transparência de escala: permite que o sistema e as aplicações aumentem em escala sem que seja necessário mudar a estrutura do sistema ou os algoritmos das aplicações.

Das formas de transparência citadas, as mais importantes são as de acesso e localização, algumas vezes chamadas, também, de transparência de rede [COU94]. 


\subsection{Aplicações de Sistemas Distribuídos}

Virtualmente em todas as empresas, os negócios estão se tornando cada vez mais descentralizados. Não faz muito tempo, a direção de uma companhia agia como se fosse o seu cérebro, processando informações e comunicando decisões a todo o seu corpo. Hoje, porém, a tomada de decisão está sendo empurrada para baixo na pirâmide da organização e ficando sob a responsabilidade das pessoas que ficam mais perto de onde ocorre a ação, aquelas que fazem contato direto com os clientes e fornecedores. E, para onde a tomada de decisão vai, os computadores devem ir, também [SYB95].

De fato, em organizações descentralizadas, os computadores estão por toda parte. Em praticamente todas as mesas há um computador pessoal. As estações de trabalho dominam a engenharia. Sistemas departamentais proliferam em subsidiárias de grandes companhias pelo mundo inteiro. Computadores portáteis viajam junto com os funcionários a qualquer lugar em que seja necessário negociar pela empresa. A computação, assim, é quase onipresente em todas as atividades empresariais [SYB95].

Dentro desse novo enfoque, os sistemas distribuídos ganham importância cada vez maior, já que seu modelo estrutural é o mais adequado para representar essa realidade. É possível encontrar inúmeras aplicações de sistemas distribuídos, nos mais variados campos da atividade humana [SYB95].

\section{Aplicações em Sistemas de Telefonia}

A AT\&T, há alguns anos atrás, precisava atualizar e distribuir novos números de telefone por 250 bancos de dados diferentes. Isso fazia com que o custo por transação fosse altíssimo, tanto em dinheiro quanto em tempo. Seus clientes, porém, queriam que os números de seus telefones fossem atualizados com precisão, imediatamente e, é claro, a um custo barato, de preferência gratuitamente, como faziam várias pequenas empresas de comunicação por todo o país. A solução foi construir um sistema distribuído com servidores replicados de banco de dados SQL em três grandes sistemas computacionais localizados em duas cidades diferentes. Hoje, a AT\&T é capaz de fazer entre 30 mil e 300 mil atualizações diárias, com um aumento considerável da confiabilidade do sistema e uma redução dramática do custo por transação [SYB95].

\section{Aplicações Financeiras}

O Chase Manhattan Bank, um dos maiores bancos do mundo, com operações em mais de 50 países, implementou uma arquitetura de sistemas para permitir aos seus gerentes de serviços serem mais proativos em antecipar as necessidades dos clientes por produtos e serviços. Através do Sybase MPP (Massively Parallel Processor), o Chase consegue consolidar 400 GB de dados de 54 sistemas distribuídos diferentes. Esses dados permitem que o pessoal de marketing, de serviços para clientes, de operações e gerentes do Chase tenham uma visão corporativa de todo o negócio, o que reduz custos anuais que chegavam a \$ 17 milhões a uma pequena fração desse montante [SYB95]. 


\section{Aplicações para Estúdios de Cinema}

A Metro-Goldwyn-Mayer possui um sistema distribuído para seu pessoal de vendas que permite acesso de qualquer lugar do mundo a informações de licenciamento e inventário dos arquivos do estúdio sobre mais de 4500 filmes. Com esses dados, um vendedor pode negociar acordos de transmissão do próprio escritório do cliente. Isto causou um aumento das vendas da MGM, enquanto os custos operacionais diminuíram [SYB95].

\section{Aplicações de Comunicação}

A Ericsson Messaging Systems, localizada em Woodbury, NY, é uma subsidiária da empresa sueca Telefonaktiebolaget LM Ericsson, um dos líderes mundiais em tecnologia avançada de comunicação, tanto para redes públicas como privadas. Baseada no DCE (Distributed Computing Environment) da OSF (Open System Foundation), um sistema distribuído desenvolvido sobre sistemas operacionais conhecidos (como UNIX, VMS, Windows e OS/2 [TAN95]), a Ericsson MS desenvolveu o sistema MXE, um sistema de troca de mensagens multimídia de alta confiabilidade que dá suporte a voz, FAX, correio eletrônico, paging de longo alcance e comunicação móvel. Com o MXE, a Ericsson garante a seus clientes em todo o mundo acesso a mensagens de qualquer lugar do planeta, sem um só extravio sequer [TRA94].

\section{Aplicações para Seguradoras}

A GE Capital Mortgage Insurance (GEMICO), uma divisão da General Electric Capital Corporation localizada em Raleigh, na Carolina do Norte, precisa estar sempre pronta para responder a mudanças no mercado financeiro. Quando as taxas de juros caem, a companhia deve ser capaz de tratar o fluxo de requisições de empréstimos que podem ocorrer em um único dia. A GEMICO processa pelo menos mil empréstimos com hipotecas por dia, sendo que a maior parte é recebida entre 3 e 11 horas da manhã. Desses mil empréstimos, $70 \%$ são segurados pelos agentes do Centro Nacional de Processamento da GEMICO e o restante é encaminhado para outras filiais. Para manter seu sistema de processamento adaptável à carga de trabalho, a GEMICO optou por construir um sistema distribuído baseado no DCE e em redes de PCs, que permite qualidade no atendimento, segurança para trabalhar em um ambiente bastante volátil, enquanto a companhia consegue acompanhar as necessidades crescentes de seus vários setores [TRA95a].

\section{Aplicações para Institutos de Pesquisa}

O NASA Langley Research Center (LaRC), uma inovadora agência de pesquisa do governo americano, tem como objetivo principal garantir a posição de vanguarda da engenharia aeronáutica e espacial dos Estados Unidos. Localizado na cidade de Hampton, no estado de Virgínia, o LaRC possui mais de 3 mil empregados espalhados por cerca de 200 prédios. A agência utiliza o DCE Distributed File System (DFS) para fornecer aos seus diversos usuários acesso compartilhado a arquivos e ferramentas com alta taxa de disponibilidade, independente do tipo de estação de trabalho ou sistema 
operacional. Com isso, o LaRC procura maximizar seus esforços de pesquisa, facilitando a administração dos projetos em andamento, ao mesmo tempo que possibilita transferir com facilidade seus resultados para outras agências governamentais, outros centros da NASA e para as indústrias ligadas ao governo. Seu trabalho contribui para o projeto, desenvolvimento e operação de futuros veículos aeroespaciais e suas missões [TRA95b].

\subsection{Considerações Finais}

Os sistemas distribuídos têm sido objeto de pesquisas cada vez mais intensas por parte da comunidade de informática no mundo inteiro. Apesar de haver divergências com relação às suas características básicas e até sobre o que eles são, de fato, não foi possível encontrar referências que ponham em dúvida sua utilidade nem sua importância. Isto leva a crer que, no futuro, as pesquisas possam eliminar, em grande parte, as diferenças de opinião entre os pesquisadores e tornar os sistemas distribuídos um produto de uso comum no dia a dia das pessoas.

O uso de plataformas baratas e de domínio público, como as redes locais baseadas em microcomputadores tipo PC, pode ser um grande facilitador desse objetivo, já que abrangem os mais variados tipos de atividades e portes empresariais. Como foi citado, o que diferencia um sistema distribuído de um sistema comum é o seu software. Uma plataforma física de ampla aceitação no mercado, aliada às vantagens indiscutíveis que os sistemas distribuídos apresentam, tornaria qualquer produto comercial desse tipo (com um preço compatível) líder de mercado em muito pouco tempo. 


\section{Capítulo 3}

\section{Arquiteturas Paralelas}

\subsection{Introdução}

Segundo Almasi [ALM94], a maioria dos projetos atuais de processadores com alto paralelismo podem ser enquadrados na seguinte definição:

"Um grande número de elementos de processamento comunicando entre si e cooperando para resolver rapidamente problemas muito grandes."

Por sua vez, processamento paralelo, segundo Hwang [HWA84], significa:

"Uma forma eficiente de processamento de informação que enfatiza a exploração de eventos concorrentes no processo computacional".

O principal aspecto motivador do processamento paralelo é a necessidade de desempenhos computacionais cada vez maiores. Os problemas dos usuários aumentam a taxas crescentes, enquanto as máquinas seqüenciais apresentam limitações tecnológicas para evoluir na velocidade necessária [ALM94].

Historicamente, o ímpeto da pesquisa em processamento paralelo vem de 3 fontes diferentes [ALM94]:

- Problemas muito grandes, que são lentos mesmo nos supercomputadores contemporâneos mais rápidos.

- Problemas que podem ser resolvidos com supercomputadores, recurso a que, infelizmente, poucos têm acesso.

- A busca por maior produtividade dos programadores, fornecendo ferramentas apropriadas para o desenvolvimento de aplicações paralelas.

Alguns fatores foram fundamentais para tornar possível o desenvolvimento da indústria de máquinas paralelas [ALM94]:

- O desenvolvimento da tecnologia de hardware (em particular, o padrão VLSI), que veio opor-se à Lei de Grosch, uma observação válida durante muito tempo, que afirmava que a melhor relação preço/desempenho era obtida com o processador central mais poderoso.

- Restrições físicas, como a velocidade da luz, tornam as dificuldades cada vez maiores para que a tecnologia sozinha consiga aumentar a velocidade de um processador seqüencial.

- Do ponto de vista do software, John Backus, o criador da Linguagem FORTRAN, afirma que a produtividade do programador está declinando em função do "gargalo de von Neumann" e que "é preciso desenvolver novas linguagens e arquiteturas com suporte melhor às equipes de desenvolvimento". 


\subsection{Classificação de Arquiteturas Paralelas}

Para compreender um modelo computacional, é importante determinar suas características e compará-las com as de outros modelos. Isso permite construir um sistema taxonômico no qual pode-se situar os modelos existentes, tornando mais fácil o trabalho de desenvolvimento de novos modelos.

O sistema de classificação de modelos computacionais paralelos mais utilizado na literatura é o proposto por Flynn [FLY72], que propõem que a essência do processo computacional é a execução de fluxos de instruções sobre fluxos de dados. Mais recentemente, Duncan [DUN90] apresenta um sistema de classificação complementar, com o objetivo de acomodar os resultados das pesquisas em arquiteturas de computadores posteriores a Flynn.

\subsubsection{Classificação de Flynn}

As quatro formas de organizar uma arquitetura de computadores, segundo Flynn, são as seguintes:

- Single Instruction stream, Single Data stream (fluxo Simples de Instruções, fluxo Simples de Dados) - SISD.

- Single Instruction stream, Multiple Data stream (fluxo Simples de Instruções, fluxo Múltiplo de Dados) - SIMD.

- Multiple Instruction stream, Single Data stream (fluxo Múltiplo de Instruções, fluxo Simples de Dados) - MISD.

- Multiple Instruction stream, Multiple Data stream (fluxo Múltiplo de Instruções, fluxo Múltiplo de Dados) - MIMD.

As arquiteturas tipo SISD representam a maioria das máquinas seriais disponíveis hoje. As instruções são executadas seqüencialmente, apesar de vários projetos permitirem a sobreposição dos estágios de execução (pipeline). Pode haver mais de uma unidade funcional num mesmo processador SISD, mas todas elas são supervisionadas pela mesma unidade de controle.

Os computadores SIMD correspondem aos processadores vetoriais. Possuem vários elementos de processamento dirigidos pela mesma unidade de controle. Todos os elementos recebem as mesmas instruções da unidade de controle, mas operam sobre informações diferentes do mesmo fluxo de dados.

Uma arquitetura MISD, em tese, possui n unidades de processamento, cada uma delas recebendo instruções distintas para operar sobre o mesmo fluxo de dados. O resultado de um processador torna-se entrada para um outro, criando um macropipeline. Essa estrutura recebeu pouca atenção dos projetistas de hardware e é considerada como impraticável por alguns arquitetos de computadores. Não há conhecimento de exemplos práticos dessa classe.

As arquiteturas MIMD englobam a maioria dos sistemas multiprocessadores e multicomputadores existentes. Dizer que uma máquina é MIMD implica que haja interação entre seus $\mathrm{n}$ processadores. Há duas formas de permitir isso: através de memória compartilhada, ou por troca de mensagens. Se o fluxo de dados de um sistema MIMD tem origem em sub-espaços disjuntos de memória, então pode-se dizer que o sistema é do tipo MSISD (Multiple SISD), que, na verdade, é um conjunto de $\mathrm{n}$ sistemas 
SISD independentes. Pode-se dizer que um sistema MIMD é fortemente acoplado se o grau de interação entre seus processadores é alto. Caso contrário, ele é fracamente acoplado. A maioria dos computadores MIMD comerciais é fracamente acoplada.

\subsubsection{Classificação de Duncan}

A classificação de Duncan procura manter e ampliar a classificação de Flynn, permitindo identificar as arquiteturas desenvolvidas posteriormente ao seu trabalho como, por exemplo, as máquinas sistólicas e hipercúbicas. As arquiteturas que apresentam apenas paralelismo de baixo nível não são consideradas, já que essas técnicas são de amplo domínio na indústria de hardware [DUN90].

A classificação inteira pode ser vista na figura 3.1. Nela, podem-se identificar dois grandes grupos de arquiteturas: as síncronas e assíncronas.

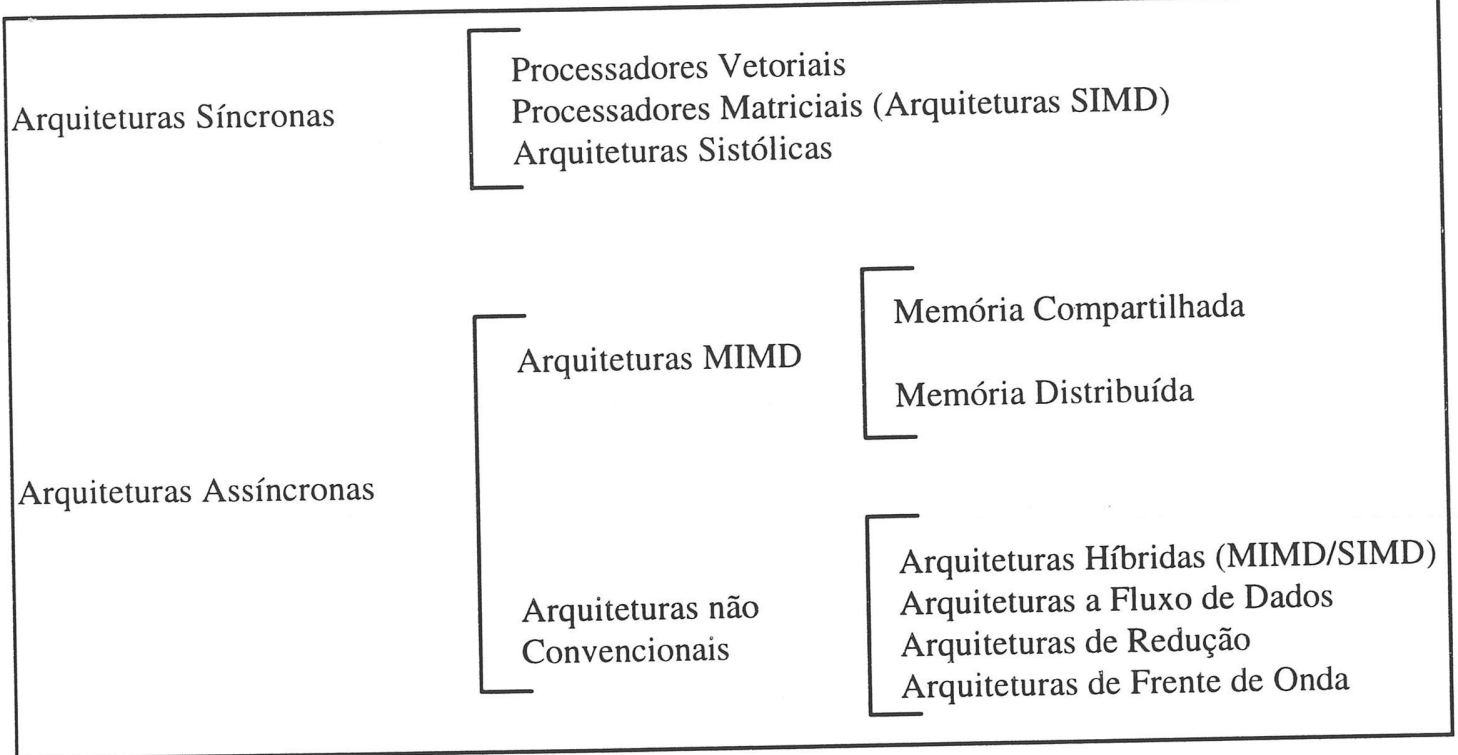

Figura 3.1. Classificação de Duncan.

\section{Arquiteturas síncronas}

Nesse tipo de arquitetura normalmente existe uma unidade de controle central e um relógio global para todo o sistema. Nessa categoria, enquadram-se [DUN90]:

- Processadores vetoriais: apresentam hardware específico para realizar operações sobre vetores.

- Arquiteturas SIMD: já descritas anteriormente, são compostas por um único fluxo de instruções atuando sobre vários fluxos de dados diferentes. Um exemplo dessa categoria são os processadores matriciais.

- Arquiteturas sistólicas: possuem vários processadores conectados em seqüência. A informação trafega de um processador para outro antes de ser armazenada na memória. O nome sistólicas foi escolhido porque os dados são movimentados de processador para processador de forma síncrona. Os elementos de processamento normalmente são simples, mas o sistema apresenta alto grau de paralelismo. 


\section{Arquiteturas assíncronas}

Essa classe representa toda a categoria MIMD de Flynn. Não possuem controle centralizado e cada unidade de processamento executa um programa específico sobre dados de sua própria memória. As arquiteturas assíncronas são divididas em dois grandes grupos [DUN90]:

- Arquiteturas MIMD convencionais: a organização da memória determina o sincronismo e a forma de comunicação entre os processadores.

- Memória compartilhada: todos os processadores têm acesso à memória inteira, mesmo que, fisicamente, ela seja dividida em blocos independentes. As máquinas são fortemente acopladas (também chamadas de multiprocessadores) devido à grande troca de informação entre os elementos de processamento.

- Memória distribuída: cada processador tem sua própria memória e a comunicação entre eles acontece por troca de mensagens através da rede de interconexão. Como o tempo de latência de uma mensagem é considerável, a comunicação entre os processadores deve ser evitada, levando a sistemas fracamente acoplados (também chamados de multicomputadores).

- Arquiteturas MIMD não convencionais: agrupa todas as máquinas que não se enquadram em nenhum dos outros grupos. Exemplos dessa categoria são:

- Máquinas híbridas (MIMD/SIMD): módulos de uma arquitetura MIMD controladas por arquiteturas SIMD.

- Fluxo de dados (Dataflow): a execução de instruções nesse modelo é baseada na demanda por operandos, ou seja, uma instrução só pode ser executada quando todos os seus operandos estiverem disponíveis. O paralelismo é bastante natural nessas máquinas, podendo ser explorado a nível de tarefas, procedimentos ou mesmo de instruções.

- Redução: também um tipo de arquitetura dirigida por demanda, na qual os processadores só executam um comando quando uma expressão necessita de seu cálculo. A idéia de redução reside em substituir porções do código fonte original de um programa pelo seu significado.

- Frente de onda: combina estruturas pipeline sistólicas com sistemas de fluxo de dados. Não possui um relógio global para sincronizar os eventos no sistema inteiro.

Todas essas máquinas são assíncronas e possuem múltiplos fluxos de instruções e de dados, mas apresentam características peculiares que impedem que sejam classificadas apenas como arquiteturas MIMD. 


\subsection{Aplicações de Arquiteturas Paralelas}

As aplicações que apresentam suficiente paralelismo para manter diversos elementos de processamento ocupados simultaneamente dividem-se principalmente em duas categorias de processamento: numérico e simbólico. Elas diferenciam-se pela taxa de movimentação de dados calculados entre os elementos de processamento. As aplicações científicas e de engenharia mais tradicionais apresentam alguns problemas de computação numérica bastante grandes, como cálculo de partículas (plasma), dinâmica de fluídos (previsão do tempo, projeto de aeronaves), projeto auxiliado por computador e muitos outros. As modernas aplicações de processamento simbólico incluem sistemas de bancos de dados, inteligência artificial aplicada (sistemas especialistas) e outras [ALM94].

\section{Aplicações Científicas}

Desde que os primeiros computadores foram construídos, as máquinas mais poderosas têm sido utilizadas para resolver grandes problemas de computação científica. Um dos grandes esforços dos pesquisadores nessa área é escrever programas científicos que fazem a maior parte de seu trabalho sobre vetores, alcançando, assim, alto desempenho quando executados sobre processadores vetoriais. Entretanto, isto não é possível para alguns algoritmos, que precisam ser resolvidos em máquinas MIMD de grande escala (com elevado número de elementos de processamento) [ALM94].

Alguns exemplos práticos desse tipo de aplicação incluem cromodinâmica quântica, o fluxo de sangue no coração, a dinâmica molecular e a evolução das galáxias no universo. Um exemplo bastante interessante de aplicação científica com intenso uso de computação paralela é a previsão de tempo [ALM94].

\section{Previsão de tempo}

Considerando os grandes benefícios que uma previsão de tempo precisa pode trazer para a economia de um país e para a qualidade de vida de seus cidadãos, não é surpresa que grandes esforços tenham sido feitos para tornar esse trabalho cada vez mais eficiente. Embora as "danças de chuva" encontradas no Almanaque dos Fazendeiros do meio-oeste dos Estados Unidos sejam fascinantes, os cientistas restringem seu interesse apenas na previsão de tempo feita com técnicas numéricas. Há vários modelos de resolução desse problema, entre eles o Modelo NASA GLAS/GISS de Circulação Geral de $4^{\underline{a}}$ Ordem de uma Atmosfera de Três Dimensões. Nesse modelo, são consideradas algumas grandezas que caracterizam o estado da atmosfera e algumas equações de hidrodinâmica associadas a essas grandezas. A atmosfera é dividida em sub-regiões, que são mapeadas em pontos de uma grade. A seguir, um conjunto de equações diferenciais parciais relativas às variáveis meteorológicas (definidas para infinitos pontos do espaço) é aplicado para o universo dos pontos da grade considerada. Por último, os valores encontrados para as grandezas meteorológicas no tempo t são utilizados para calcular os mesmos valores no tempo $\mathrm{t}+\Delta \mathrm{t}$ [ALM94].

No modelo GLAS/GISS, a atmosfera tem duas dimensões horizontais representando uma área da superfície da Terra e uma dimensão vertical representando a altitude. $\mathrm{O}$ estado da atmosfera é caracterizado por 5 variáveis primárias [ALM94]: 
- Dois componentes horizontais da velocidade do vento.

- A temperatura.

- A umidade específica.

- A diferença de pressão entre a superfície e o topo da atmosfera.

e por 3 variáveis secundárias:

- O geopotencial, que corresponde aos efeitos gravitacionais.

- O componente vertical da velocidade do vento.

- A pressão.

É interessante verificar que, conforme esse modelo, o estado meteorológico da atmosfera não inclui a precipitação nem a cobertura de nuvens. Apesar de que as observações sobre o tempo normalmente apresentam algo como "parcialmente encoberto e sujeito a pancadas de chuva no final do período", essas manifestações são consideradas variáveis terciárias do estado da atmosfera e podem ser calculadas a partir das variáveis primárias e secundárias, principalmente pela umidade e o componente vertical da velocidade do vento [ALM94].

O coração de um programa de previsão de tempo baseado nesse modelo é a forma de expressar as leis da natureza em equações diferenciais parciais associada ao procedimento de cálculo das condições em $t+\Delta t$ a partir das condições no tempo $t$ [ALM94].

\section{Aplicações de Engenharia}

A engenharia é uma das áreas que mais fazem uso de cálculo intensivo para a produção de bens. Grandes indústrias, como nos setores aeroespaciais, petróleo, energia e construção, só conseguem atingir um nível de segurança aceitável em suas atividades por meio de cálculos exaustivos sobre as condições que afetam seus produtos [ALM94].

Um dos exemplos encontrados na literatura sobre o uso de computadores paralelos na engenharia de produtos sofisticados é o projeto de processadores VLSI.

\section{Projeto de processadores VLSI auxiliado por computador}

Comparado com o processo de construir um circuito com componentes discretos, o projeto de um chip VLSI apresenta algumas diferenças bastante características. Primeiro, é preciso gastar muito mais tempo no projeto do bloco do chip antes que ele possa ser testado. Depois, a grande maioria dos pontos internos é inacessível para testes porque as entradas e saídas de sinal são em número reduzido. O efeito dessas duas restrições é pressionar a indústria para fabricar chips corretos antes que qualquer hardware seja construído [ALM94].

Para garantir que um projeto esteja correto, existem várias ferramentas disponíveis. Uma delas é a simulação extensiva do projeto lógico. Nessa simulação, é feita uma pesquisa probabilística em busca de erros, que pode consumir dezenas de milhares de horas de CPU caso o projeto em questão seja, por exemplo, o de um novo computador de grande capacidade. Felizmente, essa aplicação é bastante apropriada para o processamento paralelo [ALM94]. 
O paralelismo, em simulação de circuitos, ocorre porque o número de níveis de portas lógicas é reduzido, apesar de haver centenas de milhares de circuitos em uma CPU. Uma operação realizada durante um ciclo de execução consiste de um conjunto de bits recebidos em uma porta lógica de entrada, uma transformação e a transmissão dos bits resultantes para uma porta lógica de saída. Uma instrução pode precisar de milhares de portas (em média 10 mil por nível) para ser executada, mas todas elas divididas em poucos níveis (tipicamente de 10 a 30), o que pode ser simulado com certa facilidade numa máquina MIMD com alguns milhares de elementos de processamento [ALM94].

Um exemplo prático de simulação de circuitos é o Yorktown Simulation Engine (YSE), desenvolvido pela IBM para acelerar o desenvolvimento de grandes computadores ao possibilitar a simulação de grandes redes de portas lógicas que tais máquinas apresentam. O YSE possui 256 elementos de processamento interconectados e um processador de controle que faz a interface com um computador host. Um compilador traduz a descrição RTL (register-transfer level) da máquina a ser simulada em partições pequenas o suficiente para residir em um EP (Elemento de Processamento) e faz a distribuição por todos os EPs do sistema [ALM94].

\section{Sistemas de Banco de Dados}

Um banco de dados é um conjunto de dados organizados para facilitar o seu acesso e a sua manutenção. Tipicamente, um banco de dados apresenta um tamanho bastante elevado, sendo armazenado em discos de grande capacidade. As oportunidades de paralelismo existem em vários estágios de sua operação, mas o speedup médio conseguido em alguns sistemas foi motivo de grande controvérsia entre alguns pesquisadores [ALM94].

Uma transação, para um banco de dados, consiste em processar uma requisição (query), ou seja, descobrir onde está a informação solicitada e obtê-la (E/S). O tempo necessário para essas duas operações é comparado com freqüuencia na literatura. $\mathrm{O}$ paralelismo, então, promete reduzir os tempos de processamento de requisições, mas não consegue fazer muita coisa quanto ao tempo de E/S. Felizmente, a experiência em particionamento de bancos de dados e o desenvolvimento de técnicas de organização de buffers contribuíram para reduzir o tempo aparente de E/S [ALM94].

Um sistema multiusuário de banco de dados compartilhado possui duas fontes principais de paralelismo: entre as transações dos usuários (como faz, por exemplo, o computador Tandem) e dentro de uma transação complexa, porém única (como o computador Teradata). Ou seja, é possível incrementar o número de transações simultâneas, ou reduzir o tempo médio para executá-las. Como as transações em bancos de dados comerciais freqüientemente são independentes entre si, ambas as abordagens podem ser aplicadas, inclusive simultaneamente [ALM94].

O Tandem NonStop System é um sistema MIMD com passagem de mensagem, de 2 a 32 EPs, cada um com 3 MIPS de capacidade. Ele é utilizado para obter alto desempenho em sistemas de processamento de transações on-line distribuídos. O Teradata Data Base Computer é um sistema de até 1024 EPs conectados em árvore, operando como um sistema MIMD de passagem de mensagem. Esse sistema é conectado a um computador de grande porte e gerencia todas as suas atividades relativas a bancos de dados [ALM94]. 


\section{Sistemas de Inteligência Artificial}

Aplicações de inteligência artificial (IA) apresentam grandes possibilidades de exploração de paralelismo, em grande parte porque as técnicas de pesquisa são elementos centrais na sua capacidade de apresentar resultados [ALM94].

Dois componentes da inteligência são o conhecimento e o raciocínio. Há várias formas de representar o conhecimento e vários métodos de raciocínio que permitem criar mais conhecimento. Programas que exibem esses dois componentes apresentam inteligência artificial [ALM94].

Uma das categorias de conhecimento exploradas em IA é chamada de conhecimento especialista. Esse tipo de conhecimento é dominado por alguns profissionais de determinados campos da atividade humana, como médicos ou gerentes de suporte de sistemas, e pode ser expresso como um conjunto de, talvez, várias centenas de regras da forma "se isto e aquilo estão acontecendo, então deve-se seguir esses passos". Um sistema de produção é um programa que tem a capacidade de armazenar regras desse tipo, ou "produções", e utiliza-as para raciocinar sobre os fatos que the são apresentados como dados de entrada. Quando um conjunto dessas regras corresponde a um domínio de conhecimento especialista, tal programa é chamado de sistema especialista [ALM94].

Uma das formas mais óbvias de paralelismo em sistemas especialistas é dividir o conjunto de produções pelos elementos de processamento, que passam a pesquisar em paralelo os dados de entrada para determinar quais dados correspondem a quais produções. O sistema DADO faz exatamente isto. Desenvolvido na Universidade de Colúmbia, é um sistema MIMD organizado em árvore, especializado em pesquisas para sistemas de produção [ALM94].

\subsection{Considerações Finais}

A computação paralela veio fornecer uma saída para o chamado "gargalo de von Neumann", a mais séria restrição existente ao aumento de desempenho dos sistemas de computação tradicionais. A fronteira tecnológica parece estar se aproximando rapidamente para a indústria de informática e o dia em que o limite máximo de desempenho de um processador seqüencial será alcançado já deve estar freqüentando os pesadelos dos projetistas de sistemas.

Lamentavelmente, a solução traz consigo outro problema. As máquinas paralelas costumam ter preços proibitivos para a grande maioria dos possíveis beneficiados, o que restringe seu acesso a um grupo de felizardos bastante pequeno, como grandes empresas multinacionais, grandes institutos de pesquisa e governos de países desenvolvidos.

Alguns artigos publicados em revistas especializadas afirmam que esse problema pode ser reduzido caso a escala de produção aumente, ou seja, se houver mais procura por sistemas paralelos de alto desempenho, seu preço tende a diminuir. Entretanto, como só poucas aplicações, por enquanto, apresentam as características necessárias para justificar uma máquina de tal porte, parece que esse setor da indústria está preso em um círculo vicioso.

Especulando sobre o que tem acontecido na indústria de processadores, particularmente na plataforma Pentium [HAL93], que já incorpora algumas técnicas de paralelismo em produtos destinados a uso popular, não seria surpresa se, no futuro, a Intel anunciar processadores com recursos de supercomputadores, como, por exemplo, registradores vetoriais, ou mesmo EPs embutidos em seus chips. 


\section{Capítulo 4}

\section{Sistemas Distribuídos para Computação Paralela}

\subsection{Introdução}

O motivo principal para o desenvolvimento de sistemas distribuídos foi a necessidade de compartilhamento de recursos, normalmente separados fisicamente. Por outro lado, o processamento paralelo surgiu com o objetivo de atender à grande demanda por sistemas de alto desempenho, baixo custo e produtividade sustentada. Mas as principais conquistas que permitiram o rápido crescimento da indústria de sistemas paralelos foram os projetos bem sucedidos de processadores maciçamente paralelos (Massively Parallel Processors - MPP) e o desenvolvimento da computação distribuída [BEG94][ZAL91].

A grande diferença entre esses dois tipos de sistemas computacionais é o custo. Um sistema MPP típico pode custar vários milhões de dólares. Por outro lado, o custo de organizar um conjunto de computadores (que os usuários normalmente já possuem) para fazer processamento distribuído é bem pequeno. É claro que um sistema distribuído desse tipo não tem a capacidade necessária para resolver os problemas que, normalmente, são destinados aos sistemas MPP. Em compensação, tem capacidade suficiente para desempenhar tarefas várias vezes maiores do que as que poderiam ser feitas por um de seus computadores membros [BEG94].

Em um sistema MPP, todos os processadores são iguais. Isso já não é verdade em uma rede. Caso os computadores sejam do mesmo fabricante e tenham as mesmas características, podem ter softwares (ou configurações) diferentes. Assim, quando um programa pretende explorar um sistema distribuído, deve estar preparado para encontrar vários tipos de heterogeneidades [BEG94]:

- Arquiteturas: PCs compatíveis, estações de trabalho, multiprocessadores de memória compartilhada, computadores vetoriais, sistemas MPP, etc.

- Formatos de dados: normalmente são incompatíveis entre as diversas plataformas, o que pode tornar as mensagens de um sistema incompreensíveis para um outro.

- Velocidade de processamento: leva ao problema de organizar a computação para que as máquinas mais rápidas não precisem esperar pelas mais lentas.

- Carga de trabalho: pode variar de máquina para máquina conforme sua utilização pelos usuários, o que pode introduzir diferenças de desempenho só detectáveis no momento em que se escolhe onde um processo deve executar.

- Tráfego de rede: pode introduzir atrasos nas mensagens trocadas pelos processos, dependendo das tarefas que estão sendo feitas a cada momento.

Apesar de todas essas dificuldades, a computação distribuída oferece várias vantagens [BEG94]: 
- Custo reduzido, já que permite aproveitar o hardware existente.

- O desempenho pode ser otimizado, pois é possível executar cada tarefa na arquitetura mais apropriada.

- As diferenças podem ser exploradas, já que as aplicações podem ter acesso facilitado aos recursos só existentes em determinadas plataformas.

- Os recursos da máquina virtual podem crescer gradativamente, aproveitando os avanços tecnológicos com mais facilidade.

- Os usuários podem utilizar ferramentas conhecidas em seu trabalho. Não é necessário treinar o pessoal para utilizar uma nova plataforma, nem é preciso contratar novos especialistas.

- A computação distribuída facilita o trabalho corporativo.

Embora tenham surgido por razões diferentes, na última década os sistemas paralelos e distribuídos têm convergido para áreas em comum. Enquanto nos sistemas paralelos tem ocorrido uma gradativa substituição de arquiteturas SIMD por arquiteturas MIMD com memória distribuída, nos sistemas distribuídos a sua capacidade vem aumentando rapidamente em função do grande desenvolvimento tecnológico [ZAL91].

Essa convergência é mais acentuada em função de haver problemas em comum aos dois tipos de sistemas, como balanceamento de carga e queda de desempenho por causa da sobrecarga da comunicação entre os processadores [ZAL91].

Outro aspecto interessante é o uso recente de sistemas distribuídos para realizar processamento concorrente. Em certas aplicações de maior granularidade (ver seção 5.4) e que fazem uso de pouca comunicação, a potência computacional das modernas estações de trabalho (e de alguns computadores pessoais) permitem resultados comparáveis aos de alguns supercomputadores. Por enquanto, isso vem sendo feito nos períodos em que as estações deixam de ser utilizadas (normalmente à noite). O próximo passo é executar essas aplicações durante o horário normal dos usuários, já que algumas pesquisas indicam que, nesse caso, a carga de trabalho não ultrapassa a 10\%, em média, da capacidade real desses equipamentos [ZAL91].

Para fazer processamento paralelo em sistemas distribuídos, a comunicação entre os processadores é feita através de ambientes de passagem de mensagens. Esses ambientes têm sido aperfeiçoados nos últimos anos para cobrirem um número bastante grande de plataformas e equipamentos diferentes, além de facilitar cada vez mais o desenvolvimento de aplicações paralelas [BEG94].

\subsection{Ambientes de Passagem de Mensagens}

Um processador seqüencial é controlado por apenas um programa em um determinado instante. Esse programa determina quais instruções devem ser executadas pelo processador, qual a ordem de execução e quais posições de memória as instruções devem utilizar para realizar um determinado processamento [MCB94].

Por outro lado, uma máquina MPP é muito mais complexa. Geralmente, um computador desse tipo possui um número $P$ de processadores seqüenciais. Caso a memória do sistema seja distribuída, cada processador possui sua própria memória de trabalho, não visível para os demais. O controle de uma máquina MPP também é feito por um programa, que define e escalona as tarefas executadas por cada um dos $P$ processadores, bem como os dados residentes na memória local de cada um. Logicamente, isso equivale a $P$ programas executando em $P$ processadores, mais um 
conjunto extra de procedimentos que determina a forma de escalonar tarefas nos $P$ processadores, além de fornecer meios de acesso à memória local de cada processador pelos demais [MCB94].

Um dos muitos paradigmas utilizados para escrever programas para sistemas MPP é o de passagem de mensagens, que apresenta duas características fundamentais para esse tipo de aplicação [MCB94]:

- Sincronização de processos.

- Acesso de leitura e/ou gravação à memória local dos processadores.

Um processo faz uso de passagem de mensagens quando ele envia um item qualquer de informação (uma mensagem) residente na memória local de seu processador para um outro processo. Embora esse sistema aparente ser uma forma de acesso apenas para leitura de dados, ele permite o trabalho cooperativo entre vários processos de um sistema, de forma que aquele que recebe uma mensagem pode atualizar dados de sua memória local, permitindo, assim, acesso de leitura e/ou gravação a virtualmente qualquer posição de memória de qualquer processador [MCB94].

Um programa MPP com passagem de mensagens consiste de $\mathrm{P}$ programas seqüenciais, cada um rodando em seu processador. Cada um desses $\mathrm{P}$ programas utiliza a passagem de mensagens para sincronização e acesso à memória dos demais. Geralmente, o sistema de passagem de mensagens reside em um conjunto reduzido de procedimentos que definem um Ambiente de Passagem de Mensagens. Esses procedimentos tornam-se disponíveis para os programadores na forma de uma Biblioteca de Passagem de Mensagens, que pode ser acrescentada a uma linguagem seqüencial comum (por exemplo, C ou Fortran), permitindo que programas sequienciais sejam utilizados sem maiores adaptações para fazer processamento paralelo com alto desempenho [MCB94].

Um Ambiente de Passagem de Mensagens, composto de processadores independentes conectados por uma rede de comunicação, cada um rodando seu próprio processo, que utiliza a passagem de mensagens para se comunicar com os demais processos de um sistema, constitui um Ambiente Paralelo Virtual, uma máquina virtual composta de $\mathrm{P}$ processadores que se comportam como uma máquina de um único processador, mas com o poder somado de $\mathrm{P}$ processadores [MCB94].

Apesar de todos os sistemas de passagem de mensagens serem similares, há algumas diferenças na forma de prestação dos dois serviços fundamentais (sincronização e troca de informações), o que resulta em um grande número de sistemas desse tipo, porém incompatíveis entre si. Alguns exemplos bastante conhecidos dessa situação são: o CROS da Caltech, o EUI da IBM, o NX da Intel, o CS da Meiko, o PSE da nCUBE e o CMMD da Thinking Machines [MCB94].

Preocupados com a proliferação desses sistemas no mercado, vários grupos foram formados com a finalidade de desenvolver as chamadas Plataformas de Portabilidade de Passagem de Mensagens, que nada mais são do que Ambientes de Passagem de Mensagens cujo objetivo é generalizar características específicas de determinadas máquinas ou fabricantes, permitindo sua utilização em vários sistemas diferentes. Assim, programas escritos com uma dessas plataformas passam a ser portáveis para todos os sistemas, o que constitui uma vantagem bastante procurada pela indústria de software. Exemplos bastante conhecidos de plataformas de portabilidade são: Express, Linda, MPI, P4, PARMACS e PVM [MCB94]. 


\subsection{Exemplos de Ambientes de Passagem de Mensagens}

Essa seção descreve algumas das plataformas de portabilidade mais conhecidas. O PVM (Parallel Virtual Machine) será visto detalhadamente na próxima seção, em razão de sua importância para esse trabalho.

\section{Express}

O sistema Express é um produto comercial da empresa Parasoft. Foi desenvolvido a partir do projeto Crystalline Operating System, da Caltech [MCB94]. Inicialmente, a idéia da Parasoft era orientada a implementar o Express em várias arquiteturas, procurando alcançar o maior desempenho possível em cada uma. Mais recentemente, a ênfase do projeto tem sido a facilidade de utilização do sistema e a transparência para o usuário de muitos detalhes inerentes ao Express. Foram produzidos mapeamentos e bibliotecas de comunicação para redes em anel, malha, toroidais e outras, cada uma delas otimizada para uma plataforma de hardware específica. Além disso, surgiram tratamentos para os problemas de E/S paralelo e balanceamento de carga estático e dinâmico, ambos ignorados, até agora, pela maioria dos sistemas de passagem de mensagens [FLO94].

\section{Linda}

Linda é um ambiente independente de plataforma para a implementação de programas paralelos. O projeto foi iniciado em 1980, na Universidade de Yale e, atualmente, há duas versões comerciais disponíveis: uma para máquinas paralelas (memória compartilhada ou distribuída) e outra para conjuntos de estações de trabalho [MAT93].

Linda é um sistema de comunicação diferente de outros ambientes de passagem de mensagens. Na verdade, Linda é um sistema de memória compartilhada virtual associativa, chamada de Tuple Space (TS), que permite intercomunicação entre todos os processos de um sistema. O TS consiste de um conjunto de "tuplas", listas de campos de determinados tipos. Uma tupla não possui um endereço direto, como uma variável em uma linguagem de programação. O acesso a uma tupla qualquer é possível através de uma seleção baseada em uma combinação dos campos que a compõem. Os processos que compartilham o TS podem inserir ou retirar tuplas da memória a qualquer momento. Como não há restrição de acesso a uma tupla quando ela se encontra no TS, a comunicação entre os processos é alcançada dessa forma [MAT93][MCB94].

\section{MPI}

O MPI é uma plataforma padrão de passagem de mensagens desenvolvida em uma série de encontros ocorridos entre Novembro de 1992 e Janeiro de 1994 pelo MPI Committee, um grupo de especialistas oriundos de cerca de 40 organizações, a maioria da Europa e dos Estados Unidos. A maioria dos fabricantes de sistemas paralelos 
participaram do projeto MPI, assim como várias universidades e laboratórios governamentais envolvidos em computação paralela em todo o mundo [MCB94].

A intenção do MPI Committee era chegar a um padrão abrangente o suficiente para cobrir as melhores características de todas as plataformas e sistemas existentes, permitindo alto desempenho independente do sistema utilizado. Obviamente, esse objetivo é muito ambicioso. Na prática, algumas particularidades tiveram que ser excluídas do projeto por serem incompatíveis com as demais. Entretanto, o grande número de envolvidos possibilitou que esse padrão fosse bem aceito pelo mercado [MCB94].

O MPI permite mensagens com diversas estruturas de dados, como tipos elementares, arrays e blocos. A plataforma trabalha com grupos de processos e todas as comunicações são feitas a nível de grupos. Sua aplicação principal é em computadores MIMD concorrentes de memória distribuída. O projeto original não apresenta suporte de tolerância a falhas e assume que a rede de comunicação é confiável [WAL94].

\section{P4}

O sistema P4, desenvolvido pelo Argonne National Laboratory (ANL), foi a primeira tentativa de produzir uma plataforma de portabilidade. Originalmente chamado de MonMacs, era destinado a facilitar a programação do sistema MPP HEP (Heterogeneous Element Processor), o primeiro sistema multiprocessador comercial, adquirido pelo ANL em 1984. Em 1989, foi totalmente reescrito com o objetivo de se tornar um sistema bastante robusto, capaz de funcionar em grande número de plataformas [BUT94][MCB94].

O P4 é uma plataforma baseada em bibliotecas de macros. Possui um método único de tratamento para sistemas de memória compartilhada e distribuída. Uma de suas restrições mais importantes é utilizar apenas funções bloqueantes nos métodos de passagem de mensagens [BUT94][MCB94].

\section{PARMACS}

PARMACS (PARallel MACroS) é um sistema de passagem de mensagens baseado em macros, desenvolvido a partir do sistema P4. O projeto PARMACS foi iniciado em 1987, no Argonne National Laboratory. Originalmente, era composto de um conjunto de macros bastante básico destinado à programação portável com passagem de mensagens usando a linguagem C. Em 1988, foi iniciado o desenvolvimento do Fortran PARMACS, em colaboração com o German National Research Center for Computer Science (GMD). Ao mesmo tempo, a funcionalidade do pacote foi estendida [CAL94][MCB94].

Atualmente sendo comercializado na versão 6.0, sua equipe de desenvolvimento substituiu as macros por chamadas a sub-rotinas e foi incluído um binder para a linguagem C. Em 1993, a biblioteca inteira foi portada para a família Intel. Atualmente, estão sendo desenvolvidas implementações para várias outras plataformas [CAL94][MCB94]. 


\subsection{PVM}

O sistema PVM é um conjunto integrado de bibliotecas de funções e ferramentas de software. Sua finalidade é emular um sistema computacional concorrente, heterogêneo, flexível e de propósito geral [BEG94].

O projeto PVM foi iniciado em 1989, no Oak Ridge National Laboratory (ORNL) e, desde então, produziu três versões principais, sendo que somente as duas últimas foram distribuídas publicamente. A versão 1.0, construída por Vaidy Sunderan e Al Geist, era bastante ambiciosa, já que procurava aceitar modelos de programação heterogêneos e fornecer suporte a memória compartilhada virtual, além de métodos de passagem de mensagens. Porém, não foi liberada para uso externo ao ORNL. A versão 2.0 foi escrita na Universidade do Tennessee e liberada em Março de 1991. Nos dois anos seguintes, o PVM foi utilizado em várias aplicações científicas. Com o retorno dado pelos usuários e após várias modificações, liberadas nas versões 2.1 a 2.4, o sistema foi completamente reescrito e a versão 3.0 foi liberada em Fevereiro de 1993 [BEG94][GEI94][SUN94].

Seu modelo computacional básico permaneceu constante até agora. O PVM enxerga as aplicações como sendo constituídas por componentes, cada um deles representando parte de um algoritmo. Cada componente é um programa SPMD (Single Program Multiple Data - Programa Único, Múltiplos Dados), potencialmente de múltiplas instâncias, cooperando tanto entre si como com outras instâncias de outros componentes. A unidade de concorrência no PVM é o processo e as dependências de um processo são implementadas através de primitivas de gerenciamento e de sincronização inseridas nas construções de controle de fluxo da linguagem hospedeira. Essas primitivas são agrupadas em uma biblioteca, que precisa ser acrescentada ao código das aplicações para que elas possam utilizar o sistema PVM [BEG94][GEI94][SUN94].

O modelo de implementação, também inalterado desde a primeira versão, utiliza o conceito de host pool, um conjunto de computadores interligados formando uma máquina virtual, na qual um grupo de processos daemon (também chamado de pvmd) cooperam entre si para emular um sistema computacional concorrente. As aplicações que executam em uma máquina virtual requisitam serviços e recebem as respostas dos daemons. Basicamente, os serviços disponíveis em um sistema PVM podem ser divididos nas seguintes categorias [BEG94][GEI94][SUN94]:

- Gerenciamento de processos.

- Configuração da máquina virtual.

- Passagem de mensagens.

- Sincronização.

- Funções de verificação de estado e manutenção.

\section{O Modelo PVM}

No PVM, um conjunto de computadores seriais, paralelos e vetoriais emulam um grande computador de memória distribuída (a máquina virtual). Vários usuários podem definir máquinas virtuais na mesma rede, não necessariamente coincidentes, podendo ser sobrepostas. Cada usuário pode executar várias aplicações PVM simultaneamente. O PVM fornece as funções necessárias para iniciar tarefas em qualquer computador da máquina virtual e também para que os programas possam se comunicar e se sincronizar 
entre si. Uma tarefa é definida como uma unidade computacional análoga a um processo Unix. As aplicações podem ser escritas em Fortran ou $\mathrm{C}$ e podem ser paralelizadas usando construções de passagem de mensagens comuns à maioria dos computadores de memória distribuída. Enviando e recebendo mensagens, várias tarefas de uma aplicação podem cooperar para resolver um problema em paralelo. O modelo assume que qualquer tarefa pode enviar uma mensagem para qualquer outra e que não há limites para o tamanho ou número de tais mensagens [BEG94][SUN94].

A figura 4.1 mostra um exemplo do modelo computacional PVM (no caso, o relacionamento entre alguns módulos de um sistema paralelo) e a visão arquitetural desse modelo.

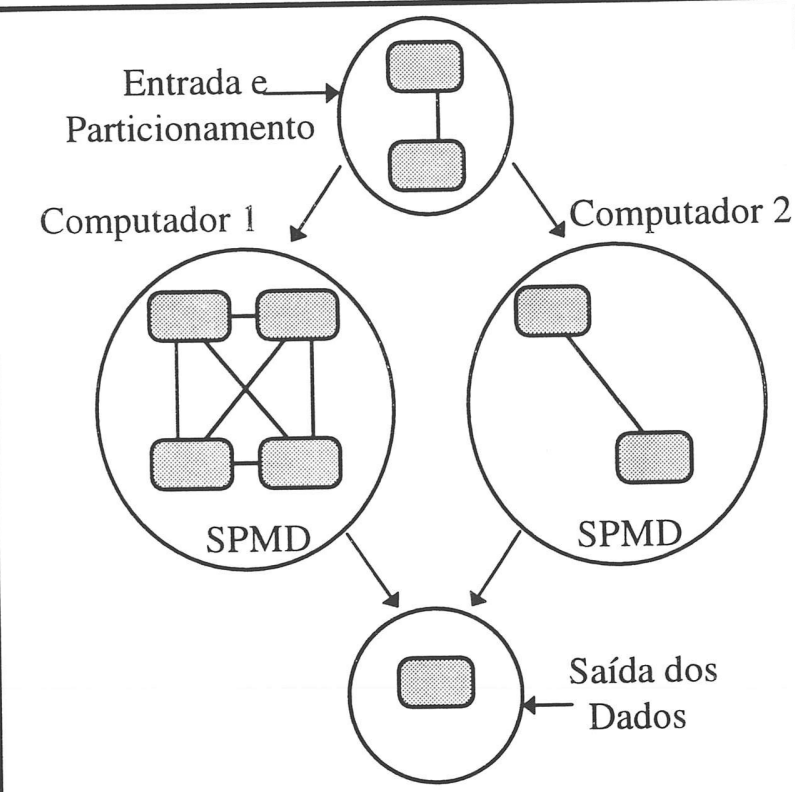

(a)

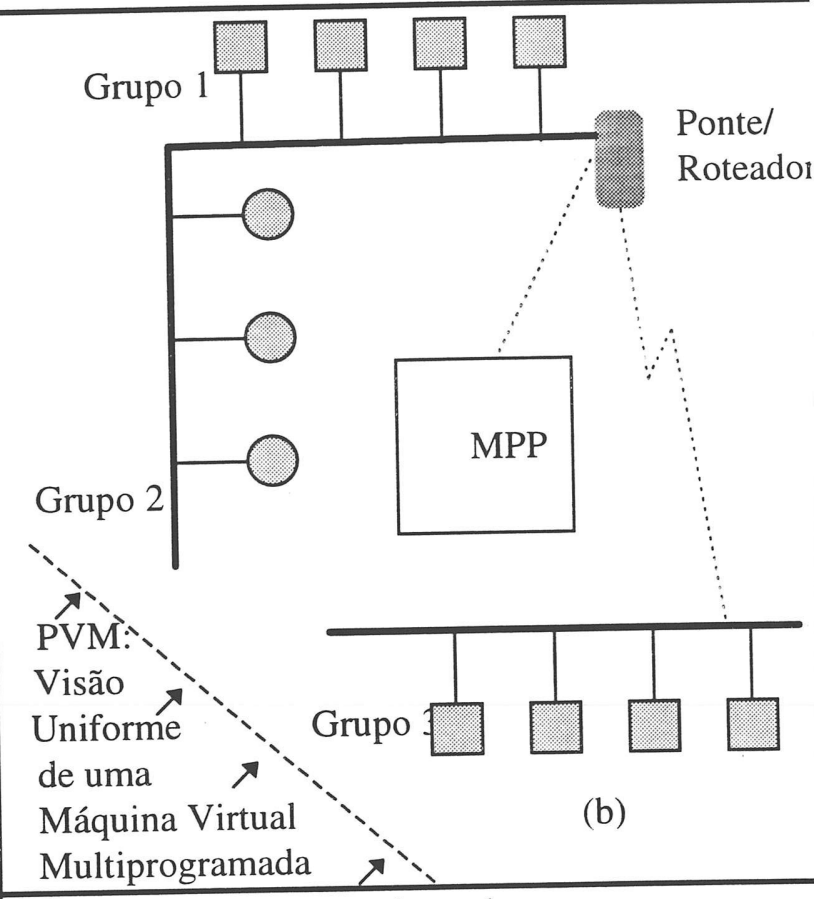

Roteado

Figura 4.1. Sistema PVM. (a) Modelo Computacional. (b) Visão Arquitetural

\section{Identificadores de Tarefas}

O PVM utiliza um inteiro de 32 bits, chamado de task identifier (TID) para endereçar os daemons, tarefas e grupos de tarefas em uma máquina virtual. Um TID identifica um único objeto em uma máquina virtual inteira. Entretanto, um TID que deixa de ser utilizado por uma aplicação pode ser reaproveitado. O TID possui 4 campos, como mostrado na figura 4.2. Atualmente, ele é dividido conforme indicado, porém os tamanhos dos campos poderão ser alterados no futuro (possivelmente de forma dinâmica, na configuração da máquina virtual) [GEI94].

\begin{tabular}{|c|c|c|c|}
\hline 3 & \multicolumn{2}{|c|}{2} & 1 \\
1098765432109876543210987654321 \\
\hline & & & \\
\hline $\mathrm{SG} \backslash \mathrm{H}$ & \multicolumn{1}{|c|}{$\mathrm{L}$} \\
\hline
\end{tabular}

Figura 4.2. Identificador de Tarefas (TID) 
Pelo exposto, é fácil verificar que o número de hosts em uma máquina virtual é limitado pelo campo $\mathrm{H}$, que possui 12 bits, podendo chegar ao máximo de $2^{12}-1$ (4095). O campo S indica o servidor (daemon) do host $\mathrm{H}$, o campo $\mathrm{G}$ é utilizado para endereçar grupos e o campo L indica uma tarefa local a um determinado host $\mathrm{H}$. Com 18 bits, um host pode comportar até $2^{18}-1$ (262143) tarefas, simultaneamente.

\section{O Daemon PVM}

Um pvmd reside em cada host de uma máquina virtual e todos eles são configurados para trabalhar em conjunto. Os pvmds de um usuário não interagem com os de outros usuários. Isto significa que, em cada host, há um pvmd para cada usuário, desde que esse host faça parte de mais de uma máquina virtual. O pvmd foi projetado para executar sob um user ID não privilegiado e atende a apenas um usuário para minimizar os riscos de segurança [GEI94].

O pvmd não realiza qualquer trabalho para as aplicações. Sua função é atuar como roteador e controlador. Ele fornece um ponto de acesso em cada host, assim como autenticação, controle de processos e detecção de falhas. Quando estão ociosos, os pvmds verificam entre si as suas condições de funcionamento. Caso um pvmd não responda aos demais, é marcado como "morto". O projeto do pvmd buscou produzir um elemento de software confiável, que consiga sobreviver mais a situações de falha do que as aplicações que fazem uso dele, inclusive para auxiliar na sua depuração [GEI94].

O primeiro pvmd executado em um sistema é designado como "mestre", enquanto os outros (disparados pelo mestre) são chamados de escravos. Na maioria das operações, todos os pvmds são considerados iguais. Somente o mestre pode disparar novos escravos e adicioná-los à maquina virtual, mas os escravos podem requisitar ao mestre que reconfigure todo o sistema. Só o mestre pode retirar hosts da máquina virtual. Se o mestre perde o contato com um escravo, ele é marcado como "morto" e retirado da configuração. Se um escravo perde o contato com o mestre, ele termina. Esse algoritmo garante que a máquina virtual não seja fracionada. Infelizmente, isso reduz consideravelmente a tolerância a falhas, porque um sistema não continua funcionando caso o mestre sofra uma pane [GEI94].

Do ponto de vista de um pvmd, tolerância a falhas significa que ele pode detectar que outro pvmd não responde mais à comunicação entre eles. Isto permite que ele se recupere da situação sem falhar por causa disso. Ou seja, não é importante que um pvmd se preocupe com possíveis falhas em um host qualquer. Sua única obrigação é encerrar qualquer operação que esteja esperando pelo host "morto". Do ponto de vista das tarefas, a detecção de falhas significa que qualquer operação que envolva um host desconectado retorna uma condição de erro, sem risco de paralisação. O programador da aplicação deve, então, usar esse recurso e fazer os tratamentos adequados [GEI94].

\section{A Biblioteca de Programação}

A biblioteca libpvm é um conjunto de funções que permite a uma tarefa fazer contato com o pvmd e com outras tarefas. Ela contém funções para compor ou decompor mensagens, enviar requisições ao pvmd e receber respostas. Intencionalmente, a libpvm é mantida tão simples e pequena quanto possível. A validação de parâmetros é mínima, deixando para o pvmd a tarefa de realizar a sua autenticação [GEI94]. 
A maior parte da libpvm é escrita independente de máquina ou sistema operacional. O nível mais baixo do código (que se relaciona diretamente com a plataforma) é mantido em separado e pode ser modificado ou substituído quando o PVM é portado para um novo sistema operacional ou MPP [GEI94].

\section{Comunicação}

A base do sistema de comunicação do PVM é construída sobre os protocolos Internet TCP e UDP. Talvez outros protocolos existentes fossem mais apropriados. Entretanto, não seriam tão difundidos quanto os escolhidos, o que poderia limitar a portabilidade do sistema [GEI94].

Outra restrição adotada no projeto é executar os protocolos como processos normais, sem introduzir modificações no sistema operacional. Isto não é tão eficiente, já que tratar timers ou gerenciar buffers é mais caro quando feito a partir do espaço de processos usuários (há trocas de contexto extras e mais operações de cópia de memória para transferir buffers do kernel para o espaço de usuário). O desempenho seria melhor se os protocolos fossem inseridos no kernel, ou caso os processos tivessem acesso direto às interfaces de rede. Porém, seria necessário entrar no código do kernel, o que não é uma tarefa simples, além de ser arriscado para a confiabilidade do sistema [GEI94].

\section{Grupos Dinâmicos de Processos}

Um processo PVM pode pertencer a vários grupos diferentes, sendo que um grupo pode ser modificado dinamicamente a qualquer momento. Para essa finalidade, o PVM fornece rotinas para que as tarefas se juntem a um grupo, ou deixem de fazer parte de um grupo. Os membros de um grupo recebem um número de zero a $\mathrm{P}-1$, onde $\mathrm{P}$ é o número de processos do grupo. Se algum processo deixa um grupo, seu número fica vago e pode ser reaproveitado por outro processo que venha a fazer parte do mesmo grupo. Um processo pode solicitar informações sobre outros membros de um grupo. Os grupos recebem seus nomes dos usuários. As funções que tratam de grupos recebem esse nome como argumento [BEG94][SUN94].

Para fazer uso de qualquer função relativa a grupos de processos, uma aplicação precisa de uma biblioteca separada, a libgpvm. O pvmd não atende requisições de grupos. Isto é feito por um servidor separado, que é executado quando a primeira função de grupos é chamada [BEG94][SUN94].

\subsection{Considerações Finais}

Os ambientes de passagem de mensagens representam um grande avanço para o desenvolvimento de aplicações destinadas a sistemas paralelos e distribuídos. Sem eles, praticamente todos os fabricantes precisariam fornecer ferramentas de desenvolvimento para seus produtos, com grandes chances de serem não apenas diferentes entre si, mas, principalmente, incompatíveis. Com seu surgimento, os diversos fabricantes ainda fornecem suas próprias ferramentas, porém os usuários têm a possibilidade de adotar esses ambientes para padronizar suas aplicações e torná-las portáveis para diversas plataformas [BEG94]. 
Entretanto, o sucesso desse tipo de sistema levou ao surgimento de diversos ambientes diferentes, resultado de projetos em vários centros de pesquisa do mundo inteiro. Atualmente, algumas das questões que as equipes de desenvolvimento sempre precisam considerar é qual desses ambientes deve ser utilizado para determinado projeto, se é preciso adotar algum deles como padrão, ou, eventualmente, se alguma aplicação precisa ser escrita em mais de um ambiente desses [MAL96].

$\mathrm{Na}$ figura 4.3, encontra-se uma comparação entre diversos ambientes de passagem de mensagens. Através dela, é possível notar que os diversos ambientes apresentam diferenças significativas entre si. Essas diferenças podem fazer com que uma aplicação, caso escrita para um determinado ambiente, não seja portável para qualquer dos outros sem alterações consideráveis [MAL96].

Por isso, é importante um esforço da indústria no sentido de padronizar esses ambientes, permitindo que se reduza o custo de desenvolvimento das aplicações que fazem uso de passagem de mensagens.

\begin{tabular}{|c|c|c|c|c|c|c|c|c|}
\hline Recurso & 1 & 2 & 3 & 4 & 5 & 6 & 7 & \multirow{15}{*}{$\begin{array}{l}\text { Recursos: } \\
\text { 1. Funções Coletivas Avançadas. } \\
\text { 2. Grupos de Processos. } \\
\text { 3. Contexto de Mensagem. } \\
\text { 4. Topologias Virtuais. } \\
\text { 5. Gerenciamento de Processos. } \\
\text { 6. E/S Paralelas. } \\
\text { 7. Análise de Desempenho }\end{array}$} \\
\hline Plataforma & & & & & & & & \\
\hline MPI & $S$ & $S$ & $\mathrm{~S}$ & $S$ & $\mathrm{~N}$ & $\mathrm{~N}$ & $S$ & \\
\hline Chameleon & $\mathrm{S}$ & $\mathrm{S}$ & $\mathrm{N}$ & $S$ & $S$ & $\mathrm{~S}$ & $\mathrm{~S}$ & \\
\hline Chimp & $\mathrm{N}$ & $S$ & $S$ & $\mathrm{~N}$ & $\mathrm{~N}$ & $\mathrm{~N}$ & $\mathrm{~N}$ & \\
\hline CMMD & $S$ & $\mathrm{~N}$ & $\mathrm{~N}$ & $\mathrm{~N}$ & $S$ & $S$ & $S$ & \\
\hline Express & $S$ & $S$ & $\mathrm{~N}$ & $\mathrm{~S}$ & $S$ & $\mathrm{~S}$ & $S$ & \\
\hline MPL & $\mathrm{S}$ & $S$ & $\mathrm{~N}$ & $\mathrm{~N}$ & $\mathrm{~N}$ & $\mathrm{~N}$ & $S$ & \\
\hline NX & $\mathrm{S}$ & $\mathrm{N}$ & $\mathrm{N}$ & $\mathrm{N}$ & $S$ & $\mathrm{~N}$ & $S$ & \\
\hline $\mathrm{P} 4$ & $\mathrm{~S}$ & $\mathrm{~N}$ & $\mathrm{~N}$ & $\mathrm{~N}$ & $\mathrm{~N}$ & $\mathrm{~N}$ & $S$ & \\
\hline PARMACS & $\mathrm{S}$ & $\mathrm{N}$ & $\mathrm{N}$ & $S$ & $\mathrm{~S}$ & $\mathrm{~N}$ & $\mathrm{~N}$ & \\
\hline \begin{tabular}{|l|} 
PICL \\
\end{tabular} & $S$ & $\mathrm{~N}$ & $\mathrm{~N}$ & $\mathrm{~N}$ & $\mathrm{~N}$ & $\mathrm{~N}$ & $\mathrm{~S}$ & \\
\hline PVM & $S$ & $\mathrm{~S}$ & $\mathrm{~N}$ & $\mathrm{~N}$ & $S$ & $\mathrm{~N}$ & $\mathrm{~S}$ & \\
\hline \begin{tabular}{|l|} 
TCGMS \\
\end{tabular} & $S$ & $\mathrm{~N}$ & $\mathrm{~N}$ & $\mathrm{~N}$ & $\mathrm{~S}$ & $\mathrm{~S}$ & $S$ & \\
\hline Zipcode & $S$ & $S$ & $S$ & $S$ & $\mathrm{~S}$ & $\mathrm{~N}$ & $\mathrm{~N}$ & \\
\hline
\end{tabular}

Figura 4.3. Panorama de alguns ambientes de passagem de mensagens [MAL96]. 


\section{Capítulo 5}

\section{Escalonamento e Balanceamento de Carga}

\subsection{Introdução}

O processamento concorrente (e paralelo) em geral, o escalonamento (scheduling) e o balanceamento de carga (load balancing) em particular, têm sido objeto de grande número de pesquisas e desenvolvimentos nas últimas duas décadas. Esse trabalho é motivado pela profunda importância e impacto dos métodos de escalonamento e balanceamento de carga nos sistemas paralelos e distribuídos [SHI95].

Se o principal objetivo dos sistemas paralelos e distribuídos tem convergido para a busca de alto desempenho, cada vez mais difícil de se alcançar com as arquiteturas von Neumann, o balanceamento de carga é a disciplina que pode permitir a esses sistemas alcançá-lo. Não basta ter sistemas com grande número de processadores ou de estações. É preciso garantir que todos esses EPs ${ }^{1}$ sejam bem aproveitados, que haja trabalho suficiente e compatível com a capacidade global do sistema e que todos os EPs tenham uma carga uniforme, evitando-se que alguns fiquem ociosos enquanto outros ficam sobrecarregados. O problema reside em como distribuir (ou escalonar) os processos entre os EPs, buscando, ao mesmo tempo, algumas metas, tais como minimizar o tempo de execução e os atrasos causados pelo sistema de comunicação e/ou maximizar a utilização dos recursos do sistema [CAS88a][POL87][SHI95].

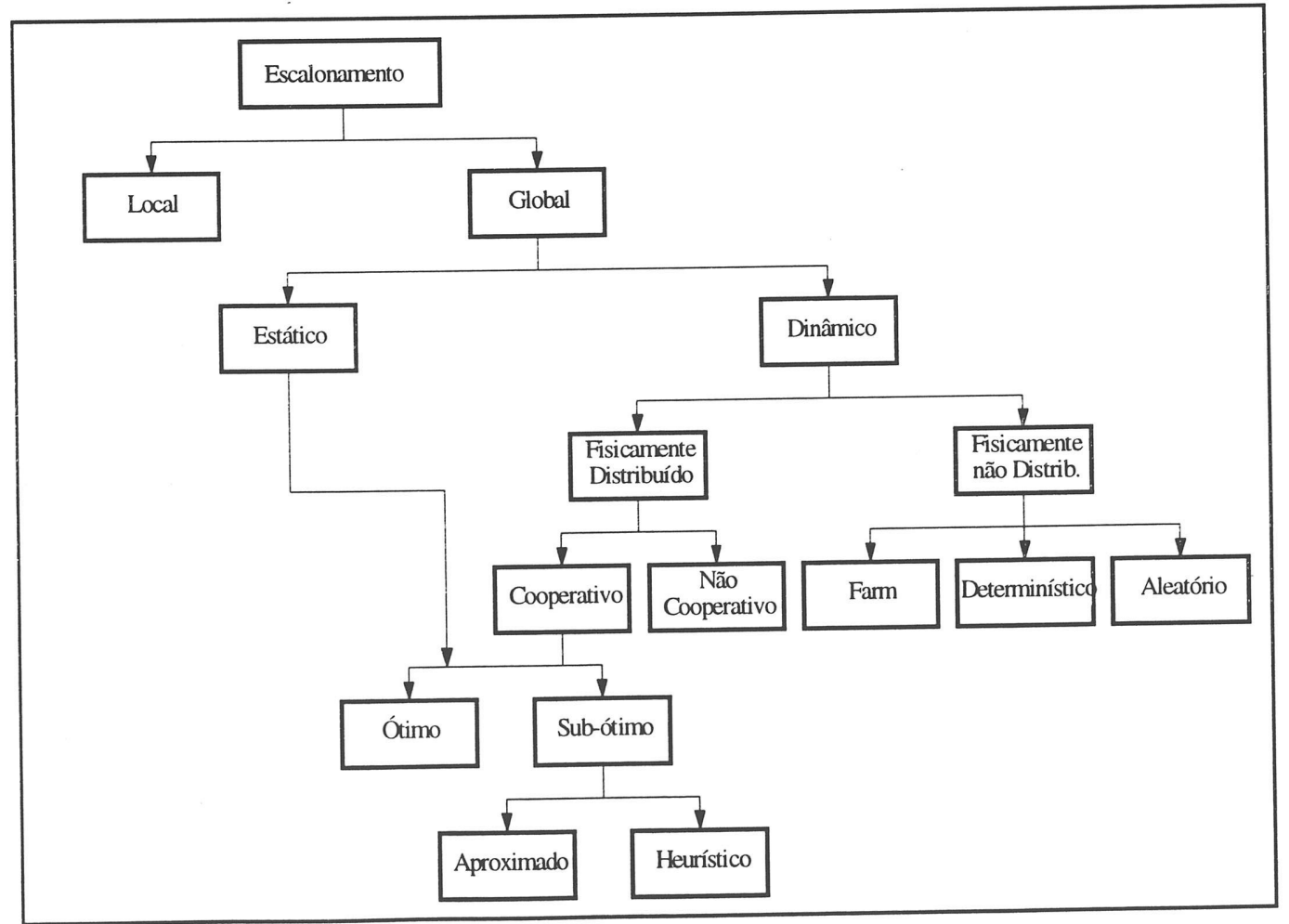

Figura 5.1. Classificação dos Métodos de Escalonamento.

${ }^{1}$ EP é a sigla para Elemento de Processamento, muito utilizada neste trabalho. 


\subsection{Classificação dos Métodos de Escalonamento}

Os métodos de escalonamento de processos podem ser classificados em várias categorias diferentes, como pode ser visto na figura 5.1. O objetivo dessa classificação é apresentar o problema do escalonamento nos seus principais aspectos. A forma hierárquica foi escolhida por permitir explorar as diversas características do problema e comparar com maior facilidade os trabalhos já apresentados nessa área. Outra motivação para essa classificação é possibilitar que futuros trabalhos possam ser inseridos nesse contexto, mesmo que modifiquem o conjunto de características considerados atualmente [CAS88].

\section{Escalonamento Local}

O escalonamento local, realizado pelo sistema operacional de um computador, consiste em distribuir os períodos de tempo de um processador entre os processos em execução (time-slice [TAN92]). Nesse caso, não é considerada a existência de outros processadores no mesmo sistema. Esse tipo de escalonamento não produz paralelismo real, mas apenas concorrência entre processos [CAS88a][SHI95].

\section{Escalonamento Global}

O escalonamento global é o método de decidir em qual EP um processo deve ser executado em um sistema multiprocessador. O controle dessa atividade pode ser feito por uma autoridade central, ou pode ser distribuído entre os vários EPs de um sistema. Também é possível dividi-lo em dois grandes grupos: o escalonamento estático e o escalonamento dinâmico (também chamado de balanceamento de carga dinâmico) [CAS88a][SHI95].

\section{Escalonamento Estático}

No escalonamento estático, também chamado de escalonamento determinístico, a distribuição de tarefas pelos processadores é feita antes que os processos comecem sua execução. Isso só é possível caso as informações sobre os tempos de execução das tarefas e os recursos de processamento sejam conhecidas em tempo de compilação. Um método desse tipo não admite a preempção de tarefas, ou seja, caso uma tarefa seja designada para um processador, ela só pode ser executada nele [CAS88a][SHI95].

A meta principal dos métodos de escalonamento estático é minimizar o tempo de execução de um programa concorrente e os atrasos causados pela comunicação. Com isso em mente, eles procuram realizar três atividades principais [LO88][SAR86] [SHI90][STO77]:

- Prever em tempo de compilação o comportamento do programa quando ele for executado, ou seja, estimar o tempo de execução e os atrasos de comunicação do processo.

- Agrupar tarefas pequenas em processos de granularidade mais grossa na tentativa de reduzir os custos de comunicação.

- Designar os processos para os processadores. 
A grande vantagem dos métodos de escalonamento estático é que todo o custo do processo é aplicado na compilação, resultando em um tempo de execução mais eficiente quando comparado aos métodos de escalonamento dinâmico. Entretanto, o escalonamento estático apresenta vários problemas. Os mais notáveis são os seguintes [SHI95]:

- Não existem métodos eficientes para estimar, durante a compilação, os tempos de execução de uma tarefa nem os atrasos causados pela comunicação entre os processos. Isso pode causar perdas de desempenho imprevisíveis.

- A maioria dos métodos de escalonamento ignora a distribuição de dados. Isso causa degradação do desempenho em função de atrasos de comunicação durante a execução para obter dados em EPs remotos.

- Não existe uma ferramenta que forneça o perfil de execução de um programa em uma arquitetura dada. Isso seria muito útil para que os usuários de uma arquitetura pudessem simular suas aplicações em outras, buscando sistemas mais eficientes.

Os métodos de escalonamento estático podem ser classificados em ótimos e subótimos.

\section{Escalonamento Estático Ótimo}

Um dos aspectos mais críticos do escalonamento estático é que, em geral, a geração de escalonamentos ótimos é um problema do tipo NP-completo [EL94][FER89][LEW96][VEL90]. Nesse tipo de problema, só é possível gerar soluções ótimas em casos específicos (por exemplo, quando o tempo de execução de todas as tarefas é igual e somente dois processadores são utilizados). Em casos gerais, isso é muito difícil, já que um problema NP-completo requer um período de tempo polinomial (também chamado de exponencial) para ser solucionado. Quando os sistemas são pequenos, é possível aplicar métodos ótimos, já que o número de combinações entre os elementos é reduzido. Porém, em sistemas grandes, a quantidade de casos que devem ser examinados é enorme, o que torna uma abordagem desse tipo impraticável [SHI95].

\section{Escalonamento Estático Sub-ótimo}

Em função dos problemas associados com os métodos ótimos, a maioria das pesquisas nessa área tem sido dirigida para soluções sub-ótimas [SHI95].

Os métodos sub-ótimos podem ser classificados nas seguintes abordagens:

- Aproximados.

- Heurísticos.

Nos métodos de escalonamento estático sub-ótimos por aproximação, o espaço de solução é pesquisado por algum método de busca conhecido. Porém, essa pesquisa não precisa ser feita inteiramente. Basta que uma solução boa (ou aceitável) seja encontrada. Os fatores que devem ser considerados para que esse método seja utilizado são [CAS88a][SHI95]: 
- Disponibilidade de uma função que avalie uma solução encontrada.

- O tempo necessário para essa avaliação.

- A habilidade para julgar o valor de uma solução, baseado em alguma unidade métrica.

- Disponibilidade de um mecanismo de "poda" do espaço de solução.

Os métodos heurísticos utilizam regras especiais para conduzir o processo de escalonamento na direção aproximada de uma solução ótima. Esses métodos representam os algoritmos mais bem estruturados do processo de escalonamento, já que as heurísticas são baseadas no conhecimento produzido por inúmeras pesquisas feitas sobre essa área. Também são os métodos que requerem mais tempo e mais recursos para realizarem suas funções [CAS88a][SHI95].

\section{Escalonamento Dinâmico}

O escalonamento dinâmico é baseado na redistribuição de processos entre os diversos processadores de um sistema durante a sua execução. Essa redistribuição é realizada transferindo-se as tarefas dos processadores com carga maior para aqueles com carga menor (operação chamada, também, de balanceamento de carga) com o objetivo de aumentar o desempenho das aplicações [EAG86][LIN87][SHI92][WAN85].

Um algoritmo de balanceamento de carga típico é definido por três políticas principais [SHI92][SHI95][ZHO88]:

- Uma política de informação, que especifica a quantidade de informação sobre a carga de trabalho que deve ficar disponível para os elementos que decidem a localização das tarefas em um sistema.

- Uma política de transferência, que determina em que condições uma tarefa deve ser transferida (por exemplo: a carga atual de trabalho de um EP, o tamanho da tarefa, se pode haver migração de tarefas, etc.).

- Uma política de colocação, que identifica para qual EP uma tarefa deve ser transferida, quando necessário.

A vantagem do balanceamento de carga dinâmico, em relação ao escalonamento estático, é que o sistema não precisa se preocupar com o comportamento de uma aplicação antes que ela seja executada. Assim, o sistema torna-se flexível e consegue se adaptar às mudanças ambientais durante a execução dos programas. Particularmente, esse método é bastante útil nos sistemas distribuídos, em que a principal meta de desempenho é aproveitar melhor a potência computacional do sistema e não apenas minimizar o tempo de execução das aplicações [SHI95].

A maior desvantagem do balanceamento de carga dinâmico é o custo adicional do processamento em função de [SHI95]:

- Transferência de informações sobre a carga de trabalho entre os processadores.

- Processo de decisão para escolher os processos e processadores para transferência de tarefas.

- Atrasos de comunicação [EL-94]. 
A distribuição das informações sobre a carga de trabalho e o processo de decisão sobre quando e para onde transferir uma tarefa representam as duas maiores fontes de sobrecarga de um sistema. Portanto, as pesquisas em balanceamento de carga deveriam ser focalizadas sobre essas áreas. Há uma expectativa entre os pesquisadores de que a ênfase nos futuros projetos deve recair sobre:

- Escalonamento híbrido (estático e dinâmico no mesmo sistema).

- Medidas efetivas de índices de carga.

- Organização hierárquica dos sistemas.

- Ferramentas incorporadas ao sistema operacional, utilizadas para implementar políticas de balanceamento de carga diferentes conforme a arquitetura e as necessidades das aplicações.

As operações de balanceamento de carga podem ser divididas em fisicamente distribuídas e não distribuídas, dependendo de como a responsabilidade por essas operações está organizada.

\section{Escalonamento Dinâmico Fisicamente não Distribuído}

Nesse caso, um único processador é responsável pelas funções de balanceamento de carga para o sistema inteiro [CAS88a][SHI95].

Há três grandes grupos representantes dessa categoria [MUN94][SHI92]:

- Distribuição Farm: nessa abordagem, um processo mestre (farmer) distribui os dados de um problema para um conjunto de processos "escravos" (workers) que residem em processadores diferentes. A distribuição dos processos é feita durante a compilação, mas esse método é considerado dinâmico porque os dados são distribuídos durante a execução, conforme a carga de trabalho de cada EP.

- Abordagem determinística: um dos mecanismos de balanceamento de carga mais simples, que impõem uma pequena sobrecarga para o sistema que o utiliza. O algoritmo de distribuição designa o $i$-ésimo processo para o processador $i \% \mathrm{~N}$ (onde \% é o operador da linguagem $\mathrm{C}$ para resto de divisão), onde $\mathrm{N}$ é o número de processadores do sistema. Esse método funciona muito bem em sistemas que possuem poucos processadores e quando os processos são independentes uns dos outros.

- Abordagem aleatória: semelhante à abordagem determinística, esse método pode ser utilizado em sistemas não homogêneos, funcionando razoavelmente, em média. Entretanto, seu pior caso pode ser desastroso, dependendo da função aleatória escolhida. Quando um processo local é gerado, verifica-se a situação do EP. Caso ele seja classificado como ocioso ou com pouca carga, o novo processo é executado localmente. Caso contrário, uma função faz a escolha de outro EP usando um método aleatório qualquer e envia o novo processo para o EP escolhido, independente de sua carga local. 


\section{Escalonamento Dinâmico Fisicamente Distribuído}

Nesse caso, o processo de decisão do escalonamento é distribuído entre os diversos processadores do sistema. O elemento chave aqui é o grau de autonomia que cada EP possui. Esse trabalho pode ser feito de forma cooperativa ou não [CAS88a]:

- Processos não cooperativos: cada EP toma decisões de balanceamento de carga independentemente dos demais, sem haver preocupações sobre os resultados que isso possa ter sobre o sistema inteiro.

- Processos cooperativos: aqui, cada EP é responsável por suas próprias tarefas, mas as decisões de cada um devem levar em consideração um objetivo comum para o sistema inteiro. Da mesma forma que no escalonamento estático, essa abordagem pode ser dividida em métodos ótimos e sub-ótimos, que, por sua vez, podem ser divididos em métodos aproximados e heurísticos.

\section{Políticas Combinadas}

Também é possível haver políticas combinadas. Por exemplo, um sistema pode adotar uma política de informação centralizada enquanto a transferência e colocação são distribuídas. Nesse caso, todos os EPs enviam informações sobre a carga de trabalho para um determinado EP do sistema (e recebem dele as informações globais), mas as decisões de quando e para onde transferir alguma tarefa são tomadas localmente. Caso a política de informação seja distribuída, cada EP mantém sua própria imagem da carga de seu sistema [SHI95].

\section{Outras Características}

Além da classificação hierárquica apresentada, os sistemas de escalonamento podem apresentar outras características que não são exclusivas de qualquer dos tipos verificados acima, mas são importantes para descrever o comportamento dos processos apresentados.

\section{Sistemas Adaptativos e não Adaptativos}

Nos sistemas adaptativos, os algoritmos que implementam a política de escalonamento modificam dinamicamente o próprio comportamento em função dos estados anterior e atual do sistema, além de em resposta às decisões anteriores do sistema de escalonamento [CAS88a][SHI92].

Por contraste, um sistema não adaptativo é aquele que não leva em consideração o histórico do sistema para tomar suas decisões, apresentando sempre o mesmo comportamento na presença de situações semelhantes [CAS88a][SHI92].

\section{Protocolo de Convite (Bidding)}

Essa classe de política apresenta um protocolo que descreve de que forma os processos são designados para os processadores. Esse protocolo apresenta dois componentes principais: o empresário (manager) e o contratante (contractor). O empresário "representa" uma tarefa que necessita de um processador e anuncia para todo 
o sistema que existe uma tarefa com determinadas características que está pronta para ser executada. Na sequiência, ele recebe convites dos contratantes que têm condições de recebê-la e escolhe um deles. A tarefa, então, inicia sua execução no processador escolhido [CAS88a][SMI80].

O fator chave para essa abordagem é a quantidade de informação trocada entre os EPs com a finalidade de tomar uma decisão. Porém, há alguns aspectos bastante interessantes nesse protocolo [CAS88a][SMI80]:

- O empresário não precisa ser fixo. Cada nova tarefa pode ter o seu.

- A decisão do empresário é soberana, o que significa que o EP que faz um convite aceita antecipadamente receber a nova tarefa, caso ele seja o escolhido.

- Por outro lado, os contratantes são autônomos para não enviar convites, caso assim decidam.

- O EP que não envia um convite em resposta ao anúncio de um empresário não é obrigado a receber qualquer tarefa para execução.

\section{Transferência Preemptiva e não Preemptiva}

A transferência preemptiva de uma tarefa (também chamada de migração de tarefa) é feita quando ela já está parcialmente executada. Geralmente, é uma operação bastante cara e difícil de se realizar porque significa reunir as informações sobre o estado da tarefa (que podem ser muitas e complexas), fazer a transferência de todos esses dados para o EP destino, onde o processo continua sua execução [ESK89][SHI92][SHI95] [THE91][ZAY87].

O estado de uma tarefa consiste de uma imagem de memória virtual, uma entrada na tabela de processos, buffers não lidos, mensagens, ponteiros de arquivos, marcadores de tempo, etc. [SHI92][TAN92].

A transferência não preemptiva de tarefas (também chamada de colocação dinâmica de tarefas), por outro lado, envolve apenas tarefas que ainda não iniciaram sua execução. Nesse caso, não é necessário transferir os seus estados. Uma vez iniciada a execução em um EP, a tarefa permanece nele até o fim [SHI92][SHI95].

\section{Estabilidade e Eficiência}

A estabilidade de um sistema está fortemente relacionada com sua capacidade de responder a sua carga de trabalho. Há duas formas de estabilidade bem conhecidas na área de transferência de tarefas [CAS88b][SHI92]:

- A perspectiva da teoria de filas.

- A perspectiva dos algoritmos de distribuição.

De acordo com a teoria de filas, quando as tarefas de um sistema apresentam uma taxa de chegada maior do que sua taxa de conclusão, as filas para usar os processadores desse sistema podem crescer indefinidamente. Um sistema nessas condições é considerado instável [CAS88b][SHI92].

Por exemplo, caso o algoritmo de distribuição de carga de um sistema comece a fazer um número excessivo de trocas de mensagens para conseguir informações sobre a 
situação de todos os nós, a soma da carga das tarefas externas com o custo imposto pelo algoritmo pode se tornar maior do que a capacidade do sistema, tornando-o instável [CAS88b][SHI92].

Por outro lado, apesar de ser estável, um algoritmo pode fazer com que um sistema tenha um desempenho pior do que um outro que não o utilize. Isso leva à necessidade de se introduzir um conceito mais restritivo para a avaliação de algoritmos: a eficiência [SHI92].

Um algoritmo de distribuição de carga é eficiente sob um determinado conjunto de condições, se ele consegue aumentar o desempenho relativo de um sistema. Assim, um algoritmo eficiente é estável, mas o contrário nem sempre é verdadeiro [SHI92].

Por outro lado, analisando-se pela perspectiva dos algoritmos de distribuição, se um algoritmo consegue realizar operações improdutivas indefinidamente com uma probabilidade diferente de zero, então esse algoritmo é instável. Por exemplo, considere a situação de degeneração (thrashing) de um sistema. A transferência de uma tarefa pode aumentar a fila do receptor além do ponto de sobrecarga, causando a necessidade de uma nova transferência. Se a carga geral do sistema é muito alta, isso pode se repetir indefinidamente. A produção pode cair a níveis muito baixos, enquanto a maioria dos nós fica dedicada apenas à transferência de tarefas [CAS88b][SHI92].

\section{Iniciativa da Transferência}

A iniciativa da transferência de uma tarefa pode ser tomada pelo EP transmissor (qualquer um que determine que sua carga de trabalho está excessiva) ou pelo receptor (EP que determina que está ocioso ou com carga de trabalho reduzida) [SHI92].

Nos algoritmos cuja iniciativa é tomada pelo transmissor, esse elemento utiliza uma política de transferência baseada em um certo limite de sua fila de processador. Quando uma nova tarefa local excede esse determinado limiar, ela deve ser transferida. Um nó pode se tornar receptor, nesse caso, se a tarefa recebida não exceder o seu próprio limiar. Esses algoritmos podem causar instabilidade no sistema [SHI92].

Quando a iniciativa é tomada pelo receptor, a política de transferência também é baseada em um limiar. Agora, entretanto, a troca de mensagens é mais eficiente, já que existe um processador que pode receber uma transferência. Assim, um algoritmo dessa categoria não provoca instabilidade. Mas, para ser mais proveitoso, esse método precisa que a transferência seja preemptiva [SHI92].

Há, também, a categoria de iniciativa simétrica, na qual tanto o transmissor quanto o receptor podem iniciar as atividades para a transferência de uma tarefa. Algoritmos desse tipo podem apresentar vantagens das duas categorias. Quando a carga do sistema é baixa, os elementos transmissores podem ter mais sucesso em encontrar nós com pouca carga de trabalho. Porém, quando a carga é alta, os receptores são os mais indicados para encontrar nós sobrecarregados [SHI92].

Por outro lado, também podem apresentar as desvantagens das duas abordagens. Quando a carga do sistema aumenta, a troca de mensagens pode causar instabilidade. E, já que apresenta iniciativa pelos receptores, a transferência precisa ser preemptiva [SHI92]. 


\subsection{Escalonamento Estático}

No escalonamento estático, este trabalho considera quatro modelos básicos para a representação de programas concorrentes:

- STG (Static Tasks Graph, ou Grafo Estático de Tarefas) [FER89][LO88] [STO77].

- DAG (Directed Acyclic Graph, ou Grafo Acíclico Dirigido) [HUR90] [POL87][SAR86][SHI90].

- TCG (Temporal Communication Graph, ou Grafo de Comunicação Temporal) [LO92].

- PG (Processor Graph, ou Grafo de Processadores) [SHI95].

\subsubsection{O Modelo STG}

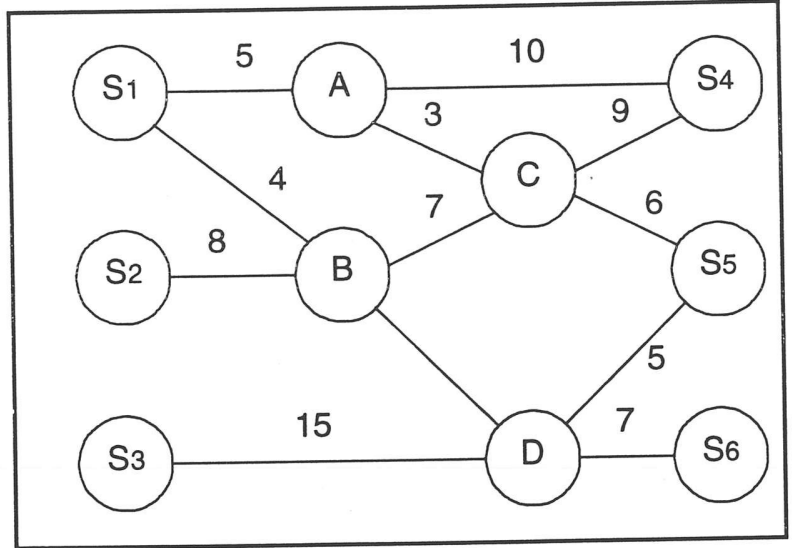

Figura 5.2. Exemplo de um STG.

No modelo STG, um programa concorrente é representado por um grafo $G$, conectado e não dirigido. Os vértices são as tarefas (ou funções) do programa e os arcos indicam o peso da comunicação entre os processos. Na figura 5.2, pode-se ver um exemplo de um STG no qual $\mathrm{S}_{1}, \mathrm{~S}_{2}$ e $\mathrm{S}_{3}$ são os nós fonte e $\mathrm{S}_{4}, \mathrm{~S}_{5}$ e $\mathrm{S}_{6}$ são os nós destino. O programa inicia sua execução nos nós fonte e termina nos nós destino. Entre esses nós pode haver vários nós intermediários, sendo que o conjunto todo é conectado por arcos com peso. O peso de um arco representa o atraso da comunicação entre os dois processos que ele conecta [FER89][LO88][SHI95][STO77]. 


\subsubsection{O Modelo DAG}

No modelo DAG, um programa concorrente é identificado por um grafo acíclico dirigido, no qual os nós representam as tarefas do programa e os arcos dirigidos representam a dependência entre os processos e a comunicação entre as tarefas. A representação algébrica de um programa, nesse modelo, tem a forma $G(T, E, C, P)$, onde [GER93a][SHI95][YAN92]:

- $T$ é o conjunto de tarefas do programa.

- $t=|T|$ é o número de tarefas.

- E é o conjunto de arcos dirigidos entre os nós T.

- $e=|E|$ é o número de arcos.

- $C$ é o conjunto dos custos de comunicação dos arcos $E$.

- $P$ é o conjunto dos custos computacionais das tarefas $T$.

- O valor $c_{i, j} \in C$ é o custo de comunicação no arco $e_{i, j}=\left(t_{i}, t_{j}\right) \in E$. Caso $t_{i}$ e $t_{j}$ sejam mapeados no mesmo processador, $e_{i, j}=0$.

- O valor $p_{i} \in P$ é o tempo de execução da tarefa $t_{i} \in T$.

$E$ representa a ordem de execução das tarefas $T$, de tal forma que, se $T i<T j$, isso implica que $T i$ deve completar a sua execução e passar alguma informação para $T j$ antes que $T j$ possa executar. Além disso, existem duas funções associadas com esse modelo:

- A função $W: T \rightarrow R$, que fornece o peso ou o tempo de execução da tarefa $T$.

- A função $C: E \rightarrow R$, que fornece o atraso da comunicação no arco $E$.

Nas duas funções, $R$ (a resposta da função) é um número real não negativo.

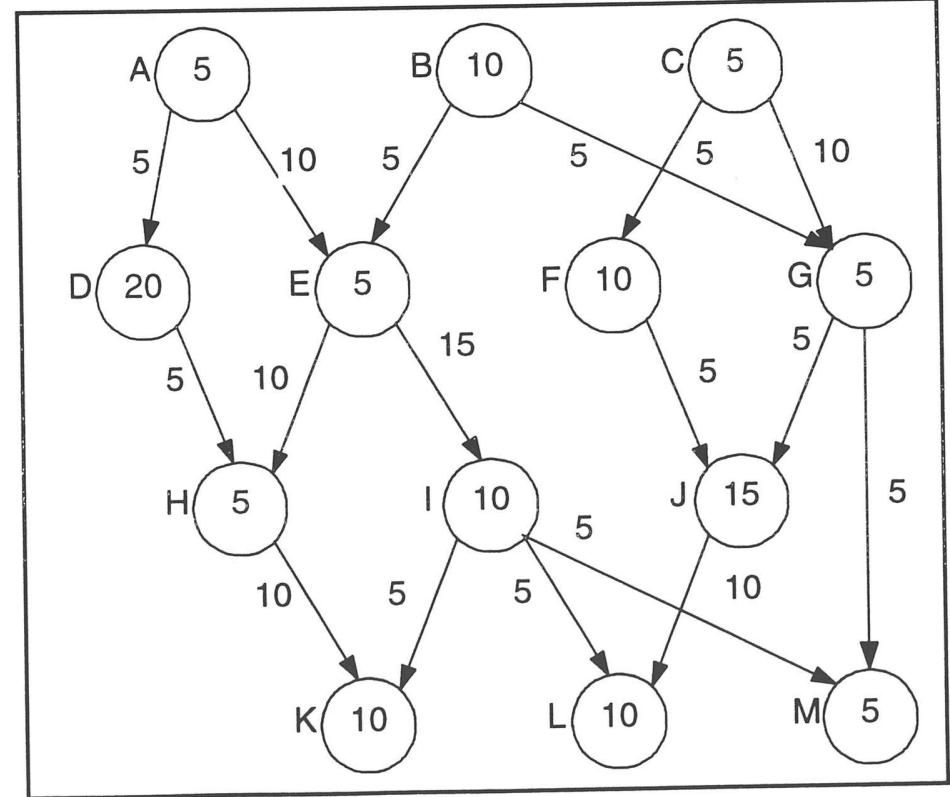

Figura 5.3. Exemplo de um DAG.

Na figura 5.3, pode-se ver o exemplo de um DAG. Os nós $A$ até $M$ são as tarefas de um programa qualquer, o número dentro de cada nó é o tempo de execução dessa 
tarefa e o número em cada arco representa o atraso da comunicação entre os nós conectados por ele [HUR90][POL87][SAR86][SHI90][SHI95].

\subsubsection{O Modelo TCG}

Um modelo mais recente, o TCG, foi proposto em 1992 pela pesquisadora Virginia Lo, da Universidade do Oregon. O TCG é um modelo de grafo híbrido (integra os modelos DAG e STG) para o mapeamento de processos paralelos em arquiteturas paralelas de passagem de mensagens. Foi projetado para enriquecer o modelo STG, adicionando informações sobre eventos temporais e fornecendo meios de descrever a regularidade (equilíbrio ou balanceamento) de uma estrutura paralela [LO92].

No modelo TCG, a atividade de um processo $p_{i}$ é considerada uma seqüência de eventos atômicos. Um evento pode ser uma computação ou uma comunicação. A seqüência de eventos de um processo é representada por um conjunto linear de nós em um grafo, com arcos dirigidos indicando a precedência entre os eventos. Uma mensagem enviada do processo $p_{i}$ para $p_{j}$ é representada por um arco dirigido (no caso, um arco de passagem de mensagem) do nó-evento send de $p_{i}$ para o nó-evento receive de $p_{j}$ [LO92].

O modelo TCG, como apresentado até aqui, é idêntico ao modelo de Diagramas de Tempo de Processamento, de Lamport [LAM78]. A diferença reside no acréscimo dos pesos associados aos nós e arcos, usados para representar os custos de processamento e comunicação. Além disso, foi criada uma função de mapeamento de subgrafos TCG para identificar as diversas fases de funcionamento de uma aplicação. Uma representação estática de um TCG pode ser vista na figura 5.4a, enquanto outra, dinâmica (também chamada de TCG-DAG), pode ser vista na figura 5.4b [LO92].

\subsubsection{Grafos PG (Processors Graphs)}

No escalonamento estático, um sistema multiprocessador é representado por um grafo de processadores da forma $P G(P E, L K)$, onde [SHI95]:

- PE é o conjunto de EPs do sistema.

- $L K$ é o conjunto de conexões entre os EPs.

Um exemplo de um grafo de processadores pode ser visto na figura 5.5 (no caso, uma malha de 4 processadores) [SHI95].

Dado um grafo $G$ de um programa e um grafo $P G$ de processadores, fazer um escalonamento estático significa mapear $G$ em $P G$, tendo sempre em vista a meta de minimizar o tempo de execução do programa. A figura 5.6 mostra um gráfico de Gantt com o mapeamento do DAG da figura 5.3 no grafo de processadores da figura 5.5 , onde é possível ver a distribuição das tarefas entre os EPs e o momento preciso em que cada uma é executada. As áreas em preto indicam os períodos de ociosidade dos processadores [SHI95]. 


\section{Arcos}
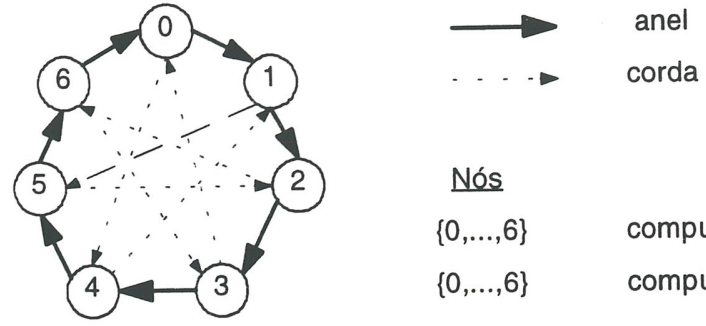

Nós
$\{0, \ldots, 6\}$
compute1
$\{0, \ldots, 6\}$
compute2

(a) TCG estático.

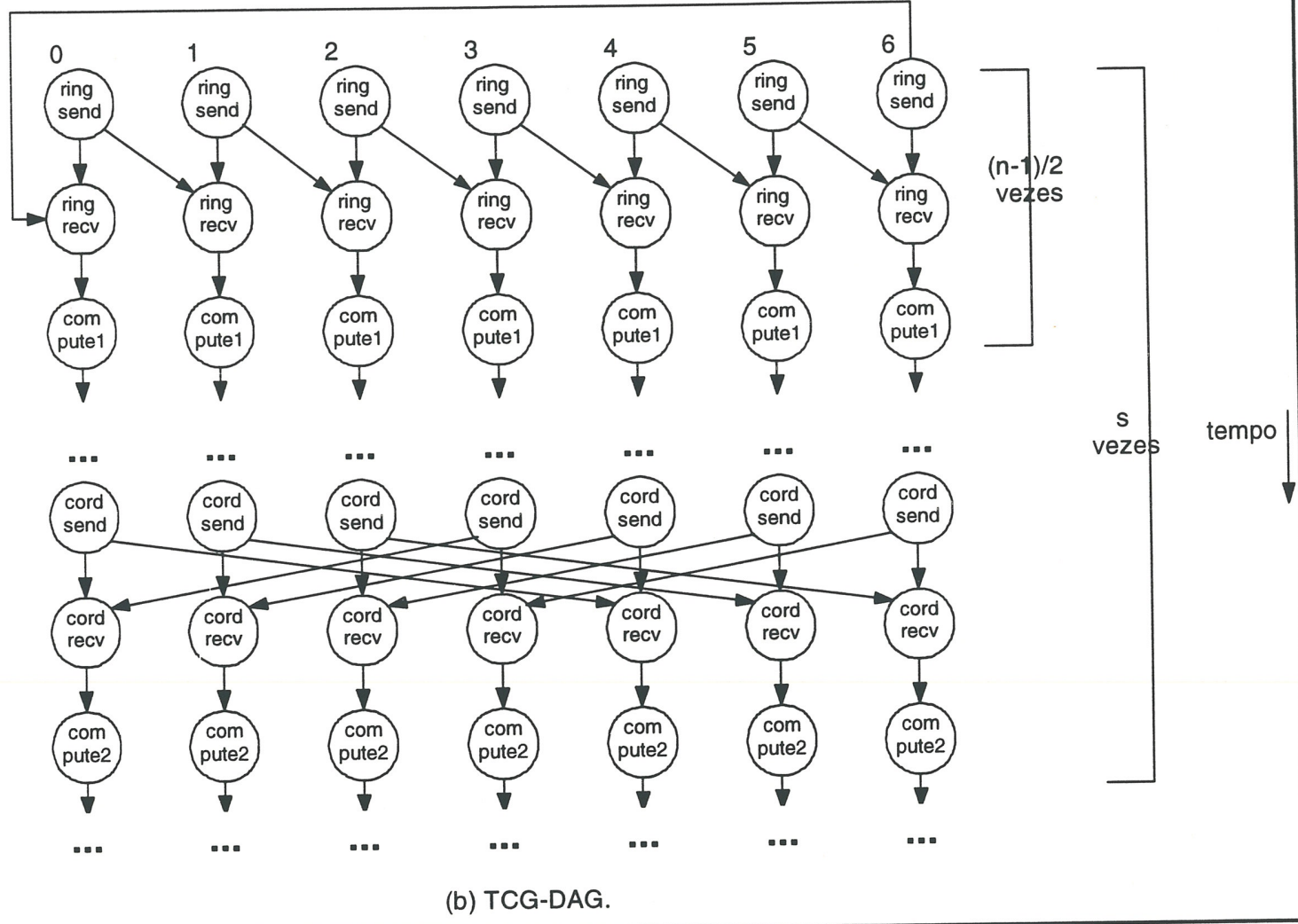

Figura 5.4. (a) Um TCG estático. (b) Um TCG-DAG para o algoritmo $n$-body.

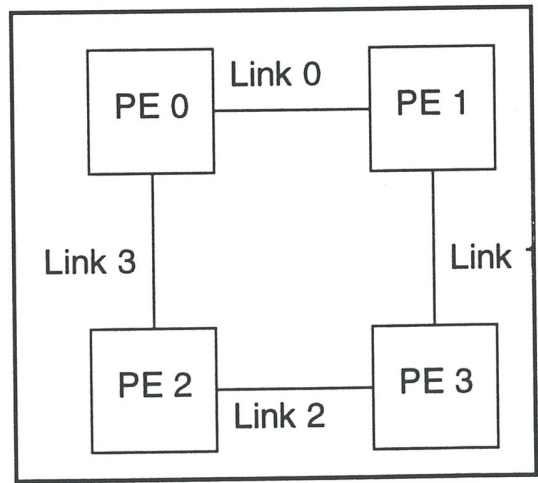

Figura 5.5. Um grafo representando uma malha de 4 processadores.

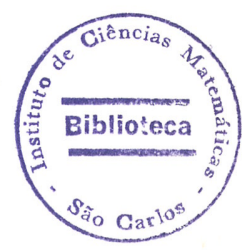




\begin{tabular}{|c|c|c|c|c|c|c|c|c|c|c|c|}
\multicolumn{1}{r|}{0} & 5 & 10 & 15 & 20 & 25 & 30 & 35 & 40 & 45 \\
\hline EP 0 & B & B & & E & I & I & H & K & K & \\
\hline EP 1 & A & D & D & D & D & & & M & & \\
\hline EP 2 & C & F & F & G & J & J & J & L & L & \\
\hline EP 3 & & & & & & & & & & \\
\hline
\end{tabular}

Figura 5.6. Gráfico de Gantt com a distribuição das tarefas entre 4 EPs e os tempos de execução.

\subsubsection{Futuros Trabalhos}

O desempenho da maioria dos principais algoritmos de escalonamento estático é bastante semelhante. Assim, as pesquisas nessa área deveriam se preocupar menos com a busca por novos métodos de desempenho superior aos já existentes e focalizar os esforços em aplicações práticas para os métodos existentes nos sistemas paralelos e distribuídos disponíveis [SHI95].

Para isso, talvez seja necessário um novo grupo de ferramentas de suporte à aplicação prática de algoritmos teóricos de escalonamento. A seguir, são apresentadas algumas das áreas de pesquisa mais promissoras, atualmente, para futuros trabalhos [SHI95].

\section{Gerador de DAGs}

Um gerador de DAGs recebe como entrada um programa paralelo, escrito em uma linguagem paralela qualquer e sua saída é um DAG equivalente desse programa, com suas dependências funcionais e as estimativas para os tempos de execução e os atrasos de comunicação. É claro que continua válido o problema de estimar esses tempos com precisão, mas alguns resultados de estudos feitos com o sistema PYRROS [YAN92] mostram que, utilizando-se comunicação assíncrona e à medida que a granularidade das tarefas torna-se maior, é possível alcançar um bom desempenho. Como a maioria das aplicações industriais e comerciais, hoje em dia, é escrita em C ou Fortran, o gerador deve aceitar essas linguagens como entrada.

\section{Ferramentas para estimativas de tempo de execução}

Como um dos mais importantes requisitos do escalonamento estático é o conhecimento prévio dos tempos de execução das tarefas, o gerador de DAGs deve possuir uma ferramenta que consiga fazer estimativas desses tempos com uma precisão razoável. Alguns caminhos para isso são:

- Estimativa pelo usuário: o programador pode anotar em seu programa os tempos estimados para determinados procedimentos, a probabilidade de seguir determinada condição e o número de iterações de um laço. Essas informações podem ser utilizadas para produzir uma estimativa final do tempo de execução de um processo.

- Estimativas baseadas em simulação: o comportamento do programa pode ser simulado durante a compilação executando-se as instruções que controlam o seu fluxo. Para as restantes, o compilador tem condições de estimar o tempo necessário para executá-las, gerando uma soma do tempo total de uma tarefa. 
- Estimativas baseadas em perfis: a idéia aqui é monitorar algumas execuções do programa, ou executá-lo sequiencialmente, coletando os tempos de execução e a frequiência com que determinadas tarefas são chamadas.

\section{Gerador de perfis de desempenho}

Ele recebe o escalonamento de um programa paralelo para uma arquitetura dada e produz um perfil gráfico do desempenho esperado desse programa. Outra função dessa ferramenta é fornecer o perfil ideal do paralelismo de uma aplicação, permitindo ao usuário ter uma idéia do paralelismo inerente de seu programa.

\section{Ferramentas de distribuição de dados}

Os métodos existentes de escalonamento são baseados na distribuição de funções, ignorando a distribuição de dados. Isso causa redução de desempenho em função dos atrasos de comunicação para obter dados em EPs remotos. Um método de escalonamento com uma ferramenta dessas seria bastante eficiente, pois a maior parte dos dados necessários (talvez até todos) para uma tarefa qualquer poderia ser colocada na memória local de seu processador.

\subsection{Granularidade e Particionamento}

A eficiência da execução de um programa paralelo depende da forma como ele é dividido em módulos (ou partições) e do método de escalonamento desses módulos no conjunto de $N$ processadores de um sistema [KRU88a][SHI95]. Segundo Cvetanovic [CVE87], existem 8 parâmetros de maior influência no desempenho de um sistema multiprocessador:

- A quantidade de paralelismo inerente nas aplicações.

- O método de decomposição de um problema em módulos.

- O método de distribuição dos módulos entre os processadores.

- A granularidade do módulo executado em determinado processador.

- A possibilidade de sobrepor o processamento com a comunicação.

- O modo de acesso aos dados (memória global, local, etc.)

- A estrutura de interconexão.

- A velocidade dos processadores, memórias e da rede de interconexão.

Escalonar é o ato de mapear os nós de um DAG nesses $N$ processadores, indicando previamente o momento do início da execução de cada tarefa. Dividir em partições, por sua vez, é o ato de mapear esses nós em $M$ módulos, sendo que todas as tarefas de um módulo devem executar no mesmo processador [GER93a].

Um particionamento é chamado de não linear se ao menos um de seus módulos contém duas tarefas paralelas independentes. Caso contrário, ele é chamado de linear (figura 5.7). A vantagem do particionamento linear é que ele consegue explorar todo o paralelismo existente em um DAG, enquanto o não linear sequiencializa tarefas independentes ao tentar reduzir a comunicação entre os módulos [EL-94][GER93a]. 
O tamanho e a complexidade dos módulos de um programa podem ter um grande impacto no tempo de execução [GER93a][GER93b]. No pico do desempenho, todos os $N$ EPs devem ficar ocupados o tempo todo. Entretanto, alcançar essa situação é muito difícil em função de atrasos causados por elementos inerentes ao multiprocessamento [ALM94][EL-94][HWA84][SHI95][TAN92]:

- A comunicação entre os processos.

- A sincronização entre as tarefas.

- A perda de eficiência quando os EPs trabalham no limite de carga possível.

- O gerenciamento das tarefas pelo sistema operacional.

A eficiência no processamento paralelo consiste em encontrar um bom equilíbrio entre vários fatores [SHI95]:

- O número de processadores necessários.

- O número de módulos do programa.

- A quantidade aceitável de sobrecarga.

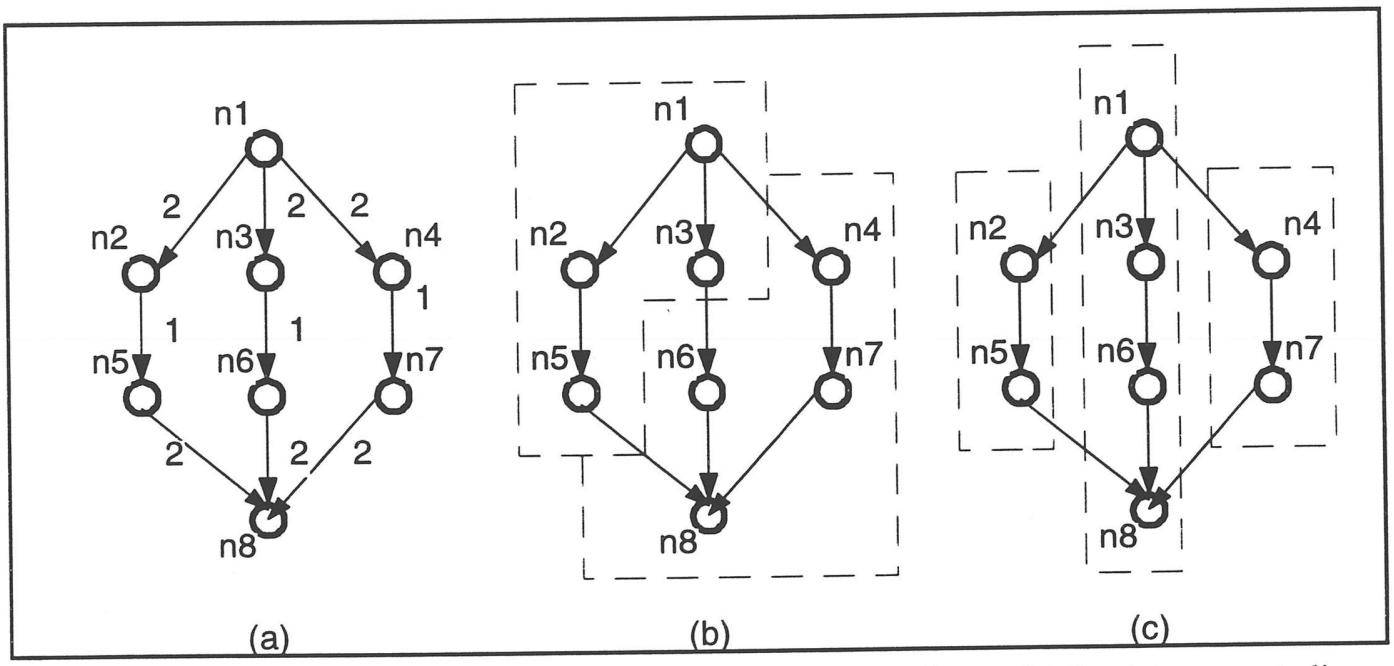

Figura 5.7. (a) Um DAG com pesos. (b) Particionamento não linear. (c) Particionamento linear.

Por exemplo, para um determinado programa, a adição de mais EPs talvez não aumente o desempenho final porque a sobrecarga de comunicação pode aumentar mais do que o ganho conseguido com os processadores.

A análise desses fatores pode ser feita através da granularidade. A granularidade de uma tarefa (em arquiteturas de passagem de mensagens e sistemas distribuídos) é definida como a relação entre os seus tempos de processamento e comunicação. Assim, considerando que [SHI95]:

- E é o tempo de execução de uma tarefa.

- $C$ é o atraso causado pela comunicação gerada por essa tarefa.

- Então, $E / C$ é a sua granularidade.

Quando a relação $E / C$ é relativamente baixa (abaixo de 10 , por exemplo), a tarefa é classificada como de granularidade fina (por exemplo, as instruções em uma máquina dataflow). Caso a relação $E / C$ seja grande (acima de 100, por exemplo), a tarefa é de 
granularidade grossa (por exemplo, funções de programas, subprogramas ou partições) [SHI95].

\section{Algoritmos de Particionamento}

O objetivo do particionamento de programas paralelos é eliminar tanto quanto possível a sobrecarga causada pela comunicação entre as tarefas, procurando manter o maior grau de paralelismo possível [CVE87]. Nesta seção, são apresentadas três classes de algoritmos de particionamento entre as mais conhecidas.

\section{Particionamento pelo Caminho Crítico}

A maioria dos algoritmos desta classe é baseada em heurísticas de caminho crítico. A idéia é que as tarefas de granularidade fina que compõem o caminho crítico do grafo de um programa precisam ser executadas seqüencialmente, de qualquer maneira. Assim, uma vez que os nós do caminho crítico sejam identificados, podem ser agrupados em uma única partição e designados para executar em um único processador. Um exemplo desse método é o sistema de particionamento em camadas verticais [LEE91], que consiste de dois passos principais:

1. Começando com o DAG de um programa de granularidade fina, uma classificação topológica é realizada para transformar o DAG em um conjunto de camadas horizontais. Assim, os nós de cada camada podem ser executados em paralelo e as camadas ficam ordenadas linearmente em relação às restrições de precedência entre os nós.

2. O caminho crítico do DAG transformado é identificado e os nós nesse caminho são agrupados em uma camada vertical, formando uma partição. Essa partição é temporariamente removida do DAG, e o passo 2 é reexecutado para o próximo caminho crítico não processado, até que todos os nós tenham sido agrupados.

Na figura 5.8a pode-se ver o DAG de um programa genérico. Após a transformação realizada pelo passo 1 do algoritmo de particionamento, o DAG fica na situação da figura $5.8 \mathrm{~b}$. O resultado final, após o passo 2, pode ser visto na figura $5.8 \mathrm{c}$.

\section{Particionamento por Eliminação da Comunicação}

Esse método utiliza a eliminação do atraso da comunicação como critério para o agrupamento de tarefas em partições. A abordagem geral é agrupar os sucessores de um determinado nó junto com ele. Assim, o custo da comunicação entre essas tarefas é desprezível. Porém, o paralelismo entre essas tarefas é perdido. O algoritmo deve levar isso em consideração e fazer o agrupamento apenas nos casos em que isso seja vantajoso [SHI95].

Os métodos propostos por McCreary [MCC89] e Yang [YAN91] são exemplos dessa classe de particionamento.

$\mathrm{Na}$ figura 5.9, pode-se verificar como funciona o algoritmo de agrupamento proposto por Gerasoulis e Yang [GER90][GER92][YAN91]. O DAG original é mostrado na figura 5.9a, onde os números em cada nó representam a relação $E / C$. Por 
exemplo, o nó $n 1$ precisa de uma unidade de tempo para executar, três para passar uma mensagem para $n 2$ e uma para passar outra mensagem para $n 3$.

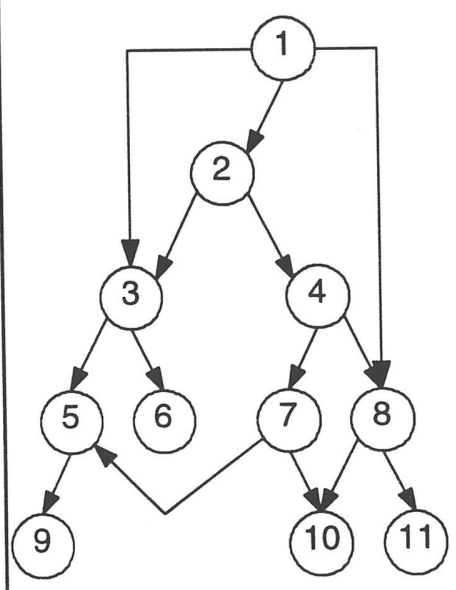

(a)

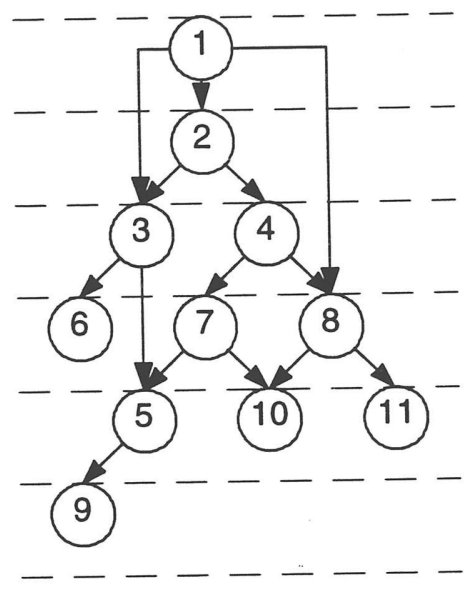

(b)

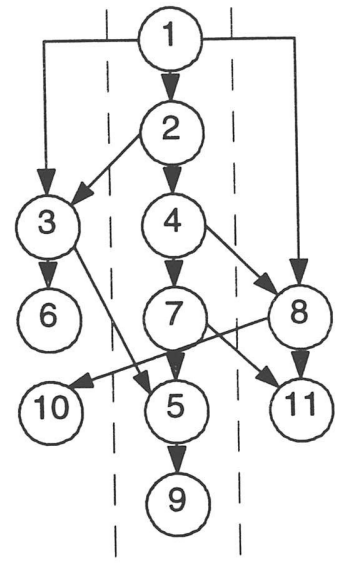

(c)

Figura 5.8. (a) Um DAG. (b) Sua classificação horizontal. (c) Seu particionamento vertical.

Começando por $n 1$, é preciso decidir se $n 1$ e $n 2$ devem ser colocados na mesma partição ou não. Se ficarem em partições diferentes, o tempo total de execução para $n l \mathrm{e}$ $n 2$ é de 6,5 unidades de tempo $(E n 1+E n 2+C n 1 n 2)$. Caso contrário, esse tempo passa a ser de 3,5 .

Em seguida, deve-se decidir se $n 3$ deve ficar na mesma partição que $n 1$ e $n 2$. Se ficarem juntos, o tempo total de execução dos três nós é de 6 unidades de tempo. Caso $n 3$ fique separado de $n 1+n 2$, esse tempo passa para 4,5 unidades. Assim, n3 não é agrupado com $n 1+n 2$.

O resultado final do particionamento do DAG da figura 5.9a pode ser visto na figura 5.9b. As duas partições devem ser executadas em processadores diferentes. Uma das vantagens desse método é que ele determina um limite máximo para o número de processadores selecionados para uma aplicação. No exemplo citado, uma tarefa com 6 módulos necessita de apenas dois processadores.

\section{Duplicação de Tarefas}

A idéia desse método é eliminar o custo de comunicação entre as tarefas por meio da sua duplicação entre os EPs. A principal vantagem dessa abordagem é que ela mantém o paralelismo original do programa. Suas desvantagens: necessita de mais espaço de memória (e mais recursos) no sistema inteiro, aumenta o custo da sincronização para o acesso aos dados entre as tarefas duplicadas e aumenta a complexidade da distribuição. A figura 5.10 apresenta o exemplo de escalonamento de um DAG em três processadores. Cada nó numerado do DAG representa uma tarefa com tempo de execução de uma unidade de tempo. Os custos de comunicação estão marcados nos arcos. No exemplo, a tarefa 1 é duplicada em todos os três processadores. Isso efetivamente elimina o custo de comunicação entre o nó 1 e os nós 2,3 e 4 [GER93a][KRU88a][SHI95]. 


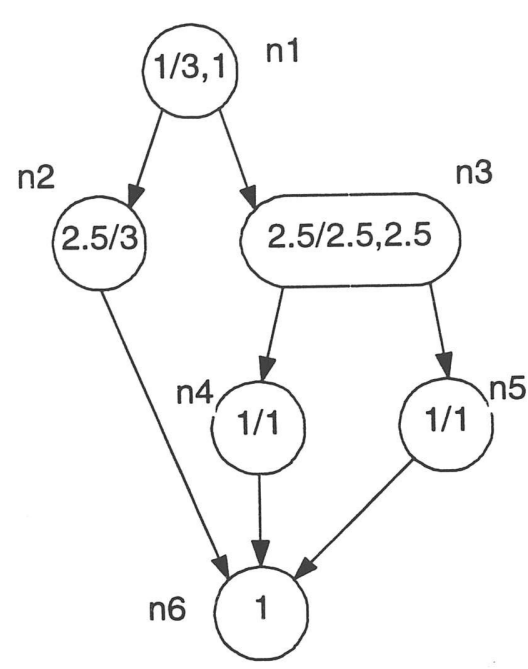

(a)

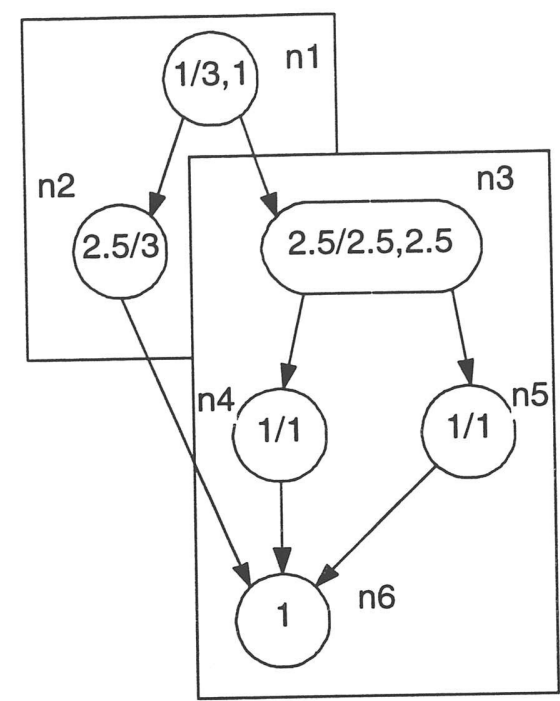

(b)

Figura 5.9. (a) Um DAG mostrando a relação E/C de cada tarefa. (b) Agrupamento das tarefas eliminando o custo de comunicação.

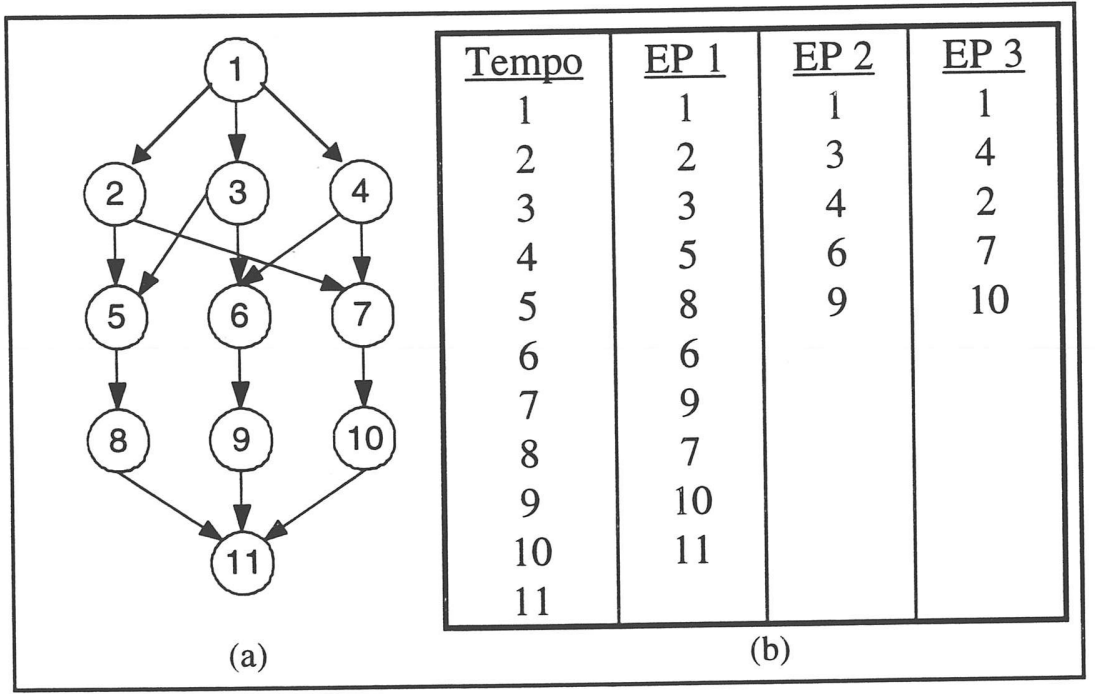

Figura 5.10. (a) O DAG de um programa genérico. (b) Seu escalonamento em 3 EPs por duplicação de tarefas.

\subsection{Balanceamento de Carga}

Ao contrário do escalonamento estático, as técnicas de balanceamento e compartilhamento de carga utilizam muito pouco (e até mesmo nenhum) conhecimento sobre as aplicações durante a compilação, dando mais ênfase na redistribuição dos processos entre os EPs durante a execução para alcançar metas de desempenho definidas [BAU89][CAS88b][AEG86][KRU87][LIT88][WAN85]. É interessante notar que a maioria dos trabalhos nessa área são voltados para os sistemas distribuídos. Nesse contexto, um EP refere-se a um nó de uma rede de estações de trabalho.

Balanceamento de carga e compartilhamento de carga são termos quase sinônimos na literatura. Enquanto o balanceamento de carga trata da redistribuição como a tarefa de designar os processos entre os processadores, compartilhamento de carga representa o compartilhamento da capacidade de processamento entre as tarefas 
[SHI95]. Mas o balanceamento de carga também é conhecido por diversos outros nomes: escalonamento dinâmico [CAS88a], compartilhamento de recursos, escalonamento de recursos, escalonamento de tarefas e migração de tarefas [LÜL93].

\subsubsection{Mecanismos de Migração de Processos}

A migração de um processo é uma tarefa difícil de se realizar, estando dividida em três grandes passos [SHI95]:

- O processo é suspenso no EP fonte.

- O processo é transferido, junto com seu estado de execução, para o EP destino.

- A execução do processo é reiniciada no EP destino.

A fim de evitar a degeneração do sistema, uma política de migração deve assegurar que um processo elegível [KRU88b]:

- Seja maior que um valor limite determinado (um limiar). Normalmente, esse tamanho é em função do tempo de processamento que ainda resta para ser executado por esse processo.

- Tenha executado no EP fonte mais do que um determinado valor (outro limiar).

- Pertença ao conjunto de processos que tenha sido transferido menos do que determinadas vezes (mais um limiar) ou menos freqüentemente entre aqueles que residem no EP fonte.

Há vários custos associados com a migração de processos. Por exemplo [KRU88b]:

- O gerenciamento da informação sobre a carga de trabalho de um sistema.

- A distribuição da informação sobre a carga de trabalho.

- O processo de decisão para realizar uma transferência.

- O atraso em função da transferência de uma tarefa.

- A transferência do estado do processo no EP fonte para o EP destino.

O maior componente do estado de um processo é a informação sobre sua memória virtual [TAN92]. Há várias formas conhecidas de transferência desses dados [SHI95]:

- Transferência da memória virtual inteira: a técnica mais primitiva e menos eficiente.

- Transferência com cópia antecipada: a transferência de um processo é realizada simultaneamente com a sua execução. Após tomada a decisão de transferência, o sistema operacional inicia a transmissão das páginas de memória virtual do processo enquanto ele ainda está executando. Quando um certo número de páginas transferidas é alcançado, o processo é suspenso e o restante é enviado ao EP destino. 
- Transferência com cópia por referência: o processo e seu estado são transferidos, porém sem a sua memória virtual. O processo é reiniciado no EP destino e as páginas de memória são transferidas à medida que são referenciadas.

- Transferência indireta com cópia por referência: idéia similar à anterior. Nesse caso, admite-se que todos os EPs compartilham o mesmo servidor de arquivos. Primeiro, o EP fonte transfere as páginas do processo para o servidor de arquivos. A seguir, são recuperadas pelo EP destino à medida que o processo faça referências às páginas ausentes.

Uma outra possibilidade é a transferência cooperativa [SIL96]. Nesse caso, a aplicação precisa colaborar para que a transferência possa ser feita. Os programas precisam entender um protocolo básico da plataforma de passagem de mensagens e devem responder a comandos especiais feitos pelo sistema. $\mathrm{O}$ protocolo pode apresentar os seguintes passos:

- O sistema determina que uma tarefa deve ser transferida e executa imediatamente o mesmo processo no EP destino, indicando que ele é um processo transferido.

- A seguir, o sistema sinaliza ao processo fonte que ele vai ser transferido.

- O processo fonte interrompe seu processamento em um ponto consolidado e constrói um ou mais pacotes de mensagens com as suas variáveis locais. Esses pacotes podem ser enviados ao sistema ou diretamente ao processo destino, dependendo da implementação.

- O processo destino inicia a sua execução pelo recebimento desses pacotes de variáveis. A seguir, reinicia seu processamento no ponto consolidado em que o processo fonte interrompeu.

- O processo fonte encerra a sua execução.

Esse método precisa que alguns cuidados sejam tomados no projeto da aplicação. Porém, tem a vantagem de não exigir que a transferência seja feita pelo sistema operacional, permitindo que os sistemas que não apresentem essa função possam fazer migração de tarefas com certa facilidade.

Como a localização dos processos de um sistema pode ser drasticamente alterada com sua migração, que pode ocorrer a qualquer momento e para destino não determinável com antecedência, é necessária a existência de um servidor de nomes para resolver todos os conflitos decorrentes desse mecanismo [SHI95].

A migração de processos não pode ser a única atividade do balanceamento de carga, pois isso seria bastante ineficiente. Mas, quando a migração recebe o acréscimo da colocação dinâmica de tarefas (a definição de onde um processo deve ser executado é feita no momento anterior a sua execução), também chamada de balanceamento de carga não preemptivo, alguns estudos demonstram que o ganho de desempenho pode ser substancial [ART89][POW83][THE85]. Krueger [KRU88b] vai mais além, afirmando que a maior parte do ganho de desempenho do balanceamento de carga vem da colocação dinâmica. Entretanto, a migração pode resultar em ganhos consideráveis, desde que a sua sobrecarga não seja significativa [SHI95]. 


\subsubsection{Algoritmos de Balanceamento de Carga}

As estratégias de balanceamento de carga podem ser classificadas de várias maneiras. Baumgartner [BAU88] propõem uma caracterização bastante sistemática, tabulando vários pontos de vista (cooperação, localização do controle, iniciativa, etc.) e propriedades diferentes (estática, dinâmica, adaptável, etc.). Entretanto, essa classificação é bastante complexa.

Lüling [LÜL93] apresenta outro sistema, mais simples e mais apropriado para quem pretende implementar uma dessas estratégias. Qualquer sistema de balanceamento de carga dinâmico apresenta duas fases principais: uma fase de decisão e outra de migração. Na fase de decisão, escolhe-se qual unidade de carga deve migrar. A decisão pode ser baseada na situação local de um EP e de seus vizinhos (decisão local) ou de algum subconjunto de EPs da rede inteira (decisão global). Na fase de migração, uma unidade de carga é transferida para outro processador com a finalidade de reduzir o desbalanceamento do sistema. A migração pode ser feita para os processadores vizinhos (espaço de migração local) ou para qualquer outro (espaço de migração global).

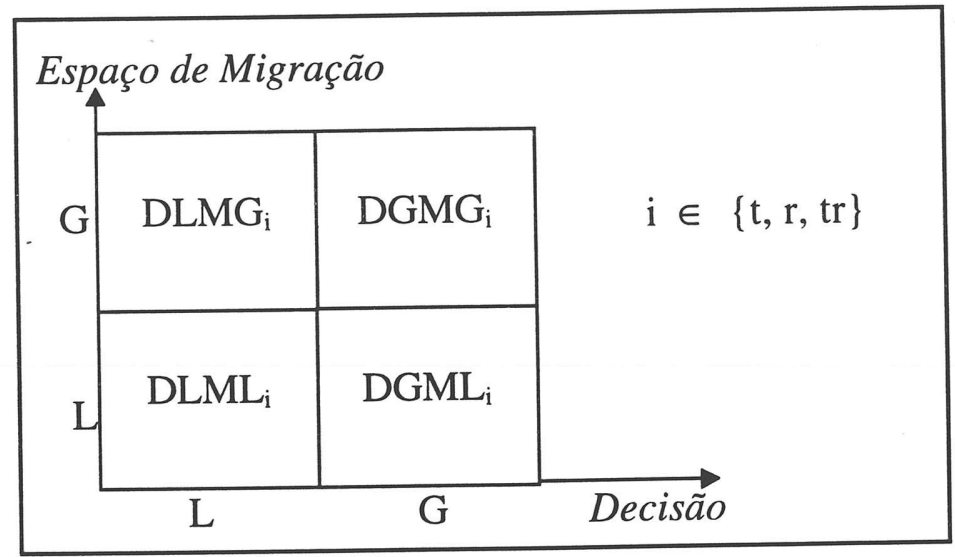

Figura 5.11. Mapeamento dos algoritmos de balanceamento de carga.

Através dessas definições, é possível fazer um mapeamento das diversas estratégias (figura 5.11) distinguindo as atividades de decisão e migração como Locais e Globais. Assim, são considerados 4 grandes grupos de algoritmos de balanceamento de carga:

- DLML: Decisão Local e Migração Local.

- DLMG: Decisão Local e Migração Global.

- DGML: Decisão Global e Migração Local.

- DGMG: Decisão Global e Migração Global.

Outra distinção possível é com relação a quem inicia a atividade de balanceamento de carga: o transmissor, o receptor ou uma forma combinada (tr) [LÜL93].

Definida a forma de agrupamento dos algoritmos, é possível apresentar alguns deles nesse sistema de classificação: 
- Estratégias DLML.

- Aleatória local (l-rnd): nessa estratégia, um processador distribui algumas de suas unidades de carga entre seus vizinhos após um intervalo fixo de tempo [ZHO88]. Essa é uma estratégia $\mathrm{DLML}_{t}$ porque a decisão de migrar uma tarefa é tomada localmente e o processo é iniciado pelo transmissor.

- Vizinho direto (d-N): caso a carga local aumente mais do que um percentual máximo ou diminua mais do que um percentual mínimo, o valor da carga local é transmitida para os vizinhos diretos. Caso a carga de um EP exceda a carga de seu vizinho menos carregado por um percentual maior do que um percentual mínimo, ele envia uma de suas tarefas para o seu vizinho [LÜL93].

- Estratégias DLMG.

- Aleatória global (g-rnd): similar à estratégia aleatória local. A única diferença é que, agora, as unidades de carga podem migrar para qualquer processador da rede [LÜL93].

- Estratégias DGML.

- Método gradiente: desenvolvido por Lin e Keller [LIN87], pertence ao grupo $\mathrm{DGML}_{\mathrm{r}}$ porque as decisões são baseadas em informações gradientes. Gradientes são vetores que mantém informações sobre a carga e a distância de todos os processadores da rede. Isso significa que cada EP tenta manter um estado global aproximado da rede inteira. As tarefas são sempre enviadas para os vizinhos imediatos (migração local). A carga de um EP pode estar em um de três estados possíveis: baixa (Low), normal ou alta ( $\underline{\text { High }}$ ). Cada EP "sabe", através dos gradientes, qual a conexão que representa o menor caminho para um EP $L$. Assim, um EP $H$ envia uma tarefa por essa conexão em direção a um EP não carregado. Se um EP modifica seu estado ou atualiza seu menor caminho para um EP $L$, essa informação é enviada para todos os seus vizinhos diretos.

- Método gradiente estendido (X-GM): semelhante ao anterior, esse método apresenta um controle para evitar custos de comunicação desnecessários quando não há EPs $L$ no sistema. Esse método pertence ao grupo DGML $_{\text {tr }}$ [LÜL93].

- Estratégias DGMG.

- Algoritmo de convite (bid): já visto na seção 5.2.3, também é controlado por estado. Esse algoritmo define que o número de EPs que podem receber tarefas de um EP $H$ depende da distância entre esses processadores. Os convites levam em conta os custos de comunicação [SMI80].

- Algoritmo de drafting (draft): cada processador mantém uma tabela de carga que contém as informações mais recentes dos chamados EPs candidatos. Um candidato é aquele processador do qual pode-se receber uma tarefa. Esse algoritmo já foi proposto com migração local 
[NI85], mas a variante com migração global e na qual é permitida mais de uma migração por tarefa, é mais flexível [LÜL93]. Todas as mensagens enviadas são acrescidas do valor de carga do transmissor. Uma mudança significativa no estado de um EP é distribuída pela rede inteira (broadcast). A iniciativa, nesse método, parte de algum EP $L$, que seleciona um EP $H$ de sua tabela de carga local para que o escolhido envie-lhe uma de suas tarefas.

- Método gradiente estendido global (GX-GM): semelhante ao método gradiente estendido, com a diferença que esse método faz transferências globais de tarefas. Pertence ao grupo DGMG $_{\mathrm{tr}}$ [LÜL93].

\subsection{Considerações Finais}

O balanceamento de carga é uma disciplina de importância indiscutível. É possível encontrar vários grupos de pesquisa nessa área em universidades e institutos do mundo inteiro. Esses grupos têm se dedicado a resolver, passo a passo, as dificuldades existentes para o uso prático dos sistemas de escalonamento e essa atividade tem produzido conquistas consideráveis. Há vários casos de sistemas que utilizam o balanceamento de carga com bons resultados, o que constitui mais incentivo para continuar essas pesquisas.

Lamentavelmente, existe um aspecto ainda não completamente esclarecido. Os principais pesquisadores da área ainda não incluíram esses estudos em seus trabalhos. Coulouris [COU94] e Tanenbaum [TAN95], dois dos principais autores da ciência da computação (seus livros são utilizados pelo MIT como livros texto em seus programas de graduação e pós-graduação, por exemplo), ignoram o balanceamento de carga em suas publicações sobre sistemas distribuídos. Algumas universidades complementam esses livros com artigos de pesquisadores consagrados da área (o já citado MIT, por exemplo). Mas é inegável que, caso esses autores incluíssem o balanceamento de carga entre os tópicos que abordam, esse assunto teria ampla divulgação entre os estudantes e profissionais da ciência da computação.

Felizmente, o esforço para a divulgação dessa disciplina tem sido bastante grande [SHI95]:

- Em 1992, o Journal of Parallel and Distributed Computing publicou uma edição especial sobre "Scheduling and Load Balancing".

- No mesmo ano, a Conferência sobre Supercomputação incluiu em seu programa um workshop sobre "Scheduling".

- Em 1993, outro workshop sobre "Scheduling and Load Balancing" foi incluído na Conferência Internacional sobre Ciências de Sistemas, no Havaí, sendo repetido em 1995 com o título de "Partitioning and Scheduling for Parallel and Distributed Systems".

- Várias conferências internacionais nas áreas de processamento paralelo e distribuído têm apresentado sessões sobre o escalonamento estático e dinâmico nos últimos anos:

- O Simpósio IEEE sobre Processamento Paralelo e Distribuído.

- A Conferência Internacional sobre Processamento Paralelo.

- O Simpósio Internacional sobre Processamento Paralelo. 
- A Conferência Internacional sobre Sistemas de Computação Distribuída.

- Várias publicações apresentam, com freqüência, artigos sobre escalonamento estático e balanceamento de carga dinâmico:

- IEEE Transactions on Parallel and Distributed Systems.

- Journal of Parallel and Distributed Computing.

- IEEE Transactions on Software Engineering.

- IEEE Parallel and Distributed Technology.

- Parallel Computing.

- Communications of The ACM.

- Software Practice and Experience.

- O número de páginas HTML na Internet que tratam sobre o assunto. Fazendo uma pesquisa através do Altavista, sistema de pesquisa na Internet da Digital (http://www.altavista.digital.com), é possível encontrar números expressivos de referências aos principais temas deste trabalho:

- "Load Balancing":

9000.

- "Load Sharing":

2000.

- "Task Migration":

163.

- "Balanceamento de Carga":

10.

Nesse esforço, um papel importante é realizado por diversos profissionais que colocam seus trabalhos à disposição através da Internet, atitude não muito comum para a maioria dos pesquisadores. Um caso, pelo menos, é digno de nota:

- Os professores Tao Yang e Apostolos Gerasoulis, da Universidade Rutgers, em New Brunswick, New Jersey. Seus trabalhos são citados diversas vezes por vários pesquisadores, o que demonstra sua importância. Ainda assim, possuem diversas páginas HTML onde é possível encontrar dezenas de artigos pertinentes com acesso liberado a qualquer pessoa. 


\section{Capítulo 6}

\section{Avaliação dos Métodos de Balanceamento de Carga}

\subsection{Introdução}

O hardware utilizado neste trabalho foi o seguinte:

- Servidor Novell 3.12: 486 DX2-66, 32 MB de RAM, HD SCSI 2 GB.

- 5 computadores PC com sistema operacional Windows 95:

- LASD01: 486 DX2-66, 20 MB de RAM, 2 HD de 540 MB.

- LASD02: 486 DX2-66, 12 MB de RAM, HD de 540 MB.

- LASD03: 486 DX2-66, 8 MB de RAM, HD de 540 MB.

- LASD04: 486 DX4-100, 12 MB de RAM, 2 HD de 540 MB.

- LASD06: Pentium 100, 16 MB de RAM, HD de 1 GB.

O servidor recebeu uma versão única do PVM-W95 [SOU96] que foi utilizada por todos os computadores. O compilador escolhido foi o Borland $\mathrm{C}++5.0$, em função da geração de código nativo para o Windows 95.

Com o ambiente de trabalho definido, o próximo passo foi verificar os algoritmos de balanceamento de carga encontrados na pesquisa bibliográfica. Alguns deles não apresentavam o código, mas apenas uma descrição teórica de seu funcionamento. Assim sendo, foi necessário um estudo específico de cada caso para permitir sua implementação no ambiente do projeto. 


\subsection{Algoritmos de Balanceamento de Carga}

Os algoritmos de balanceamento de carga considerados neste trabalho foram divididos em dois grupos principais:

- Algoritmos de distribuição dinâmica.

- Algoritmos com migração de tarefas.

A idéia desta divisão foi não desprezar alguns algoritmos de distribuição dinâmica, mesmo sabendo que o seu desempenho fica abaixo do desejável quando o ambiente apresenta variações dinâmicas.

Os algoritmos de distribuição dinâmica escolhidos são [CAS88a][MUN94] [SHI92][SHI95]:

- Método Determinístico.

- Método Aleatório.

- Distribuição Farm (ou Método Mestre-Escravo).

Por sua vez, os algoritmos com migração de tarefas são:

- Método Aleatório Local [ZHO88]

- Método do Vizinho Direto [LÜL93].

- Método Aleatório Global [LÜL93].

- Método Gradiente [LIN87].

- Método Gradiente Estendido [LÜL93].

- Método Gradiente Estendido Global [LÜL93].

Estes métodos foram escolhidos porque foram os métodos de uso geral encontrados na pesquisa bibliográfica. Alguns métodos eram específicos para determinada aplicação. Por isso, foram descartados. Também não foram aproveitados os métodos Draft [NI85] e de Convite [SMI80], por apresentarem muita comunicação intrínseca ao seu funcionamento, o que os torna inadequados para a plataforma distribuída adotada.

\subsubsection{Algoritmos de balanceamento de carga - distribuição dinâmica}

Nos algoritmos deste grupo, são considerados apenas os métodos que distribuem os processos pelos hosts (chamados de EPs - Elementos de Processamento - neste trabalho), onde devem ser executados, sem fazer qualquer verificação durante sua execução. Podem parecer demasiado simples para o propósito de balanceamento de carga, já que não fazem transferências de tarefas, mas representam algoritmos que funcionam bem quando não há concorrência entre diversos processos nos computadores utilizados. 


\section{Método Determinístico.}

Constitui um dos mecanismos de balanceamento de carga mais simples, que impõe uma pequena sobrecarga para o sistema que o utiliza. O algoritmo de distribuição designa o $i$-ésimo processo $(\mathrm{Pi})$ para o processador $i \% \mathrm{~N}$ (\% é o operador da linguagem $\mathrm{C}$ para resto de divisão, e $\mathrm{N}$ é o número de processadores do sistema) - $\mathrm{EP}_{\mathrm{i} \% \mathrm{~N}}$. Assim ${ }^{2}$ :

$$
P_{i} \Rightarrow E P_{i \% N}
$$

\section{Método Aleatório}

Semelhante à abordagem determinística, esse método pode ser utilizado em sistemas não homogêneos, funcionando razoavelmente, em média. Entretanto, seu pior caso pode ser desastroso, dependendo da função aleatória escolhida. Quando um processo local é gerado, verifica-se a situação do EP. Caso ele seja classificado como ocioso ou com pouca carga, o novo processo é executado localmente. Caso contrário, uma função faz a escolha de outro EP usando um método aleatório qualquer e envia o novo processo para o EP escolhido, independente de sua carga local.

$$
\begin{aligned}
& \text { Se carga-EP } P_{\text {local }}<\text { 'High' } \\
& \mathrm{P}_{i} \Rightarrow E \mathrm{P}_{\text {local }} \\
& \text { senão } \\
& \mathrm{P}_{i} \Rightarrow E P_{\text {random }}
\end{aligned}
$$

\section{Distribuição Farm}

Nessa abordagem, um processo mestre (farmer) distribui os dados de um problema para um conjunto de processos "escravos" (workers) que residem em processadores diferentes. A distribuição dos processos é feita durante a compilação, mas esse método é considerado dinâmico porque os dados são distribuídos durante a execução, conforme a carga de trabalho de cada EP. Para a finalidade deste trabalho, a distribuição fica a critério do programador e é fixada dentro do programa.

$$
\begin{aligned}
& \text { Trabalho Total }=\mathrm{M} \text { lotes }(\mathrm{L}) \text { de tarefas } \\
& \text { Para todo } i, \text { de } i=1 \text { até } N \text {, faça } \\
& P_{i} \Rightarrow E P_{i} \\
& \text { Para todo } j \text {, de } j=1 \text { até } M \text {, faça } \\
& \text { Se carga de } \mathrm{P}_{\text {јям }}<\mathrm{H} \\
& L_{j} \Rightarrow P_{j \& M}
\end{aligned}
$$




\subsubsection{Algoritmos de balanceamento de carga - migração de tarefas}

Para este trabalho, não é considerada a migração de processos propriamente dita, mas sim a migração de tarefas. O trabalho total de determinado problema é dividido em lotes de tarefas que são distribuídos pelos vários processos previamente disparados. Durante a execução, cada processo controla a quantidade de trabalho mais adequada para a carga de seu host. Caso um processo verifique que sua carga de trabalho está acima do indicado para o equilíbrio de todo o sistema, ele transfere para outro processo um ou mais lotes de tarefas, procurando a melhor distribuição possível.

Este sistema de balanceamento de carga é chamado de Movimento Adaptativo de Dados (MAD) [OTT94]. Basicamente, é uma metodologia de programação ao nível da aplicação, que fornece recursos ao programador para o desenvolvimento de algoritmos adaptativos à carga de trabalho, em função da redistribuição de dados. A quantidade de trabalho, no caso, é relacionada à quantidade de dados a serem processados.

A abordagem MAD não apresenta transparência para o programador, mas o balanceamento de carga é mais preciso e o desempenho é melhor, comparando com o balanceamento baseado em migração de processos [OTT94].

A utilização da abordagem MAD exige respostas rápidas aos eventos que disparam a migração para que o método seja efetivo em aproveitar a ociosidade dos recursos da máquina virtual. Na prática, isso tem duas implicações [OTT94]:

- Na presença de um evento que desencadeia uma migração, a aplicação tem que suspender rapidamente o seu trabalho e iniciar os procedimentos de balanceamento.

- A migração em si precisa ser rápida para que a aplicação paralela não seja bloqueada em função do balanceamento.

Essas exigências obrigam que tanto o código para verificação das condições do sistema quanto o que faz a redistribuição de dados sejam embutidos no laço principal do algoritmo paralelo [OTT94].

É interessante verificar que o método MAD apresenta grande portabilidade, pois não apresenta limitações de plataforma. No caso da migração de tarefas, já é preciso considerar o sistema operacional, formato dos processos, etc. De fato, a grande vantagem desse sistema reside na facilidade de trabalho em sistemas heterogêneos e na possibilidade de balanceamento de carga com granularidade mais fina, alcançando um tipo de balanceamento quase ideal [OTT94].

Essa abordagem procura realizar o balanceamento de carga da aplicação, garantindo o equilíbrio entre os diversos componentes de uma aplicação paralela. Com isso, pretende-se que os tempos de execução dos processos que compõem uma aplicação paralela não apresentem grandes variações entre si, o que implicaria na existência de processos mais lentos do que os demais e conseqüente atraso da aplicação como um todo, em função de componentes de menor desempenho.

$\mathrm{O}$ controle externo às aplicações é possível caso se faça o balanceamento de carga do sistema como um todo. Nesse caso, o conjunto de informações utilizada pelos métodos de balanceamento tem que ser modificado. Passa a ser necessário considerar o número de processos executando em cada computador, o tamanho da fila de processos à 
espera do processador, a memória utilizada e disponível, a quantidade de operações de swap em determinado período, etc. Nesse caso, o ideal é que o balanceamento de carga seja feito pelo próprio sistema operacional do sistema distribuído utilizado. Se o sistema operacional utilizado não apresentar esse recurso, é preciso que um processo exerça a função de gerente da atividade de balanceamento de carga. Esse gerente precisa ter privilégios especiais para manipular outros processos e ter acesso às tabelas de controle do sistema operacional.

É interessante observar que carga de trabalho na plataforma estudada (computadores PC com Windows 95) normalmente significa uma aplicação interativa (um editor de texto, uma planilha eletrônica, um programa de busca WWW, etc.) manipulada naquele instante por um usuário qualquer. Nesse caso, o balanceamento de carga tem a função de facilitar a utilização dos computadores da máquina virtual pelos usuários e aproveitar as máquinas ociosas para o processamento paralelo.

\section{Método Aleatório Local}

Nessa estratégia, um processador distribui alguns lotes de tarefas $\left(\mathrm{L}_{\mathrm{x}}\right)$ entre seus vizinhos, após um intervalo fixo de tempo, depois de verificar que sua carga de trabalho é excessiva. A decisão de migrar uma tarefa é tomada localmente e a transferência é iniciada pelo transmissor. (PV):

Considerando que um elemento de processamento (EP) tem $\mathrm{N}$ processos vizinhos

$$
\begin{aligned}
& \text { Se } \operatorname{carga}-E P_{10 c a l}=\text { 'High' } \\
& L_{x} \Rightarrow P V_{\text {random }(\mathrm{N})}
\end{aligned}
$$

\section{Método do Vizinho Direto}

Caso a carga local aumente mais do que um percentual máximo (\%Vmax), o valor da carga local é transmitida para os vizinhos diretos. Caso a carga de um EP exceda a carga de um vizinho menos carregado por um percentual maior do que um percentual mínimo (\%Tmin), ele envia uma de suas tarefas para o seu vizinho.

Considerando que um EP tem $\mathrm{N}$ processos vizinhos (PV), a disseminação da informação sobre as cargas de trabalho é feita por:

Se variação da carga $-\mathrm{EP}_{\text {local }}>$ \%Vmax então

Para todo $i$, de $i=1$ até $N$, faça

$$
\text { Valor da carga- } \mathrm{EP}_{\text {local }} \Rightarrow \mathrm{PV}_{\mathrm{i}}
$$

enquanto que a transferência de tarefas é feita por:

$$
\begin{aligned}
& \text { Para todo } i, \text { de } i=1 \text { até } N \text {, faça } \\
& \text { Se }\left(\text { carga-EP } \mathrm{EP}_{\text {local }}-\operatorname{carga}-\mathrm{EP}_{\mathrm{i}}\right)>\% \mathrm{Tmin} \\
& \mathrm{L}_{\mathrm{x}} \Rightarrow \mathrm{PV}_{\mathrm{i}}
\end{aligned}
$$




\section{Método Aleatório Global}

Similar à estratégia aleatória local. A única diferença é que, agora, as unidades de carga podem migrar para qualquer processador da rede. Assim, o valor $\mathrm{N}$ não se restringe apenas aos vizinhos de um processo, mas ao número de EPs de toda a rede.

\section{Método Gradiente}

As decisões de transferência de tarefas deste método são baseadas em informações gradientes. Gradientes são vetores que mantêm informações sobre a carga e a distância de todos os processadores da rede. Isso significa que cada computador tenta manter um estado global aproximado da rede inteira. As tarefas são sempre enviadas para os vizinhos imediatos (migração local). A carga de um computador pode estar em um de três estados possíveis: baixa (Low), normal ou alta $(\underline{H} i g h)$. Cada processo tem condições de identificar, através dos gradientes, qual a conexão que representa o menor caminho para um computador $L$. Assim, um processo $H$ envia uma tarefa por essa conexão em direção a um processo não carregado. Se um computador modifica seu estado ou atualiza seu menor caminho para um processo $L$, essa informação é enviada para todos os seus vizinhos diretos.

Este método é o mais importante deste trabalho. Os algoritmos de balanceamento implementados determinam as condições dos hosts por comparação. Isso significa que um processo identifica que o host onde está executando tem uma carga $H$ comparando a sua produção com a de outros hosts da máquina virtual. A situação dos outros hosts chega a um processo por disseminação via troca de mensagens. Assim, a idéia de vetores gradientes foi utilizada na implementação de todos os métodos de balanceamento de carga citados.

Basicamente, a informação contida nos gradientes é a seguinte:

- Informação fixa:

- Para cada host da rede, o tempo de processamento de uma iteração sem concorrência.

- Informação dinâmica:

- Tempo para calcular a última iteração.

- Número de lotes de tarefas que ainda faltam processar.

- Tempo total para processar os lotes que faltam.

- Situação do computador $(L, N$ ou $H)$.

A informação gradiente é enviada por cada processo após o término de cada iteração. A recepção destas informações é feita com o mínimo de sobrecarga porque os processos não esperam para recebê-las. Eles simplesmente verificam se há alguma mensagem gradiente na fila do PVM-W95. Caso não haja, continuam processando. Se houver, ela já foi carregada para os buffers do programa. Neste caso, só é necessário tratá-la.

O algoritmo de transferência é similar aos já citados anteriormente, assim como o controle de limiar que dispara as migrações. 


\section{Método Gradiente Estendido.}

Semelhante ao anterior, esse método apresenta um controle para evitar custos de comunicação desnecessários quando não há computadores $L$ no sistema.

Basicamente, a idéia aqui é que a ausência de EPs $L$ no sistema implica em que os receptores naturais não existem. Assim, um EP $N$ que se torne um receptor pode ultrapassar o seu limiar de carga e tornar-se um EP $H$, ou seja, um EP que em determinado momento tentará transferir parte de sua carga de trabalho. Caso este comportamento se torne freqüente, a produção do sistema pode cair a níveis pouco interessantes.

\section{Método Gradiente Estendido Global.}

Semelhante ao método gradiente estendido, com a diferença que esse método faz transferências globais de tarefas.

\subsection{Aplicações}

As aplicações numéricas escolhidas para o presente trabalho foram as seguintes:

- Resolução de sistemas lineares pelo método de inversão de matrizes através de cofatores [CAR82].

- Resolução do problema do caixeiro viajante [PRE88].

- Transformada de Fourier Discreta [PRE88].

A literatura pesquisada enfatiza bastante que as aplicações paralelas destinadas a execução em um sistema distribuído precisam ter alto grau de processamento e pouca necessidade de comunicação [BEG94]. Isso significa que as aplicações precisam apresentar granularidade grossa (ver seção 5.4). O motivo desta restrição é em função do comportamento do PVM em redes de baixa velocidade, onde o custo para enviar uma mensagem é relativamente alto, podendo chegar a alguns segundos dependendo do tamanho da mensagem. Assim, só vale a pena utilizar a versão paralela de um algoritmo se a relação processamento/comunicação for vantajosa [SHI95]. Aqui cabe ressaltar que a Transformada de Fourier não se enquadra nessa regra, por ser um algoritmo complexo que leva a um alto grau de comunicação. Como será destacado mais à frente, essa aplicação foi a única que não pode ser aproveitada.

\subsubsection{Resolução de sistemas lineares pelo método de inversão de matrizes através de cofatores}

O método de inversão de matrizes pela utilização de cofatores revelou-se bastante interessante para a finalidade do presente trabalho, visto que é um algoritmo que faz uso intenso de recursividade, apresenta uma quantidade de cálculos exponencial à medida em que se aumenta o número de elementos da matriz que se quer inverter, faz uso de iterações independentes (portanto, permite sua paralelização com facilidade) e seu 
tempo de solução passa a ser bastante alto para matrizes com mais de $10 \times 10$ elementos, mesmo em computadores tipo PC de alta capacidade.

Considerando-se um sistema de $n$ equações lineares a $n$ incógnitas:

$$
\begin{aligned}
& a_{11} x_{1}+a_{12} x_{2}+\ldots+a_{1 n} x_{n}=b_{1} \\
& a_{21} x_{1}+a_{22} x_{2}+\ldots+a_{2 n} x_{n}=b_{2} \\
& a_{n 1} x_{1}+a_{n 2} x_{2}+\ldots+a_{n n} x_{n}=b_{n}
\end{aligned}
$$

É importante ressaltar que só são consideradas as matrizes quadradas.

A partir do sistema linear acima, pode-se extrair as seguintes matrizes:

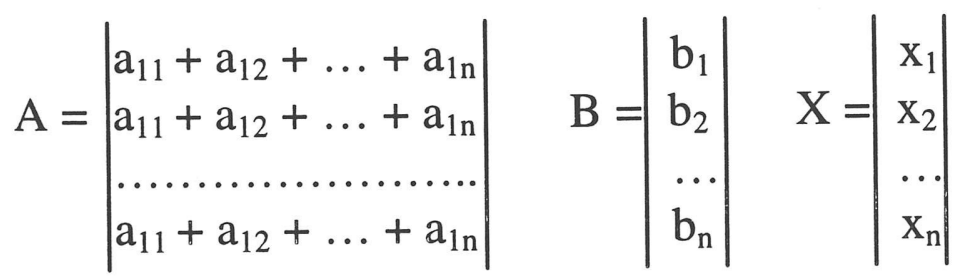

Pode-se representar o sistema linear acima pela seguinte equação matricial:

$$
\mathrm{AX}=\mathrm{B}
$$

Supondo que det $\mathrm{A} \neq 0$, multiplicam-se ambos os membros à esquerda por $\mathrm{A}^{-1}$, obtendo-se a solução:

$$
X=A^{-1} B
$$

Definida a abordagem para a solução, o próximo passo é determinar qual é a matriz inversa para o problema em questão. Isto é feito através do método de cofatores.

$\mathrm{O}$ cofator de um elemento $\mathrm{a}_{\mathrm{ij}}$ da matriz A é determinado por:

$$
\operatorname{cof} a_{i j}=(-1)^{(i+j)} \cdot \operatorname{det} R
$$

sendo que $\mathrm{R}$ é a matriz reduzida de $\mathrm{A}$, encontrada excluindo-se da matriz A a linha $i$ e a coluna $j$.

Por sua vez, tomando qualquer linha ou coluna da matriz R (por exemplo, a linha 0 ), o det R é encontrado pela seguinte fórmula:

$$
\operatorname{det} \mathrm{R}=\sum_{\mathrm{i}=0}^{\mathrm{n}}\left(\mathrm{a}_{0 \mathrm{i}} * \operatorname{cof} \mathrm{a}_{0 \mathrm{i}}\right)
$$

desde que $\mathrm{R}$ tenha dimensão maior do que 1 x 1 . Caso a recursão chegue a uma matriz 1 $\mathrm{x} 1$, o determinante é o seu único elemento. Aqui é possível ver claramente a recursividade deste método.

Para encontrar a matriz inversa de A, primeiro monta-se a matriz de cofatores de $\mathrm{A}$, que contém o cofator de cada elemento $\mathrm{a}_{\mathrm{ij}}$ de $\mathrm{A}$. Em seguida, determina-se a matriz adjunta de $\mathrm{A}$, em que todo elemento $\mathrm{a}_{\mathrm{ij}}$ da matriz de cofatores passa a ser o elemento $\mathrm{a}_{\mathrm{ji}}$ da matriz adjunta. 
Finalmente, a matriz inversa de A é conseguida dividindo-se a matriz adjunta pelo determinante de $\mathrm{A}$.

Foram feitos alguns testes com uma versão seqüencial deste algoritmo. Primeiro, uma versão de 16 bits do programa com uma matriz 10 x 10 rodando num PC Pentium 100 gastou cerca de 3 horas de execução. O computador deixou de responder a qualquer comando (mouse, teclado, etc.) até o término da execução, apesar de o Windows 95 ser um ambiente multi-tarefa. O mesmo programa, compilado para 32 bits, teve seu tempo de execução reduzido para 12 minutos no mesmo computador. Isso representa cerca de $6,7 \%$ do tempo da versão de 16 bits. Além do ganho de tempo, o sistema responde normalmente aos comandos do usuário.

Com uma matriz 11 x 11, executando uma versão 32 bits em um PC 486 DX2-66 (LASD02) com Windows 95, $12 \mathrm{MB}$ de memória e $540 \mathrm{MB}$ de disco, o programa demorou cerca de 9500 segundos para encontrar a matriz inversa. Em outro computador, um PC 486 DX4-100 (LASD04) com a mesma configuração, o programa gastou 6150 segundos. Finalmente, em um PC Pentium 100 (LASD06), 16 MB de memória e 1 GB de disco, o tempo gasto foi de 4000 segundos.

\subsubsection{Resolução do problema do caixeiro viajante}

Este problema apresenta um enunciado bastante simples. Em uma certa área há um número determinado de cidades. O problema reside em encontrar o menor trajeto para que uma pessoa, saindo de uma cidade qualquer, retorne a esta mesma cidade, passando apenas uma vez em cada uma das cidades da área em questão.

Apesar da aparente simplicidade, este problema é um típico caso de uma distribuição do tipo NP-completa. Portanto, quando o número de cidades do problema aumenta, o tempo necessário para encontrar a solução aumenta exponencialmente.

Basicamente, o algoritmo, para resolver o problema, trabalha da seguinte forma:

- No problema, há $n$ cidades para serem visitadas.

- O programa escolhe uma cidade qualquer para iniciar o trajeto. Ele deve considerar, também, que a cidade escolhida é a última a ser visitada.

- Das n - 1 cidades restantes, o programa seleciona uma outra como a $2^{\mathrm{a}}$ a ser visitada.

- Este processo segue até que a primeira cidade seja selecionada novamente.

Aqui já é possível perceber que o número de combinações é dado por:

$$
\mathrm{n}^{\mathrm{o}} \text { comb. }=\mathrm{n} \cdot(\mathrm{n}-1) \cdot(\mathrm{n}-2) \ldots .3 \cdot 2 \cdot 1=\mathrm{n} \text { ! }
$$

Após encontrar um trajeto, o programa calcula o seu tamanho pela soma dos segmentos que ligam cidade a cidade. O menor trajeto é armazenado e cada nova combinação é comparada com este valor. Se ela for menor, passa a ser o menor trajeto. Este processo é repetido até que não haja mais combinações para comparar.

Encontrar o menor trajeto, ou ótimo, para um grande número de cidades é uma tarefa inviável. Assim, a bordagem utilizada nesse caso é dividir o problema em grupos com um número viável de cidades, encontrar o menor caminho dentro de cada grupo e conectá-los entre si. 


\subsubsection{Transformada de Fourier Discreta}

Os métodos de Transformadas de Fourier representam uma grande classe de problemas computacionais. Basicamente, esses métodos são ferramentas bastante eficientes para a manipulação de certos conjuntos de dados.

Considere-se qualquer processo físico. Basicamente, ele pode ser descrito no domínio do tempo, pelos valores de alguma quantidade $\boldsymbol{h}$ como uma função do tempo $\boldsymbol{t}$ - $\boldsymbol{h}(\boldsymbol{t})$ - ou no domínio da freqüência, onde o processo é especificado por sua amplitude $\boldsymbol{H}$ (geralmente um número complexo que indica a fase) como uma função da frequiência $f$ - $\boldsymbol{H}(\boldsymbol{f})$ - com $-\infty<\boldsymbol{f}<\infty$. Por muitas razões, é útil pensar sobre $\boldsymbol{h}(\boldsymbol{t})$ e $\boldsymbol{H}(\boldsymbol{f})$ como duas representações diferentes da mesma função.

Pode-se realizar a passagem de uma representação para a outra por meio das Transformadas de Fourier:

$$
H(f)=\int_{-\infty}^{\infty} h(t) e^{2 \pi i f t} d t
$$

O algoritmo de Transformada de Fourier Discreta trabalha sobre amostras de pontos da função separados por intervalos fixos de tempo. Sua grande dificuldade reside na aplicação de funções trigonométricas sobre grandes conjuntos de pontos, normalmente separados por pequenos incrementos. $\mathrm{O}$ algoritmo procura alcançar a Transformada de Fourier por aproximações sucessivas. O tempo de processamento depende do grau de precisão, do intervalo sobre o qual a função é aplicada e do incremento de amostragem.

\subsection{Determinação da carga de trabalho}

Um dos problemas principais encontrados no início da implementação foi como determinar a carga de trabalho de um determinado computador.

O fato de um programa executar sozinho ou junto com outras aplicações influi diretamente no seu resultado. Algumas observações levaram à constatação de que um programa não precisa estar processando algum comando do usuário para consumir tempo de processador. O Windows 95 [PET96] trabalha com uma fila de mensagens para todos os programas escritos no formato windows (com janelas, menus, etc., controlados via uma interface com o Windows 95). Esta fila apresenta para o programa todos os eventos que acontecem com o seu ambiente: um clique do mouse, uma entrada do teclado, o arrasto de uma janela, etc. O Windows 95 recebe esses eventos e coloca-os na fila serializados. Assim, o programa não precisa se preocupar com a ordem dos eventos que lhe interessam. O Windows 95 resolve isso para ele.

Mas há vários tipos de eventos que podem ser gerados pelo Windows 95: temporizadores, solicitações diversas, etc. [PET96]. Mesmo que o programa ignore 
grande parte desses eventos, pelo menos um tratamento básico deve ser feito para cada um. Assim, qualquer programa termina consumindo processador mesmo que esteja aguardando que o usuário solicite alguma coisa.

Quanto mais programas são carregados em um computador, pior é o seu desempenho. Isso não se reflete necessariamente sobre outros recursos importantes para o sistema. Por exemplo, a quantidade de memória disponível não varia muito porque o Windows 95 tem um sistema de memória virtual, com a utilização de espaço em disco para armazenar blocos de memória que não são utilizados. O pior desempenho também não significa que os processos parem de executar. Como o Windows 95 não apresenta prioridades para os programas usuários, é garantido que a distribuição do processador é uniforme para todos os processos em execução.

Algumas observações feitas com o Medidor de Recursos, um programa que acompanha o sistema operacional, indicam que o Windows 95 não considera que o desempenho cai com o aumento de programas residentes. De fato, não há problemas para se executar novos programas. O sistema não encontra maiores dificuldades por causa disso. Entretanto, se uma das aplicações é executada para se tomar alguns tempos, é possível verificar perdas de velocidade de até $50 \%$.

Assim, era necessário encontrar outra solução. A escolha caiu sobre um método bastante simples: a comparação de tempos.

Considere-se um determinado algoritmo que apresente iterações. Ele é executado sozinho em um determinado computador para se verificar quanto tempo é necessário para processar uma iteração. Este é o tempo base deste algoritmo para este computador. Depois, no ambiente de produção, o programa escravo vai acompanhando os tempos de processamento de cada iteração e faz comparações com o tempo base. A porcentagem de acréscimo de tempo de processamento determina se a carga de trabalho é $L, N$ ou $H$. Por exemplo, até $20 \%$ de diferença a carga é $L$. Até $40 \%$, a carga é $N$. Acima disso, a carga é $H$.

Esse método é interessante não apenas por permitir que a carga de um computador genérico seja determinada, mas também por possibilitar a comparação de computadores com potências diferentes.

\subsection{Estudos Comparativos}

Nos gráficos a seguir, os algoritmos de balanceamento são identificados pelas seguintes letras:

- D: distribuição determinante.

- A: distribuição aleatória.

- F: distribuição Farm.

- LR: método aleatório local.

- LN: método vizinho local.

- GR: método aleatório global.

- G: método gradiente.

- X: método gradiente estendido.

- XG: método gradiente estendido global. 
Na primeira etapa, foram feitos testes com a aplicação de cálculo de cofatores (AP1), para duas, três, quatro e cinco máquinas, sendo que todas elas não apresentavam carga de trabalho extra. Os resultados podem ser vistos nos gráficos de 1 a 4 . A comparação é feita através do speed-up em relação ao algoritmo sequiencial. Em geral, foram feitas 20 execuções para cada caso. As máquinas utilizadas foram LASD01, LASD02, LASD03, LASD04 e LASD06, nessa ordem.

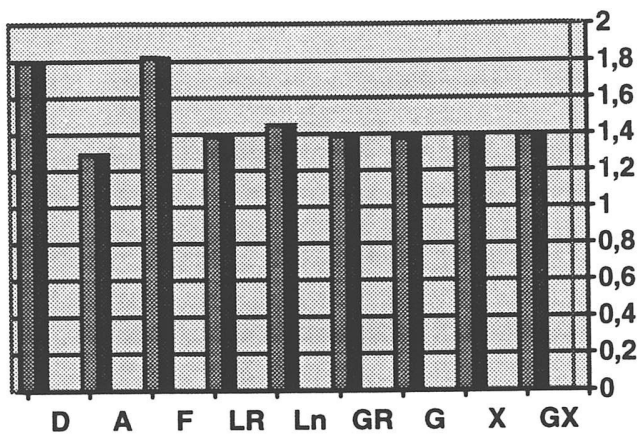

Gráfico 6.1. AP1, 2 máquinas.

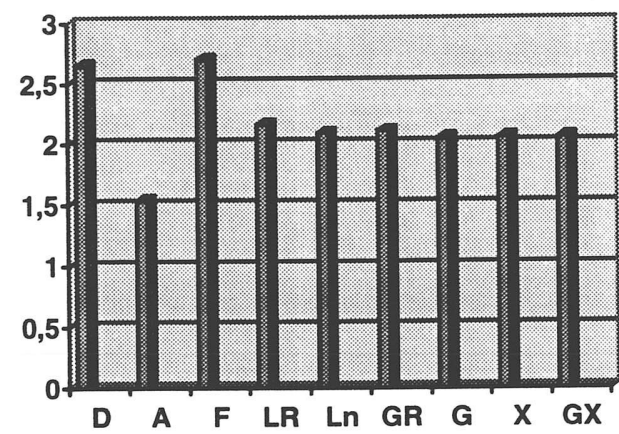

Gráfico 6.2. AP1, 3 máquinas.

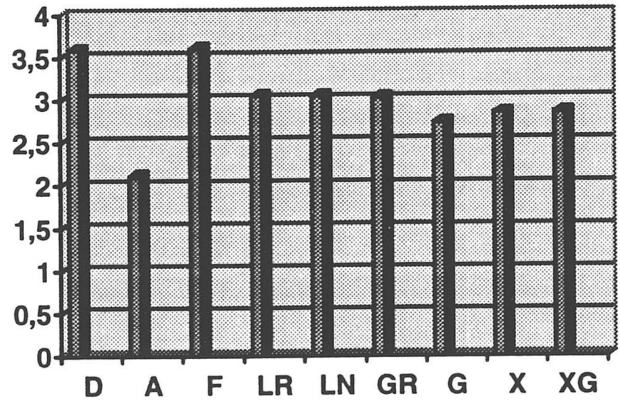

Gráfico 6.3. AP1, 4 máquinas. 


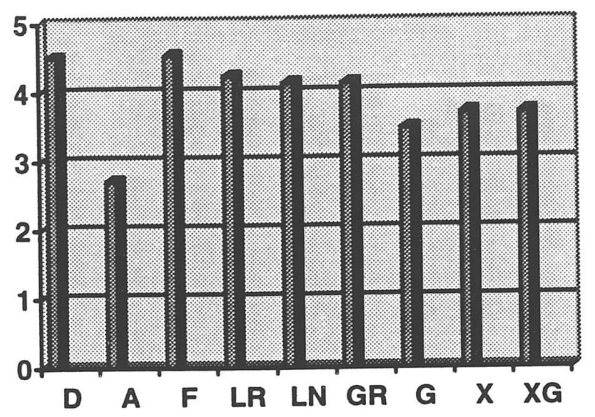

Gráfico 6.4. AP1, 5 máquinas.

O resultado encontrado aqui indica que os métodos de distribuição são mais eficientes do que aqueles que fazem transferência de tarefas. O método de distribuição aleatória é o pior de todos e os métodos mais simples de balanceamento são mais eficientes do que os baseados em gradientes. Isso indica que a diferença de capacidade entre os equipamentos, nos casos de 4 e 5 máquinas, onde LASD04 e LASD06 possuem capacidade superior às demais, não chega a ser suficiente para justificar a introdução de métodos complexos de balanceamento de carga. O custo da troca de mensagens é superior ao ganho que esses algoritmos possibilitam.

Resultado semelhante é encontrado na aplicação do caixeiro viajante (AP2), cujos resultados podem ser vistos nos gráficos de 5 a 8 .

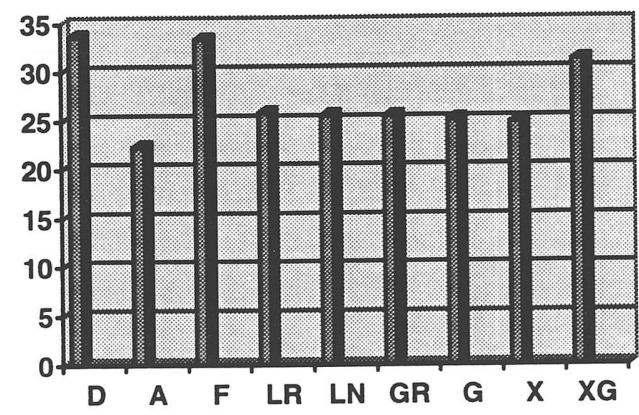

Gráfico 6.5. AP2, 2 máquinas.

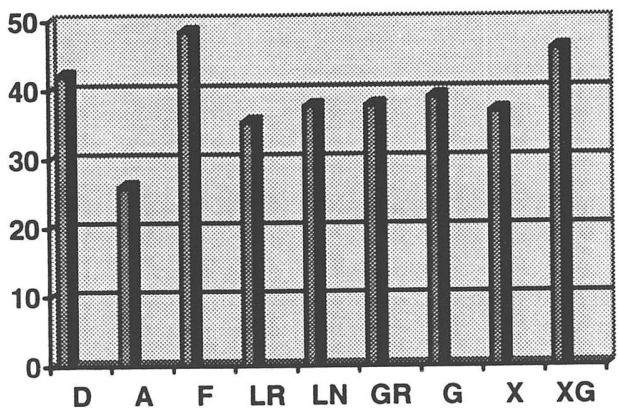

Gráfico 6.6. AP2, 3 máquinas. 


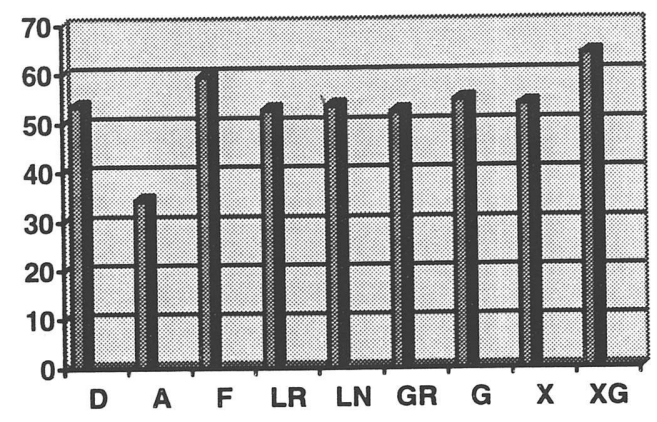

Gráfico 6.7. AP2, 4 máquinas.

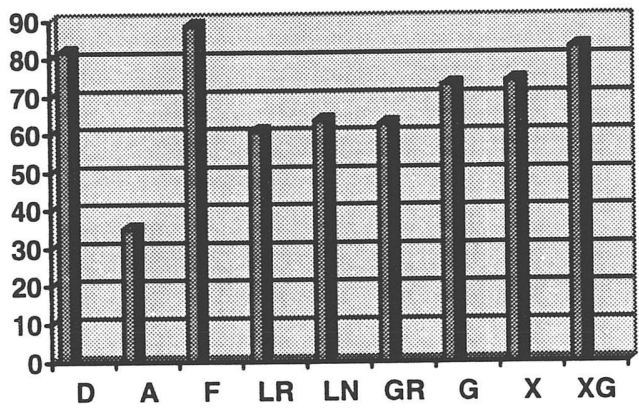

Gráfico 6.8. AP2, 5 máquinas.

Agora, entretanto, os métodos gradientes (particularmente o método estendido global) têm desempenho melhor do que os métodos mais simples de balanceamento, chegando a ser semelhantes, ou mesmo superiores, aos métodos de distribuição.

A diferença aqui é que o tamanho das mensagens é maior do que na aplicação do cálculo de cofatores. Na aplicação da matriz inversa, o programa mestre envia todos os dados para todos os processos escravos, enquanto que, na aplicação do caixeiro viajante, cada escravo recebe apenas as cidades com as quais ele vai trabalhar. Na aplicação da matriz inversa, transferir um lote de tarefas significa transferir alguns índices de elementos da matriz. No caixeiro viajante, significa transferir um vetor inteiro de cidades. Estudos feitos anteriormente no Grupo de Sistemas Distribuídos e Programação Concorrente [SOU97a] demonstram que as bibliotecas de passagem de mensagens têm desempenho melhor quando as mensagens são maiores, porque a sobrecarga de enviar uma mensagem é melhor aproveitada pelos processos que enviam e recebem mensagens. Há outros estudos comprovando essa observação [OTT94][SOU97a]. Em todos os casos, verifica-se que a transmissão de uma mensagem apresenta componentes de custo fixos e variáveis. À medida que o tamanho da mensagem cresce, os custos fixos são diluídos. Assim, o custo geral de transmissão de uma mensagem passa a ser proporcional à quantidade de dados.

Analisando esses casos pela transferência média de tarefas dos algoritmos de balanceamento, para a aplicação de cálculo de cofatores (TAP1), os resultados podem ser vistos nos gráficos de 9 a 12 . 


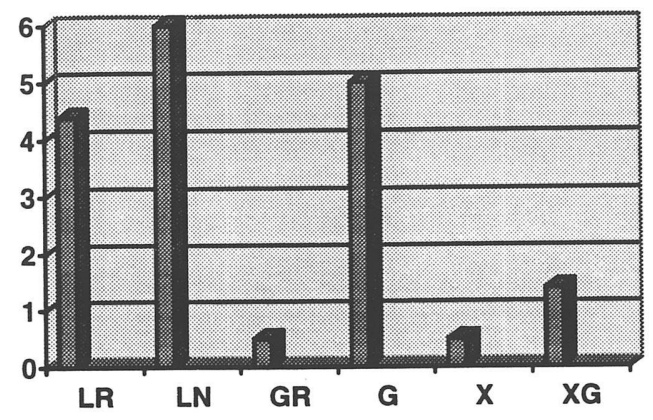

Gráfico 6.9. TAP1, 2 máquinas.

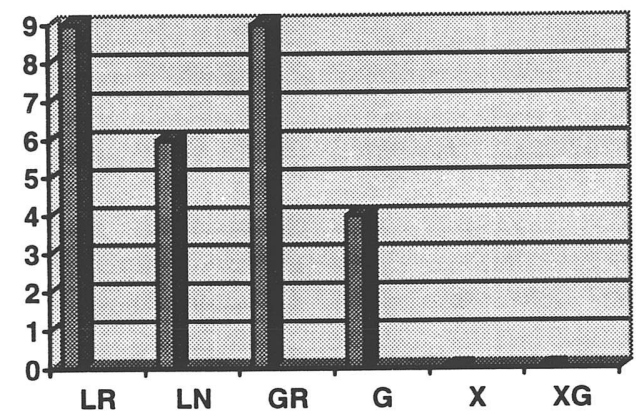

Gráfico 6.10. TAP1, 3 máquinas.

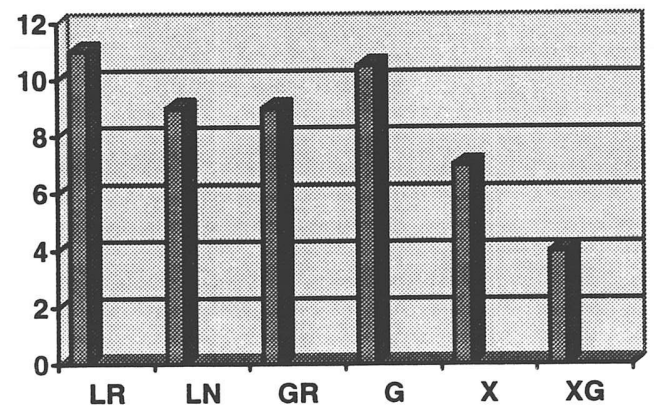

Gráfico 6.11. TAP1, 4 máquinas.

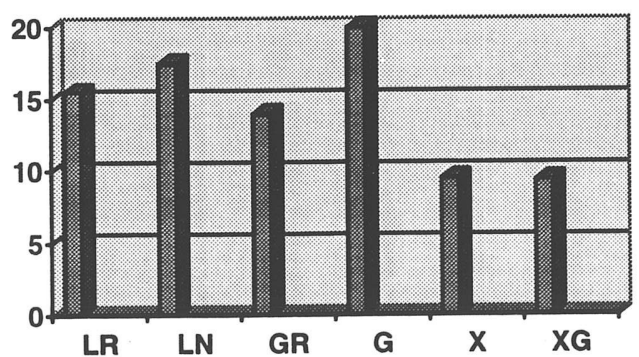

Gráfico 6.12. TAP1, 5 máquinas.

Esses gráficos indicam que os métodos gradientes apresentam a menor taxa de transferência de tarefas dentre todos os métodos de balanceamento de carga, o que 
significa uma vantagem significativa, considerando que o custo de transferência é bastante alto.

Considerem-se os casos de 2 e 3 máquinas (gráficos 9 e 10). As máquinas utilizadas nesses testes (LASD01, LASD02 e LASD03) possuem a mesma potência computacional (todas possuem processadores 486 DX2-66). Como a única carga de trabalho presente era o teste em questão, o equilíbrio da aplicação já estava estabelecido. Isso foi verificado nos testes porque, considerando um processo determinado, o número de lotes transferidos foi praticamente igual ao número de lotes recebidos. Ou seja, o processo fazia a transferência de um lote em um determinado momento para recebê-lo de volta certo tempo depois. A explicação para a existência de transferências está em desequilíbrios momentâneos que o programa detecta, mas que não são desequilíbrios de fato. Por exemplo: atrasos no envio e recebimento dos tempos de execução das iterações, diferenças de sincronismo, etc.

Assim, os testes feitos demonstram que os métodos gradientes não levam em consideração esse tipo de desequilíbrio, evitando transferências de tarefas desnecessárias.

Nos casos de 4 e 5 máquinas, há um desequilíbrio natural porque a máquina virtual passa a ter computadores de potências diferentes. Apesar disso, os testes demonstraram que as transferências feitas pelos métodos não gradientes podem ser exageradas, levando os receptores naturais do sistema a apresentarem excessos de carga que precisam ser re-equilibrados. De novo, os métodos gradientes apresentam controles que provocam a transferência apenas das cargas necessárias para que a aplicação fique balanceada.

Valores semelhantes são apresentados no problema do caixeiro viajante (TAP2), conforme os gráficos 13 a 16 .

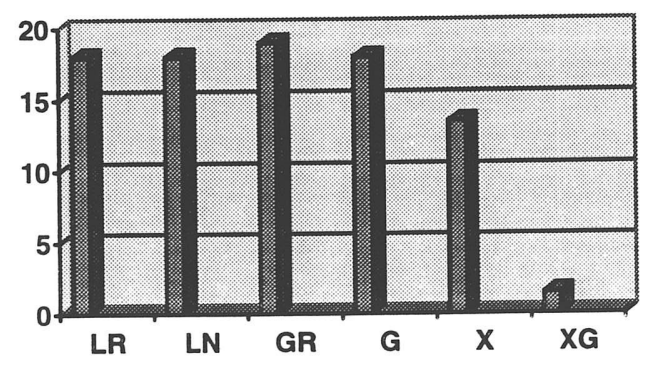

Gráfico 6.13. TAP2, 2 máquinas.

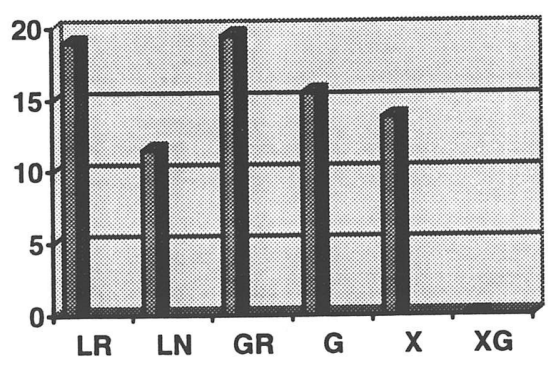

Gráfico 6.14. TAP2, 3 máquinas. 


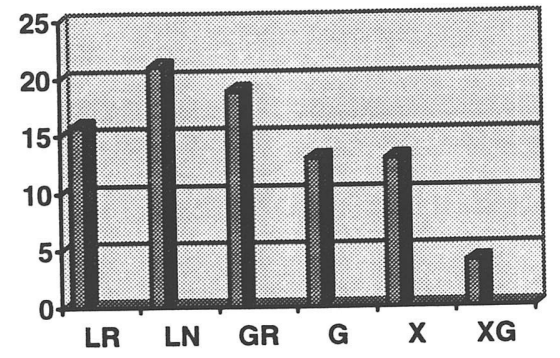

Gráfico 6.15. TAP2, 4 máquinas.

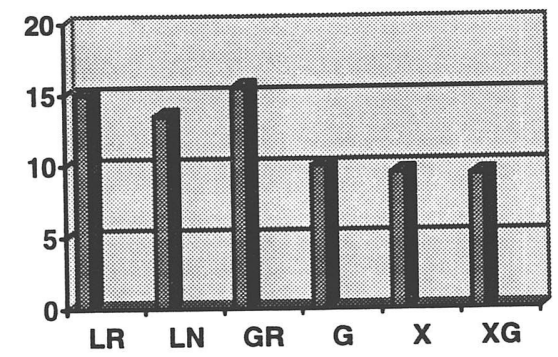

Gráfico 6.16. TAP2, 5 máquinas.

A seguir, são apresentados os testes com a aplicação de uma carga controlada em uma das máquinas. A carga é um programa de cálculo intensivo aplicado sempre na máquina LASD01, que está presente em todas as configurações.

Os gráficos de 17 a 20 apresentam o speed-up encontrado para o problema de cálculo de cofatores (CAP1).

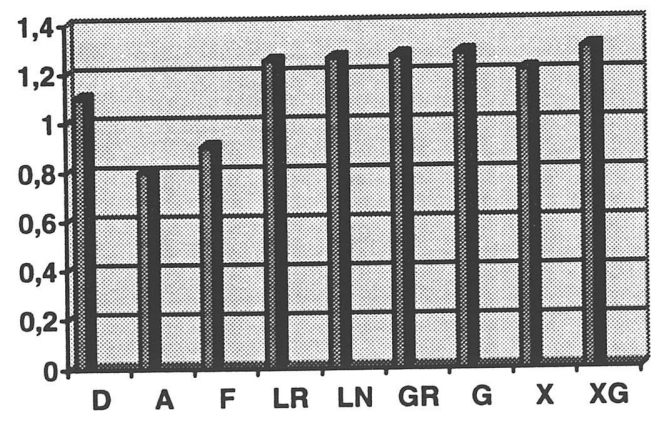

Gráfico 6.17. CAP1, 2 máquinas.

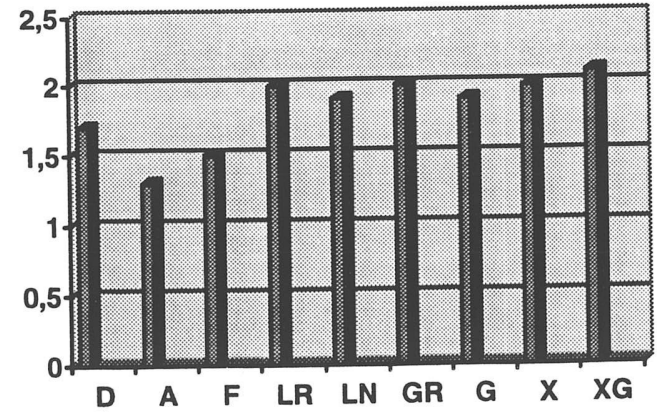

Gráfico 6.18. CAP1, 3 máquinas. 


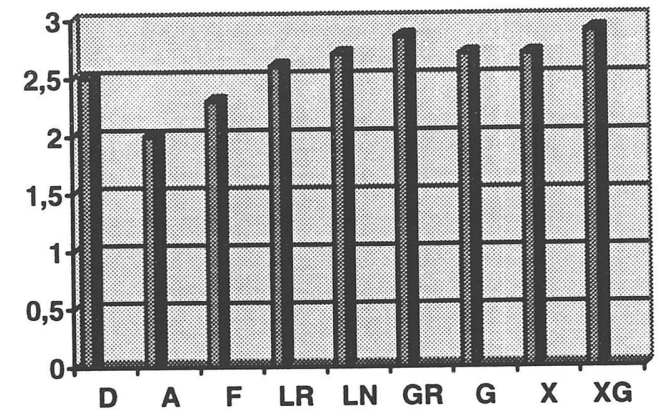

Gráfico 6.19. CAP1, 4 máquinas.

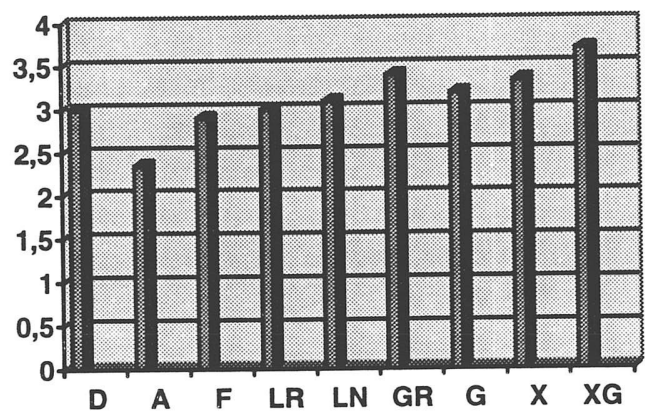

Gráfico 6.20. CAP1, 5 máquinas.

Os resultados indicam que os métodos de distribuição aleatória e Farm são os piores possíveis para o trabalho com carga excedente. A distribuição Farm simplesmente não utiliza uma máquina cuja carga de trabalho seja alta. Essa opção não é satisfatória, já que o Windows 95 garante a distribuição do processador por todos processos em execução, como já dito anteriormente. Assim, mesmo uma máquina com excesso de carga de trabalho pode dar a sua contribuição para uma aplicação paralela.

Nos demais casos, há uma ligeira vantagem para os métodos globais em relação aos métodos locais. A explicação reside em que os métodos globais evitam transferências intermediárias entre os computadores. Um processo que apresenta um excesso de carga de trabalho pode transferi-la diretamente para o processo que apresenta as condições para recebê-la. Isso evita desequilíbrios nos processos intermediários.

Além disso, os métodos gradientes apresentam vantagens quando comparados com os métodos mais simples. Na prática, a aplicação de uma carga de trabalho extra ao sistema tem o mesmo resultado que a introdução no sistema de um computador com maior potência computacional. No caso, o computador com carga extra de trabalho passa a ser, na prática, um computador com potência menor do que as outras. Portanto, as observações feitas para os casos em que há diferenças de potência computacional também são válidas quando se introduzem cargas extras de trabalho na máquina virtual.

Os gráficos 21 a 23 mostram os resultados obtidos na aplicação do caixeiro viajante (CAP2). 


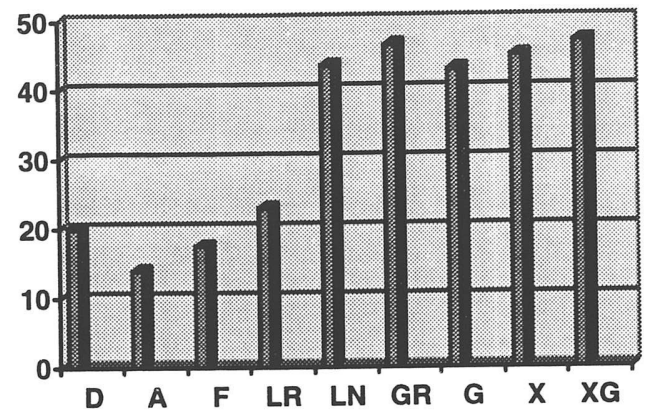

Gráfico 6.21. CAP2, 2 máquinas.

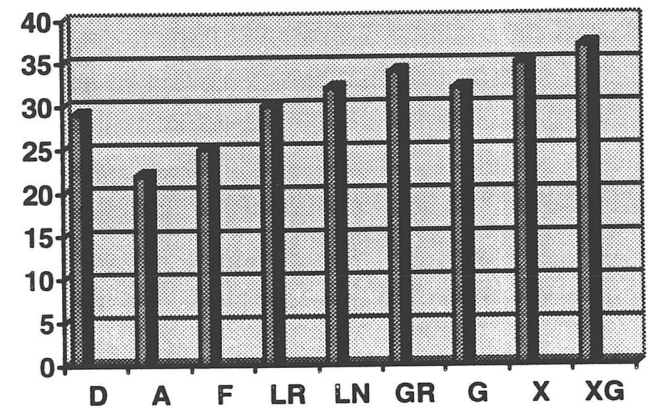

Gráfico 6.22. CAP2, 3 máquinas.

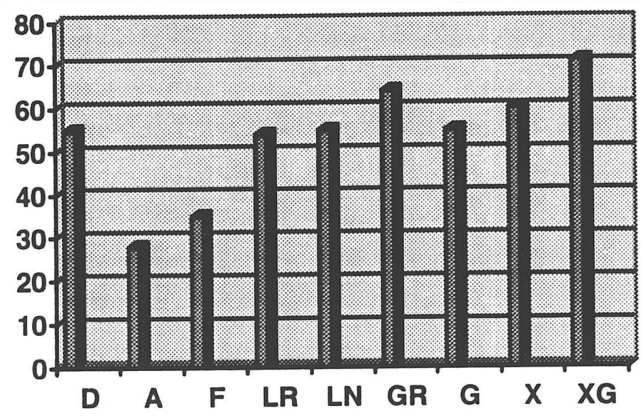

Gráfico 6.23. CAP2, 4 máquinas.

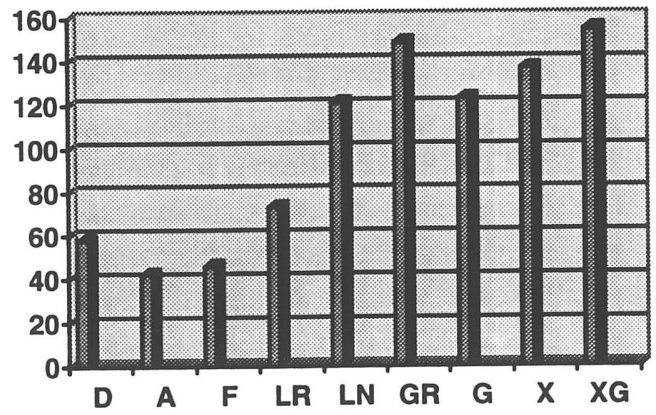

Gráfico 6.24. CAP2, 5 máquinas. 
Aqui, também se verificam as mesmas conclusões da aplicação de cálculo de cofatores. Entretanto, os resultados são mais evidentes porque essa aplicação apresenta ganhos de desempenho em função do tamanho das mensagens. 


\subsection{Problemas encontrados}

Apesar dos bons resultados observados nos diversos experimentos desenvolvidos neste trabalho, algumas dificuldades práticas foram encontradas durante as fases de implementação e testes. Em resumo, as principais dificuldades encontradas se relacionam com:

- PVM-W95.

- Algoritmos realmente paralelos.

- Transformada de Fourier.

\subsubsection{PVM-W95}

Os testes foram divididos em lotes de execuções de programas construídos para cada caso, combinando as aplicações utilizadas com os algoritmos de balanceamento de carga. Foram feitas 20 execuções de cada caso, quando possível. Os programas são complexos, têm um tempo de execução grande e utilizam bastante memória. Portanto, exigem vários recursos dos computadores em que executam.

Um dos grandes problemas em relação ao PVM-W95 é a taxa observada de extravio de mensagens [SOU97b], relativamente alta. Em 20 execuções de um mesmo programa, uma ou mais execuções apresentam extravios, o que significa bloqueio do programa mestre a espera de uma ou mais respostas dos escravos, com consequiente parada do processamento e perda do tempo dessa execução e do período em que o teste fica bloqueado. Em alguns casos, a taxa de extravios chega a $15 \%$ das mensagens enviadas.

Apesar de o próprio manual do PVM afirmar que a tolerância a falhas é de responsabilidade do usuário [BEG94], na prática essa solução é pouco interessante. Introduzir tolerância a falhas num programa PVM significa mandar mensagens com algum esquema de confirmação, o que implica em tempo perdido na espera pelas mensagens de reconhecimento e, conseqüentemente, mais mensagens trafegando pela rede, com mais sobrecarga. Por observação, verificou-se que alguns extravios acontecem por determinadas condições internas do sistema, o que significa que a retransmissão do mesmo pacote leva a novos extravios. Em teste específico sobre isso, todas as mensagens de um programa foram enviadas duas vezes. Verificou-se que a taxa de extravios é a mesma e que nem assim foi garantido que todos os lotes chegavam ao destino, resultando, novamente, em bloqueio do programa mestre.

Assim, para os testes feitos neste trabalho, não foi utilizado qualquer método de tolerância a falhas. Optou-se por executar todos os conjuntos de programas até que todas as execuções fossem bem sucedidas.

Outro problema do PVM é o alto custo das rotinas que manipulam mensagens. Por exemplo, a função pvm_nrecv(), cuja função é verificar a presença de mensagens para um programa sem que ele bloqueie caso não estejam presentes, gasta em média 1 segundo para retornar sem mensagem em teste feito na máquina LASD06, um Pentium 100. O custo somado passa a ser alto, considerando a estrutura dos programas utilizados: 
- O programa é baseado nas iterações do algoritmo paralelo.

- Para cada iteração, é tomado o tempo de sua execução.

- Esse tempo é enviado para todos os processos escravos - pvm_bcast().

- Cada processo verifica se há tempos enviados por outros processos. Isso pode significar até $\mathrm{N}$ execuções de pvm_nrecv(), sendo $\mathrm{N}=\mathrm{N}^{\mathrm{o}}$ de escravos - 1 .

- A seguir, cada processo verifica se há outros processos em condições de receber um lote de tarefas. Isso pode significar $\mathrm{N}$ execuções de pvm_send().

- Finalmente, o processo verifica se alguém enviou algum lote de tarefas. Isso pode significar $\mathbf{N}$ execuções de pvm_nrecv().

Aqui é preciso ressaltar que os tempos das iterações dos programas testados é pequeno, da ordem de poucos segundos. É possível que uma aplicação real com tempos mais significativos admita a utilização de um sistema de tolerância a falhas, desde que se garanta que sua utilização seja, de fato, eventual.

Os problemas observados também acontecem em outras plataformas que utilizam o PVM. Como o PVM-W95 é o resultado da migração de uma versão do PVM de plataforma Unix para a plataforma Windows 95, trouxe consigo tanto as boas como as más características da plataforma original. Segundo estudo feito no grupo de Sistemas Distribuídos e Programação Concorrente [SOU97b], o problema reside na implementação do protocolo TCP/IP que serve de base para a passagem a comunicação entre processos do PVM.

\subsubsection{Algoritmos realmente paralelos}

Um problema real enfrentado neste trabalho foi a obtenção de algoritmos adequados para o processamento paralelo. Os algoritmos utilizados foram adaptações de algoritmos seqüenciais, o que não é uma boa escolha quando o que importa é a eficiência.

Nos aplicativos utilizados, parte dos algoritmos do Caixeiro Viajante e da Transformada de Fourier tiveram que se mantidos na forma sequiencial, o que representa perda de tempo de processamento.

Para a finalidade deste trabalho, isso não chega a causar maiores dificuldades porque todos os testes comprovam que as versões paralelas apresentam um speed-up positivo em relação à versão seqüencial, o que é uma das premissas iniciais do projeto.

\subsubsection{Transformada de Fourier}

A aplicação mais interessante deste trabalho, por ser um algoritmo complexo e de larga utilização em várias aplicações científicas e numéricas de grande importância (como, por exemplo, a previsão meteorológica), não pode ser utilizada porque apresenta uma taxa de comunicação extremamente alta.

$\mathrm{O}$ algoritmo da Transformada de Fourier recebe como entrada um vetor de números complexos. O número de elementos do vetor tem que ser um múltiplo de 2 . $\mathrm{O}$ programa seqüencial tem um alto desempenho, que pode ser verificado na tabela abaixo: 


\begin{tabular}{|c|c|c|c|}
\hline Qtde. elementos & LASD01 & LASD04 & LASD06 \\
\hline $64 \mathrm{~K}$ & 5 & 4 & 2 \\
\hline $128 \mathrm{~K}$ & 7 & 6 & 3 \\
\hline $256 \mathrm{~K}$ & 15 & 13 & 6 \\
\hline $512 \mathrm{~K}$ & 32 & 24 & 14 \\
\hline $1 \mathrm{M}$ & 75 & 106 & 38 \\
\hline $2 \mathrm{M}$ & 734 & $?$ & $?$ \\
\hline
\end{tabular}

Tabela 6.1. Tempos de execução (em segundos) da Transformada de Fourier em algumas máquinas.

Na tabela, dois valores são indicados por uma interrogação (?). Esses tempos são superiores a dois dias!

A explicação para isso está no funcionamento do algoritmo. A Transformada de Fourier apresenta trocas e cálculos entre elementos de regiões diferentes do vetor de entrada. A escolha desses elementos é feita por cálculos que levam em consideração a configuração de bits dos índices envolvidos. No caso, os índices de dois elementos que vão ser trocados entre si devem ter um único bit de diferença. 2 Mega elementos de um vetor complexo ocupam $32 \mathrm{MB}$ de memória no Windows 95. Como as máquinas utilizadas não apresentam essa memória, o Windows 95 faz trocas constantes das páginas do vetor entre a memória e o disco, trazendo as páginas utilizadas pelo algoritmo à medida que ele necessita. O resultado prático disso é que a execução é quase toda feita em disco.

A versão paralela deste algoritmo apresenta um alto grau de comunicação, o que vai de encontro às premissas pré-estabelecidas para as aplicações destinadas às plataformas de sistemas distribuídos. O número de mensagens trocadas entre os processos é bastante elevado, mesmo para vetores de entrada de poucos elementos. Nesse caso, o PVM-W95 não consegue manter o número de buffers suficientes.

Nos testes feitos, 128 elementos foi o máximo conseguido sem provocar erros de execução. Além desse valor, que é ínfimo considerando os tempos da tabela 1 , o alto número de mensagens torna evidente o problema de extravios citado anteriormente, o que inviabilizou a utilização dessa aplicação para o presente trabalho. 


\section{Conclusões}

\subsection{Considerações iniciais}

Neste trabalho, foi feito um levantamento da teoria existente sobre sistemas distribuídos, arquiteturas paralelas, plataformas de passagem de mensagem em geral, PVM e diversos aspectos da atividade de balanceamento de carga. O principal objetivo deste trabalho foi aplicar técnicas existentes de balanceamento de carga em ambientes paralelos virtuais.

Um Ambiente Paralelo Virtual é um tipo de sistema distribuído construído com computadores independentes destinados à execução de aplicações paralelas desenvolvidas com um sistema de passagem de mensagens. Neste trabalho, foi utilizado um APV construído com computadores da linha PC com sistema operacional Windows 95. A plataforma de passagem de mensagens escolhida foi o PVM-W95 [SOU96], uma ferramenta desenvolvida no grupo de Sistemas Distribuídos e Programação Concorrente do ICMSC-USP à partir da migração do código já existente do PVM [BEG94] para o ambiente Unix.

A partir da teoria encontrada, foram desenvolvidos vários algoritmos de balanceamento de carga e algumas aplicações numéricas paralelas. Foram feitos diversos testes combinando os algoritmos com as aplicações, considerando ambientes carregados e não carregados, de forma a que se pudesse concluir sobre a viabilidade da utilização dos métodos de balanceamento e das aplicações numéricas na plataforma escolhida.

\subsection{Conclusões}

Como conclusão do trabalho detalhado nesta dissertação, destacam-se:

- Considerando que o custo da comunicação via passagem de mensagens em sistemas distribuídos é muito alto, as aplicações que fazem uso intensivo de troca de mensagens ficam prejudicadas, chegando, em alguns casos, a não serem viáveis na plataforma estudada.

- Para as aplicações que apresentam bom desempenho, aquelas que têm uma melhor relação comunicação/processamento apresentam melhores resultados, assim como as aplicações que trocam mensagens de maior tamanho, já que aproveitam melhor a sobrecarga do envio/recebimento de mensagens.

- Considerando os métodos de balanceamento de carga estudados, caso o usuário de uma aplicação paralela tenha total controle da carga de trabalho dos computadores da máquina virtual, podendo garantir que sua aplicação pode executar sem a concorrência de outros programas, então não vale a pena introduzir métodos complexos de balanceamento de carga. Os métodos de distribuição são suficientes para se obter bons resultados. De novo, ressalte-se que a capacidade do Windows 95 de garantir a divisão do processador entre todos os processos residentes em um computador é extremamente importante, pois, mesmo executando em um ambiente com alta carga de trabalho, um processo pode dar sua contribuição para uma aplicação paralela. 
- Caso a aplicação paralela tenha que concorrer com outros programas ou caso os computadores possam ser utilizados por algum usuário, um método de balanceamento de carga pode permitir que o sistema apresente melhores tempos de resposta e facilite o trabalho do usuário.

- Ao fazer uso de um método de balanceamento de carga, é preciso considerar o tamanho das mensagens trocadas pela aplicação. Mensagens maiores permitem melhores resultados, em função do melhor aproveitamento dos custos fixos de transmissão de mensagens. É preciso considerar o custo-benefício da introdução de um sistema de tolerância à falhas na aplicação.

- Considerando os métodos gradientes, sistemas equilibrados conseguem manter o equilíbrio sem o acréscimo de sobrecargas de transferências desnecessárias de tarefas. Desse modo, a aplicação paralela é menos prejudicada. Os demais métodos consideram algumas instabilidades que não significam desequilíbrios de fato, produzindo transferências de tarefas que poderiam ser evitadas. Caso um sistema apresente algum desequilíbrio, os métodos gradientes conseguem atingir o balanceamento de forma mais eficiente, sem sobrecarregar os receptores naturais do sistema. Evitam, assim, que haja refluxo de transferências de tarefas.

- Os métodos globais são mais eficientes porque evitam transferências intermediárias, que sobrecarregam os processos não receptores. A descentralização do processo de balanceamento de carga evita gargalos indesejáveis no sistema. Assim, é interessante que os métodos de balanceamento sejam distribuídos, com o disparo das transferências de tarefas iniciado pelos processos receptores.

- Dos métodos estudados, o método de distribuição aleatória é o pior método de balanceamento de carga, já que apresenta o pior desempenho em todas situações estudadas. O método de distribuição Farm apresenta um desempenho baixo na presença de cargas extras de trabalho, mas pode ser utilizado sem problemas nas situações em que a aplicação paralela não tenha concorrência.

\subsection{Contribuições deste trabalho}

Entre os diversos resultados observados a partir deste trabalho, destacam-se as seguintes contribuições:

- Através dos testes realizados, o usuário de ambientes paralelos virtuais identifica que sua aplicação precisa ter uma relação de granularidade grossa entre a quantidade de processamento e a comunicação para ter um bom desempenho.

- Além disso, o usuário pode utilizar os algoritmos de balanceamento de carga orientado a dados (MAD) desenvolvidos neste trabalho em suas aplicações, com o objetivo de aproveitar melhor a potência computacional de uma rede de computadores.

- O aproveitamento desse recurso computacional pode ser alcançado sem prejuízo de possíveis usuários dessas máquinas para outras atividades, como edição de textos, compilação, etc. 
- Os métodos estudados de balanceamento de carga apresentam comportamento diferente dependendo de alguns parâmetros como controle da carga existente, quantidade e diversidade de computadores da máquina virtual, número de processos envolvidos, etc. Assim, o usuário pode escolher o método mais apropriado à situação de seu ambiente.

\subsection{Trabalhos futuros}

O balanceamento de carga é uma disciplina para dar eficiência às aplicações paralelas. Também é um método para aproveitar os recursos computacionais tanto de sistemas distribuídos quanto de arquiteturas paralelas. Assim, é um campo de atuação intimamente relacionado com essas plataformas.

Assim, há várias possibilidades para futuras pesquisas nessa área. Primeiro, considerando alguns aspectos básicos do balanceamento de carga, existe uma carência de vários elementos:

- Uma ferramenta que faça o mapeamento de aplicações paralelas em sistemas multiprocessadores, com a geração dos respectivos DAGs (Direct Acyclic Graph, ou Grafo Acíclico Dirigido).

- Mecanismos que identifiquem índices de carga em Ambientes Paralelos Virtuais em geral.

- Métodos mais precisos de colocação de processos, considerando a arquitetura, o host destino segundo determinados critérios, o tipo de sistema operacional, a plataforma de passagem de mensagens, o tipo de aplicação, etc.

- Um monitor gráfico que permita acompanhar o desempenho dos computadores de uma rede com a possibilidade de interferir nos diversos parâmetros de balanceamento de carga (políticas de informação, transferência e colocação, limiares dos diversos algoritmos, etc.), reservar ou liberar determinados hosts, etc.

Considerando o presente trabalho e a arquitetura em que se baseia, ainda há a necessidade do que segue:

- Métodos mais eficientes de distribuição da informação sobre a carga de trabalho.

- Criação de uma ferramenta ou biblioteca de funções que possibilite transferir um processo de um host para outro de forma transparente e eficiente, a fim de permitir o balanceamento de carga com migração de processos.

- Controle dinâmico de ambiente dando prioridade ao usuário, de tal forma que seja possível liberar um computador quando alguém começar a utilizá-lo, e manter a execução das aplicações paralelas e demais ferramentas quando o usuário fecha a sua sessão em um computador qualquer.

- Generalizar as bibliotecas atuais para que seja possível a inclusão de máquinas com Windows-NT.

- Inclusão da tolerância à falhas no PVM de forma transparente para as aplicações e mecanismos que aumentem a eficiência das rotinas que compõem a biblioteca do PVM. 
- Manutenção do código do PVM-W95 de forma a aproveitar algumas possibilidades existentes no Windows-95 (por exemplo, o uso de threads).

- Biblioteca de funções com os algoritmos desenvolvidos no presente trabalho (a ser feito após a defesa desta tese). 


\section{Referências Bibliográficas}

[ACE86] ACETTA, M., Baron, R., Golub, D., Rashid, R., Tevanian, A., Young, M., "Mach: A New Kernel Foundation for UNIX Development", Anais da Conferência USENIX Verão 1986, pp. 93-112, 1986.

[ALM94] ALMASI, G. S., Gottlieb, A., Highly Parallel Computing, 2a ed., The Benjamin Cummings, 1994.

[ANS89] ANSA, The Advanced Network Systems Architecture (ANSA) Reference Manual, ANSA, 1989.

[ART89] ARTSY, Y., Finkel, R., "Designing a Process Migration Facility. The Charlotte Experience”, Computer, v. 22, pp. 47-56, Setembro de 1989.

[BAU88] BAUMGARTNER, K. M., Wah, B. W., “A Global Load Balancing Strategy for a Distributed Computer System", Anais do Workshop sobre Futuras Tendências de Sistemas de Computação Distribuída nos Anos 90, IEEE Computer Society Press, pp. 93-102, 1988.

[BAU89] BAUMGARTNER, K. M., Wah, B. W., "GAMMON: A Load Balancing Strategy for Local Computer Systems with Multi-access Networks", IEEE Transactions on Computers, v. 38, pp. 1098-1109, 1989.

[BEG94] BEGUELIN, A., Geist, A., Dongarra, J., Jiang, W., Manchek, R., Sunderan, V., PVM: Parallel Virtual Machine. A User's Guide and Tutorial for Networked Parallel Computing, The MIT Press, 1994.

[BLA87] BLACK, A., Hutchinson, N., Jul, E., Levy, H., Carter, L., "Distribution and Abstract Types in Emerald", IEEE Transactions in Software Engineering, v. 13, pp. 65-76, 1987.

[BUT94] BUTLER, R. M., Lusk, E. L., "Monitors, Messages, and Clusters: The P4 Parallel Programming System", Parallel Computing, v. 20, pp. 547-564, 1994.

[CAL94] CALKIN, R., Hempel, R., Hoppe, H. C., Wypior, P., "Portable Programming with the PARMACS message-passing library", Parallel Computing, v. 20, pp. 615-632, 1994.

[CAR82] CAROLI, A., Callioli, C. A., Feitosa, M. O., Matrizes Vetores Geometria Analítica, Livraria Nobel Editora - Distribuidora, 1982.

[CAS88a] CASAVANT, T. L., Kuhl, J. G., "A Taxonomy of Scheduling in GeneralPurpose Distributed Computing Systems", IEEE Transactions on Software Engineering, pp. 141-154, Fevereiro de 1988. 
[CAS88b] CASAVANT, T. L., Kuhl, J. G., "Effects of Response and Stability on Scheduling in Distributed Computing Systems", IEEE Transactions on Software Engineering, v. 14, pp. 1578-1588, 1988.

[COU88] COULOURIS, G., Dollimore, J., Kindberg, T., Distributed Systems Concepts and Design, $1^{\underline{\underline{a}}}$ ed., Addison-Wesley Publishing Company, 1988.

[COU94] COULOURIS, G., Dollimore, J., Kindberg, T., Distributed Systems Concepts and Design, $2^{\underline{a}}$ ed., Addison-Wesley Publishing Company, 1994.

[CVE87] CVETANOVIC, Z., "The Effects of Problem Partitioning, Allocation, and Granularity on The Performance of Multiple-Processor Systems", IEEE Transactions on Computers, v. 36, pp. 421-432, 1987.

[DAS91] DASGUPTA, P., LeBlanc Jr., R. J., Ahamad, M., Ramachandran, U., "The Clouds Distributed Operating System”, IEEE Computer, v. 24, pp. 34-44, 1991.

[DUN90] DUNCAN, R., "A Survey of Parallel Computer Architectures", IEEE Computer, pp.5-16, Fevereiro, 1990.

[EAG86] EAGER, D. L., Lazowska, E. D., Zahorjan, J., "Adaptive Load Sharing in Homogeneous Distributed Systems", IEEE Transactions on Software Engineering, v. 12, pp. 662-675, 1986.

[EL-94] EL-REWINI, H., Lewis, T. G., Ali, H. H., Task Scheduling in Parallel and Distributed Systems, $1^{\text {a }}$ ed., Prentice Hall, 1994.

[ESK89] ESKICIOGLU, M. R., "Design Issues of Process Migration Facilities in Distributed Systems", IEEE Technical Committee on Operating Systems Newsletter, v. 4, pp. 3-13, Inverno de 1989.

[FER89] FERNÁNDEZ-BACA, D., "Allocating Modules to Processors in a Distributed System", IEEE Transactions on Software Engineering, v. 15, pp. 1427-1436, 1989.

[FLO94] FLOWER, J., Kolawa, A., "Express is Not Just a Message Passing System. Current and Future Directions in Express", Parallel Computing, v. 20, pp. 597614, 1994.

[FLY72] FLYNN, M. J., "Some Computer Organizations and Their Effectiveness", IEEE Transactions on Computers, v. C-21, pp.948-960, 1972.

[GEI94] GEIST, A., Beguelin, A., Dongarra, J., Jiang, W., Manchek, R., Sunderan, V., PVM 3 User's Guide and Reference Manual, Oak Ridge National Laboratory, 1994.

[GER90] GERASOULIS, A., Venugopal, S., Yang, T., "Clustering Task Graphs for Message Passing Architectures", Anais da ICS90 ( $4^{a}$ Conferência Internacional ACM em Supercomputação), ACM Press, pp. 447-456, 1990. 
[GER92] GERASOULIS, A., Yang, T., "A Comparison of Clustering Heuristics for Scheduling Directed Acyclic Graphs on Multiprocessors", Journal of Parallel and Distributed Computing, v. 16, pp. 276-291, 1992.

[GER93a] GERASOULIS, A., Yang, T., "On The Granularity and Clustering of Directed Acyclic Task Graphs", IEEE Transactions on Parallel and Distributed Systems, v. 4, pp. 686-701, 1993.

[GER93b] GERASOULIS, A., Yang, T., "Scheduling Program Task Graphs on MIMD Architectures", Parallel Algorithm Derivation and Program Transformation, pp. 153-186, Kluwer Academic Publishers, 1993.

[HAL93] HALFHILL, T. R., "Intel Launches Rocket in a Socket", Byte, pp. 92-108, Maio, 1993.

[HUR90] HURSON, A. R., Lee, B., Shirazi, B., Wang, M., "A Program Allocation

Scheme for Data Flow Computers", Anais da Conferência Internacional em Processamento Paralelo, Universidade do Estado da Pensilvânia, v. I, pp. 415423, 1990.

[HWA84] HWANG, K., Briggs, F. A., Computer Architecture and Parallel Processing, $1^{\underline{\underline{a}}}$ ed., McGraw-Hill, 1984.

[ISO92] ISO, Basic Reference Model of Open Distributed Processing. Part I: Overview and Guide to Use, International Standards Organization, 1992.

[KRU87] KRUEGER, P., Livny, M., "The Diverse Objectives of Distributed Scheduling Policies", Anais da $7^{\underline{a}}$ Conferência Internacional IEEE sobre Sistemas de Computação Distribuída, pp. 242-249, 1987.

[KRU88a] KRUATRACHUE, B., Lewis, T., "Grain Size Determination for Parallel Processing”, IEEE Software, v. 5, pp. 23-32, 1988.

[KRU88b] KRUEGER, P., Livny, M., "A Comparison of Preemptive and NonPreemptive Load Distribution", Relatório técnico do Departamento de Ciência da Computação, Universidade de Wisconsin-Madison, 1988.

[LAM78] LAMPORT, L., "Time, Clocks, and The Ordering of Events in a Distributed System", Communications of the ACM, v. 21, pp. 558-565, 1978.

[LEE91] LEE, B., Hurson, A. R., Feng, T.-Y., "A Vertically Layered Allocation Scheme for Data Flow Systems", Journal of Parallel and Distributed Computing, v. 11, pp. 175-187, 1991.

[LEW96] LEWIS, F. D., "Solving NP-Complete Problems", Texto do Curso de Algoritmos Heurísticos, página HTML (http://al.cs.engr.uky.edu:80/ lewis/csheuristic), Departamento de Ciência da Computação, Universidade do Kentucky, 1996. 
[LIN87] LIN, F. C. H., Keller, R. M., "The Gradient Model Load Balancing Method", IEEE Transactions on Software Engineering, v. SE-13, pp. 32-38, 1987.

[LIS88] LISKOV, B., "Distributed programming in Argus", Communications of The ACM, v. 31, pp. 300-312, 1988.

[LIT88] LITZKOW, M. J., Livny, M., Mutka, M. W., "Condor - A Hunter of Idle Workstations", Anais da $8^{\underline{a}}$ Conferência Internacional IEEE sobre Sistemas de Computação Distribuída, pp. 104-111, 1988.

[LO88] LO, V. M., "Heuristic Algorithms for Task Assignment in Distributed Systems", IEEE Transactions on Computers, pp. 1384-1397, Novembro de 1988.

[LO92] LO, V. M., "Temporal Communication Graphs: Lamport's Process-Time Graphs Augmented for the Purpose of Mapping and Scheduling", Journal of Parallel and Distributed Computing, v. 16, pp. 378-384, 1992.

[LÜL93] LÜLING, R., Monien, B., Ramme, F., "Load Balancing in Large Networks: A Comparative Study", Relatório Técnico do Departamento de Matemática e Ciência da Computação, Universidade de Paderborn (Alemanha), 1993.

[MAL96] MALARD, J., "MPI: A Message-Passing Interface Standard. History, Overview and Current Status", página HTML (http://www.epcc.ed.ac.uk/epcctec/documents/techwatch-mpi/mpi-tw.book_l.html), Edinburgh Parallel Computing Center, Universidade de Edinburgo, 1996.

[MAT93] MATRONE, A., Schiano, P., Puoti, V., "LINDA and PVM: A Comparison between Two Environments for Parallel Programming", Parallel Computing, v. 19, pp. 949-957, 1993.

[MCB94] MCBRYAN, O. A., "An Overview of Message Passing Environments", Parallel Computing, v. 20, pp. 417-444, 1994.

[MCC89] MCCREARY, C., Gill, H., "Automatic Determination of Grain Size for Efficient Parallel Processing", Communications of the ACM, pp. 1073-1078, Setembro, 1989.

[MOR86] MORRIS, J., Satyanarayanan, M., Conner, M. H., Howard, J. H., Rosenthal, D. S., Smith, F. D., "Andrew: A Distributed Personal Computing Environment”, Communications of The ACM, v. 29, pp. 184-201, 1986.

[MUL89] MULlENDER, S. (ed.), Distributed Systems, $1^{\underline{a}}$ ed., Addison-Wesley Publishing Company, 1989.

[MUL93] MULlENDER, S. (ed.), Distributed Systems, 2aㅗ., Addison-Wesley Publishing Company, 1993.

[MUN94] MUNIZ, F. J., "Parallel Load-Balancing on Message Passing Architectures", Dissertação de Doutorado, Universidade de Southampton, Março de 1994. 
[NI85] NI, L. M., Xu, C. W., Gendreau, T. B., "Drafting Algorithm - A Dynamic Process Migration Protocol for Distributed Systems", $5^{\underline{a}}$ Conferência Internacional IEEE sobre Sistemas de Computação Distribuída, pp. 539-546, 1985.

[OTT94] OTTO, S. W., Casas, J., Konuru, R., Prouty, R., Walpole, J., "Adaptive Load Migration Systems for PVM", Anais da Conferência sobre Supercomputação, Março, 1994.

[PET96] PETZOLD, C., Programming Windows 95, Microsoft Press, 1996.

[POL87] POLYCHRONOPOULOS, C. D., Kuck, D. J., "Guided Self-Scheduling: A Practical Scheme for Parallel Supercomputers", IEEE Transactions on Computers, pp. 1425-1439, Dezembro de 1987.

[POP85] POPEK, G., Walker, B. J. (ed.), The LOCUS Distributed System Architecture, MIT Press, 1985.

[POW83] POWELL, M. L., Miller, B. P., "Process Migration in DEMOS/MP", Anais da $9^{o}$ Simpósio ACM sobre Princípios de Sistemas Operacionais, pp. 110-119, 1983.

[PRE88] PRESS, W. H., Flannery, B. P., Teukolsky, S. A., Vetterling, W. T., Numerical Recipes in C, Cambridge University Press, 1988.

[ROZ88] ROZIER, M., Abrossimov, V., Armand, F., Boule, I., Gien, M., Guillemont, M., Herrman, F., Kaiser, C., Langlois, S., Leonard, P., Neuhauser, W., "Chorus Distributed Operating System", Computing Systems Journal, v. 1, pp. 305-370, 1988.

[ROZ90] ROZIER, M., Abrossimov, V., Armand, F., Boule, I., Gien, M., Guillemont, M., Herrman, F., Kaiser, C., Langlois, S., Leonard, P., Neuhauser, W., "Overview of the Chorus Distributed Operating System", Chorus Systèmes (Relatório Técnico), 1990.

[SAR86] SARKAR, V., Henessy, J., "Compile-time Partitioning and Scheduling of Parallel Programs", Anais do SIGPLAN'86 Symposium on Compiler Construction, pp. 17-26, 1986.

[SHI90] SHIRAZI, B., Wang, M., Pathak, G., "Analisys and Evaluation of Heuristic Methods for Static Task Scheduling", Journal of Parallel and Distributed Computing, v. 10, pp. 222-232, 1990.

[SHI92] SHIVARATRI, N. G., Kreuger, P., Singhal, M., "Load Distribution for Locally Distributed Systems", Computer, v. 25, pp. 33-44, Dezembro de 1992.

[SHI95] SHIRAZI, B. A., Hurson, A. R., Kavi, K. M., Scheduling and Load Balancing in Parallel and Distributed Systems, $1^{\underline{a}}$ ed., IEEE Computer Society Press, 1995. 
[SHR89] SHRIVASTAVA, S., Dixon, G. N., Parrington, G. D., Hedayati, F., Wheater, S., Little, M., "The Design and Implementation of Arjuna", Anais da $3^{\underline{a}}$ Conferência sobre Programação Orientada a Objetos, 1989.

[SHR91] SHRIVASTAVA, S., Dixon, G. N., Parrington, G. D., "An Overview of The Arjuna Distributed Programming System”, IEEE Software, pp. 66-73, Janeiro, 1991.

[SIL96] SILVA, F. A. B., "Balanceamento de Carga em Ambientes Paralelos Virtuais com Aplicações no PVM-W95", Mini-dissertação de Qualificação para $O$ Programa de Mestrado, ICMSC-USP, Abril, 1996.

[SMI80] SMITH, R. G., "The Contract Net Protocol: High-Level Communication and Control in A Distributed Problem Solver", IEEE Transactions on Computers, v. 29, pp. 1104-1113, 1980.

[SOU96] SOUZA, P. S. L., "Máquina Paralela Virtual em Ambiente Windows", Tese de Mestrado, ICMSC-USP, Junho, 1996.

[SOU97a] SOUZA, M. A., "Avaliação das Rotinas de Comunicação Ponto-a-Ponto do MPI”, Tese de Mestrado, ICMSC-USP, Janeiro, 1997.

[SOU97b] SOUZA, P. S. L. de, Santana, M. J., Santana, R. H. C., Senger, L. J., Picinato, R., "O Impacto do Protocolo TCP/IP na Computação Paralela Distribuída no Ambiente Windows 95", Anais do $15^{\circ}$ Simpósio Brasileiro de Redes de Computadores (SBRC 97), pp. 36-47, Maio, 1997.

[STE88] STEINER, J., Neuman, C., Schiller, J., "Kerberos: An Authentication Service for Open Network Systems", Anais da Conferência Usenix Inverno, 1988.

[STO77] STONE, H. S., "Multiprocessor Scheduling with the Aid of Network Flow Algorithms", IEEE Transactions on Software Engineering, pp. 85-93, Janeiro de 1977.

[SUN94] SUNDERAN, V. S., Geist, G. A., Dongarra, J., Manchek, R., "The PVM Concurrent Computing System: Evolution, Experiences, and Trends", Parallel Computing, v. 20, pp. 531-545, 1994.

[SYB95] SYBASE, Inc., "Single Architecture, Optimized Products: Integrating the Distributed Enterprise", página HTML (http://www.sybase.com/Offerings/ System 11/3x3.html), 1995.

[TAN85] TANENBAUM, A. S., van Renesse, R., "Distributed Operating Systems", ACM Computing Surveys, v. 17, nº 4, Dezembro, 1985.

[TAN90] TANENBAUM, A. S., van Renesse, R., van Staveren, H., Sharp, G., Mullender, S., Jansen, J., van Rossum, G., "Experiences with The Amoeba Distributed Operating System", Communications of The ACM, v. 33, pp. 46-63, 1990. 
[TAN92] TANENBAUM, A. S., Modern Operating Systems, Prentice Hall, 1992.

[TAN93] TANENBAUM, A. S., "The Amoeba Distributed Operating System", Relatório Técnico do Departamento de Informática da Universidade de Vrije, 1993.

[TAN95] TANENBaum, A. S., Distributed Operating Systems, Prentice Hall, $1^{\underline{a}}$ ed., 1995.

[THE85] THEIMER, M. M., Lantz, K. A., Cheriton, D. R., "Preemptable Remote Execution Facilities for The V-System", Anais do $10^{\circ}$ Simpósio ACM sobre Princípios de Sistemas Operacionais, pp. 2-12, 1985.

[THE91] THEIMER, M. M., Hayes, B., "Heterogeneous Process Migration by Recompilation", Anais da $11^{\underline{a}}$ Conferência Internacional IEEE sobre Sistemas de Computação Distribuída, pp. 18-25, 1991.

[TRA94] TRANSARC Co., "Ericsson Messaging Systems Guarantees Message Reliability with DCE and Encina", página HTML (http://www.transarc.com/ afs/transarc.com/public/www/Public/ProdServ/Solutions/ericsson.html), 1994.

[TRA95a] TRANSARC Co., "DCE and Encina Streamline Transaction-Intense Loan Processing System", página HTML (http://www.transarc.com/afs/transarc. com/public/www/Public/ProdServ/Solutions/ge.html), 1995.

[TRA95b] TRANSARC Co., "NASA LaRC Deploys Robust, Common Computing Environment with DCE DFS", página HTML, (http://www.transarc.com/afs/ transarc.com/public/www/Public/ProdServ/Solutions/larc.html), 1995.

[VEL90] VELTMAN, B., Lageweg, B. J., Lenstra, J. K., "Multiprocessor Scheduling with Communication Delays", Parallel Computing, v. 16, pp. 173-182, 1990.

[WAL94] WALKER, D. W., "The Design of a Standard Message Passing Interface for Distributed Memory Concurrent Computers", Parallel Computing, v. 20, pp. 657673, 1994.

[WAN85] WANG, Y. -T., Morris, R. J. T., "Load Sharing in Distributed Systems", IEEE Transactions on Computers, v. 34, pp. 204-217, 1985.

[WIL87] WILBUR, S., Bacarisse, B., "Building Distributed Systems with Remote Procedure Call”, Software Engineering Journal, pp. 148-159, Setembro, 1987.

[YAN91] YANG, T., Gerasoulis, A., "A Fast Static Scheduling Algorithm for DAGs on an Unbounded Number of Processors", Anais da Conferência IEEE/ACM sobre Supercomputação, pp. 633-642, 1991.

[YAN92] YANG, T., Gerasoulis, A., "PYRROS: Static Task Scheduling and Code Generation for Message Passing Multiprocessors", Anais da $6^{a}$ Conferência Internacional da ACM em Supercomputação, ACM Press, pp. 428-437, 1992. 
[ZAL91] ZALUSKA, E. J., "Research Lines in Distributed Computing Systems and Concurrent Computation", Anais do Workshop em Programação Concorrente, Sistemas Distribuidos e Engenharia de Software, ICMSC-USP, pp. 132-155, 1991.

[ZAY87] ZAYAS, E. R., “Attacking The Process Migration Bottleneck”, Anais do $22^{\underline{ }}$ Simpósio ACM sobre Princípios de Sistemas Operacionais, pp. 13-24, 1987.

[ZHO88] ZHOU, S., "A Trace-Driven Simulation Study of Dynamic Load Balancing", IEEE Transactions on Software Engineering, v. 14, pp. 1327-1341, 1988. 